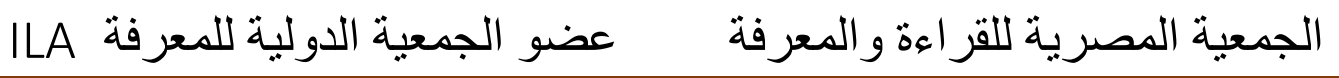

\section{أثر الإرشاد الأسري في مواجهة الضغوط الاجتماعية لاى أمهات أطفال ذوي الإعاقة العقلية بمحافظة الأحساء \\ The Effect of Family Counseling in Facing Social Pressures for a Family of a Children Having a Mental Retardation in Al-Ahsa Governorate}

إعداد

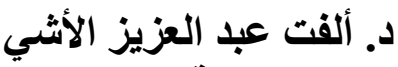

الأستاذ المشارك بجامعة الملك عبد ألعزيز بجدة الأبد

كلية الدراسات العليا التربوية

\author{
أ. امال أحمد الأقتم

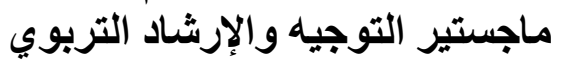

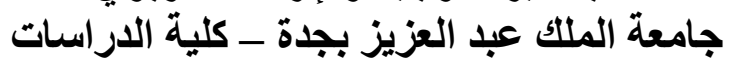 \\ العليا التربوية التزة
}




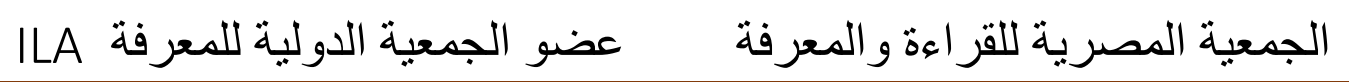


أثر الإرشاد الأسري في مواجهة الضغوط الاجتماعية لاى أمهات أطفال ذوي الإعاقة الإنة العقلية بمحافظة الأحساء

\section{The Effect of Family Counseling in Facing Social Pressures for a Family of a Children Having a Mental Retardation in Al-Ahsa Governorate}

د. ألفت عبد العزيز الأشي

الأستاذ المشارك بجامعة الملك عبد الّزيز الاثيز بجدة

كلية الدراسات العليا التربوية

\author{
أ. امـال أحمد الأقنم \\ ماجستير التوجيه والإرشاد التربيو الإيوي

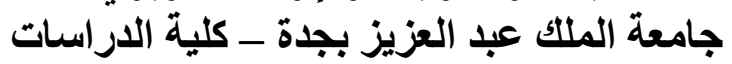 \\ العليا التربوية التزة
}

\section{المقدمة : - المبان}

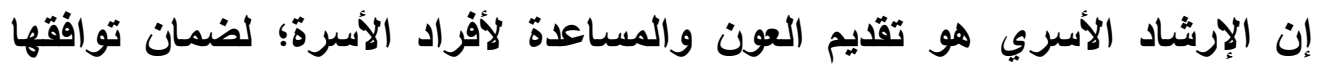

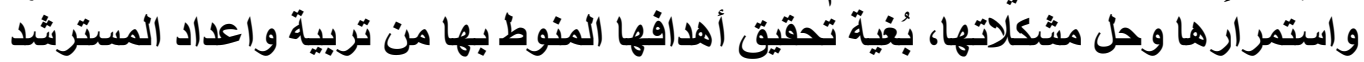

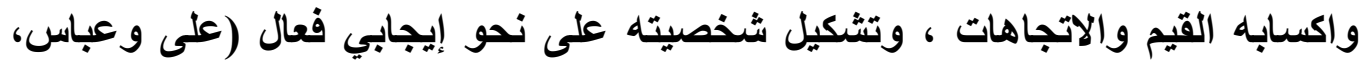

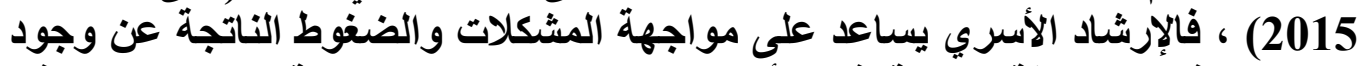

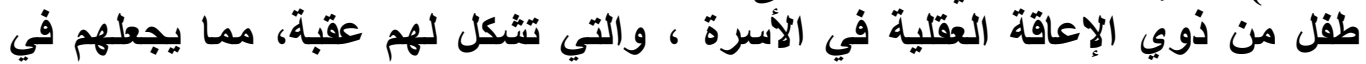

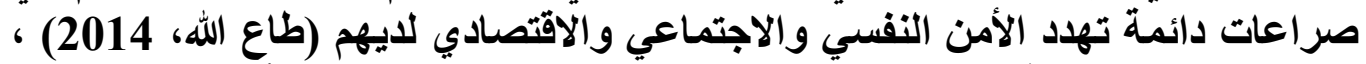

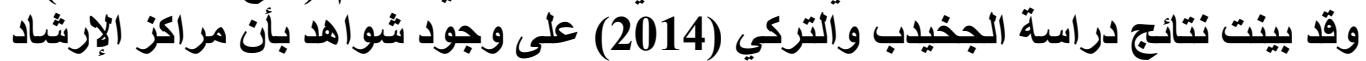

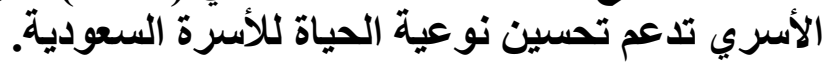

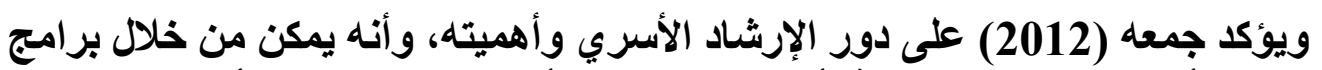

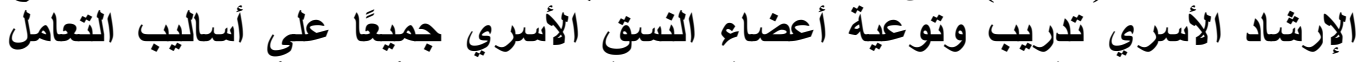

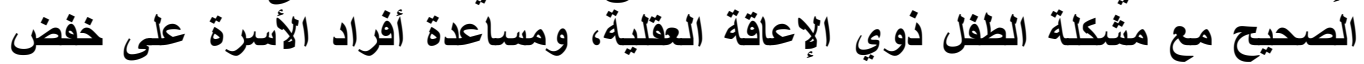

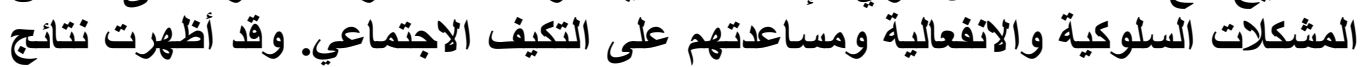

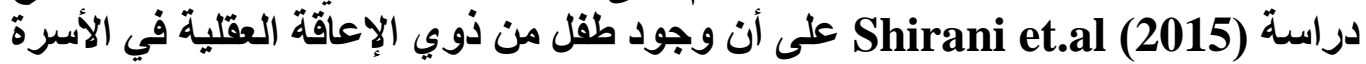

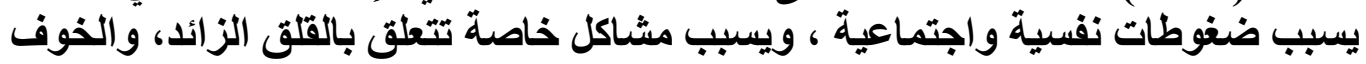
والتوتر، وسرعة الغضب لأى جميع أفراد الأسرة.

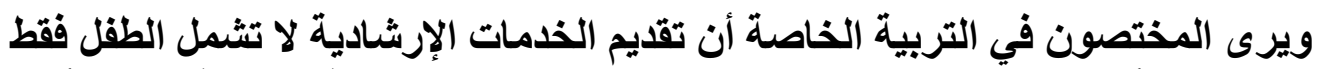

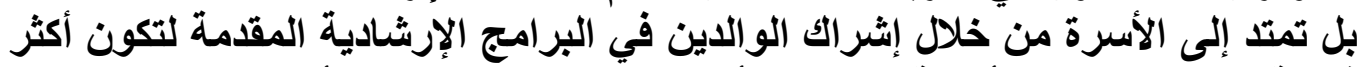

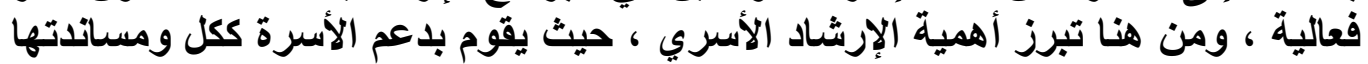

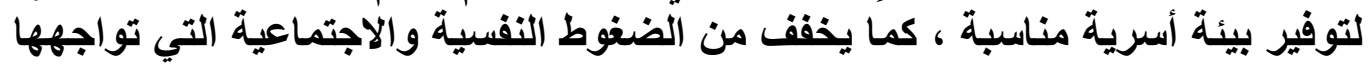

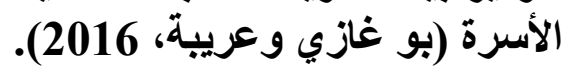


ويوضح الرفاعي (2004) أن الضغوط التي تمر بها الأسرة هي مجموعة من وئن

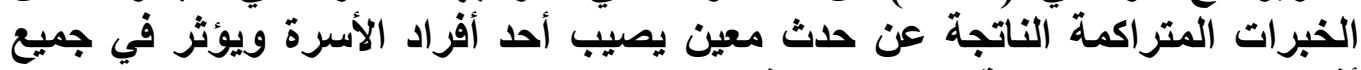

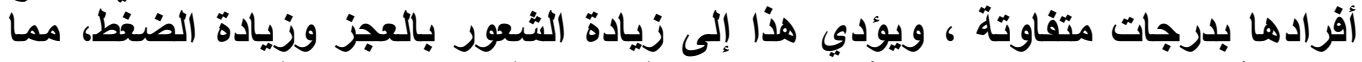

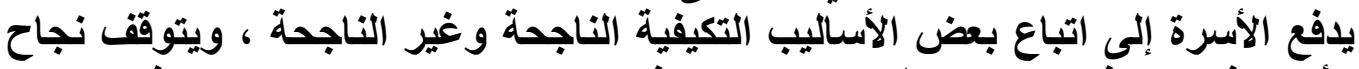

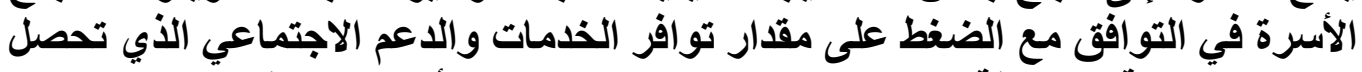

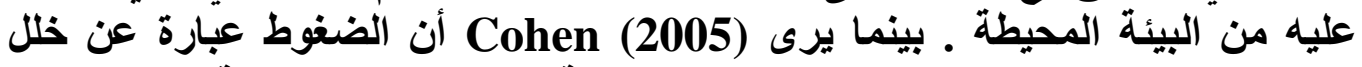
مدرك بين المطالب والامكانيات يصاحبه مجموعة من المظاهر السلبية مثل الغضب الفي و والقلق والاحباط.

وقد تختلف مواجهة الأسرة للضغوط النفسية والاجتماعية بحسب العلاقات السائدة

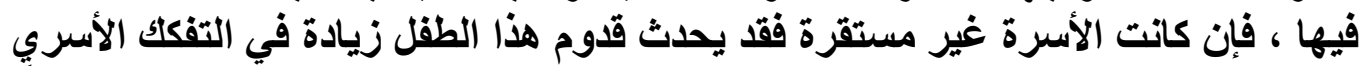

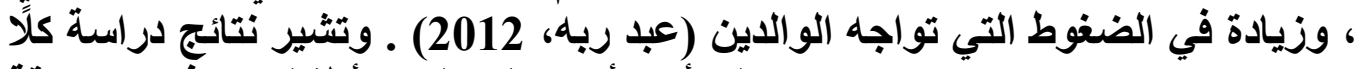
Brandon and Hogan(2011) غالبا ما تتعرض إلى مشكلات نفسية متعدة تسبيها العوامل الامل الاجتماعية والاقتصادية.

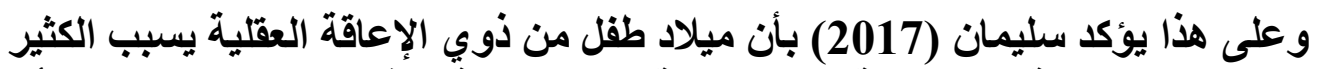

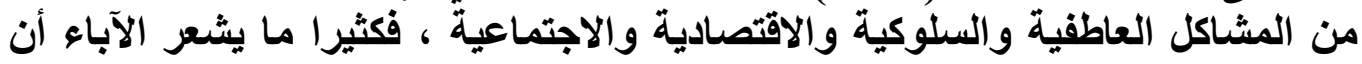

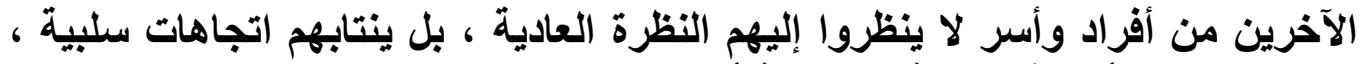
حيث يثعرون بأنهم في مكانة اجتماعية أقل من الآباء الآخرين.

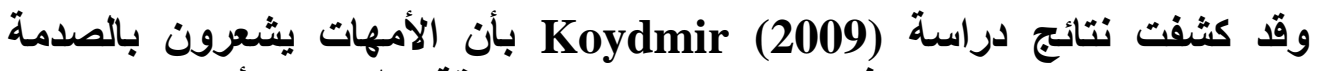

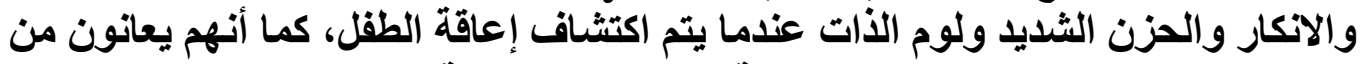

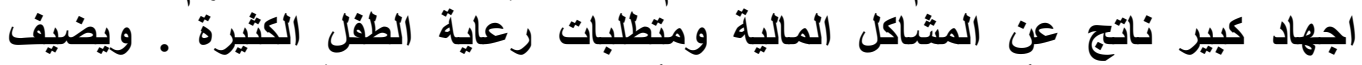

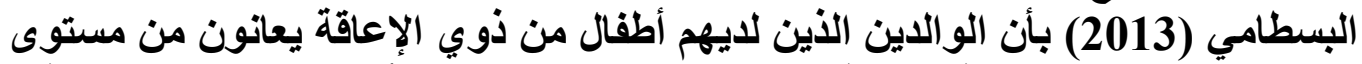

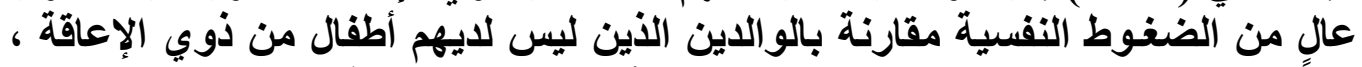

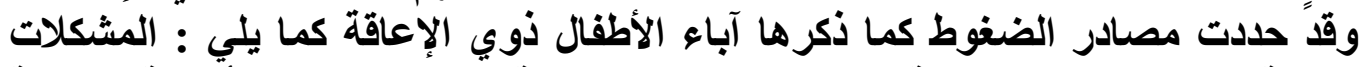

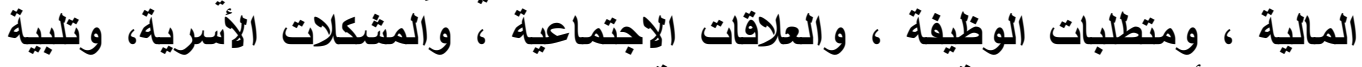
احتياجات أطفالهم ، وتلبية احتياجاتهم الخاصة.

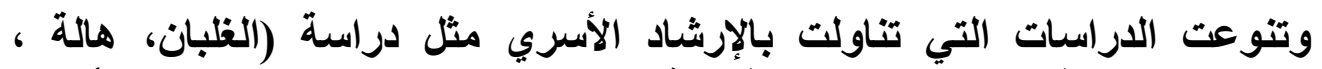

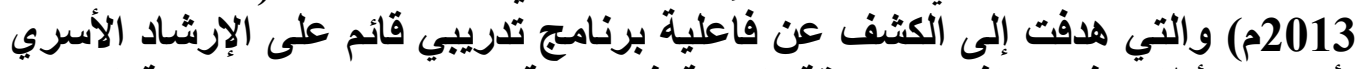

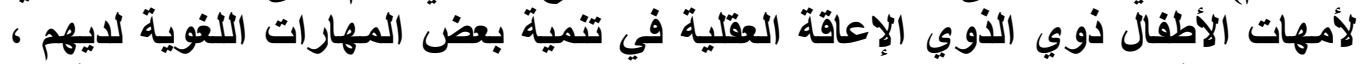

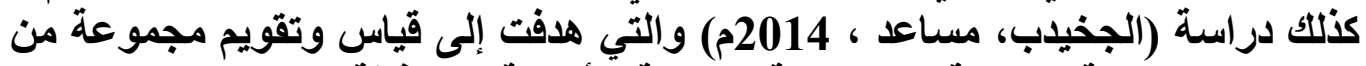

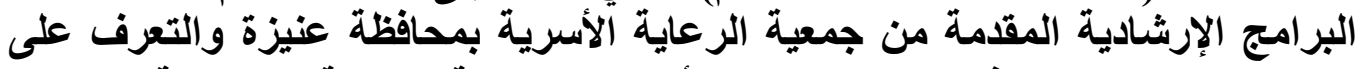

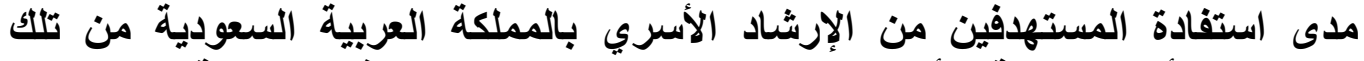

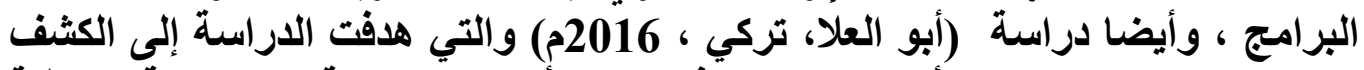
عن دور برنامج الإرشاد الأسري الهاتفي في تعديل أساليب التنشئة الاجتماعية الخاطئة 


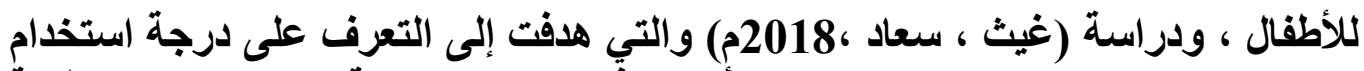

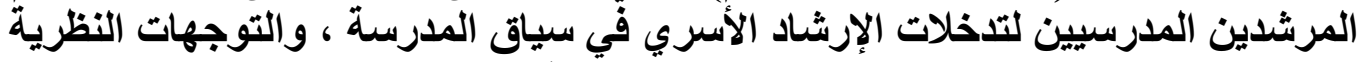

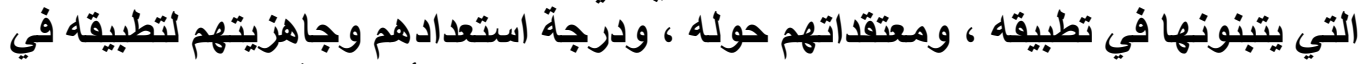

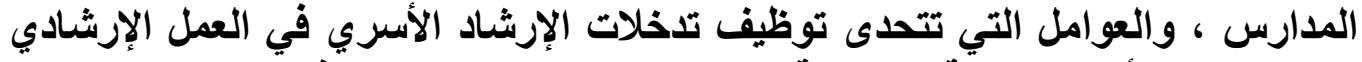

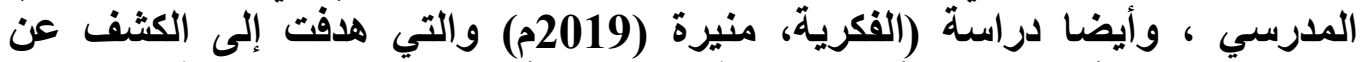

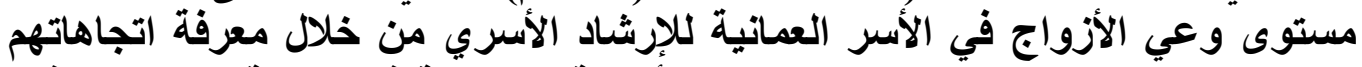

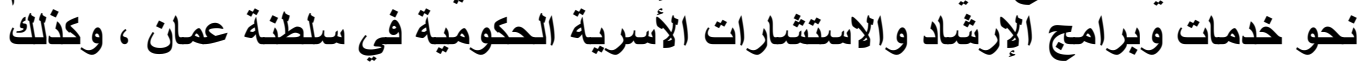

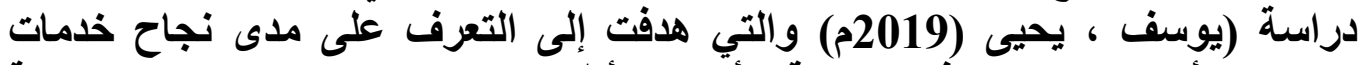

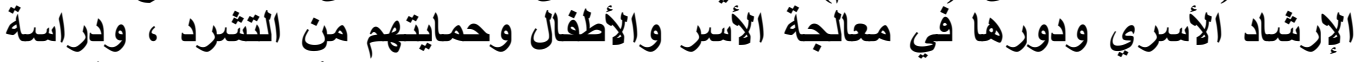

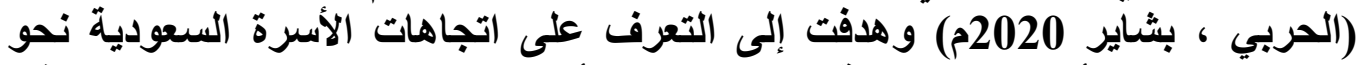

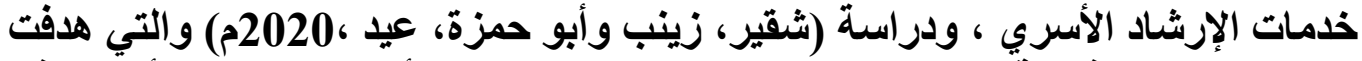

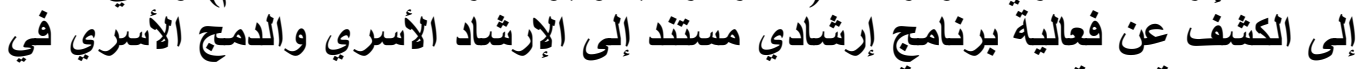

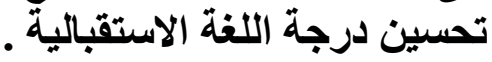

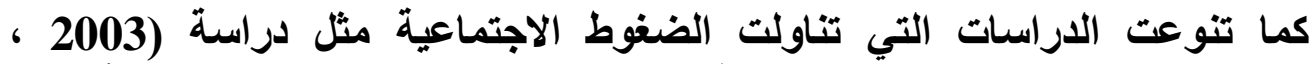
(Emerson

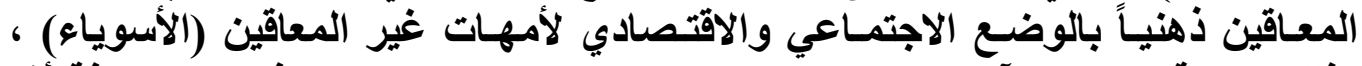

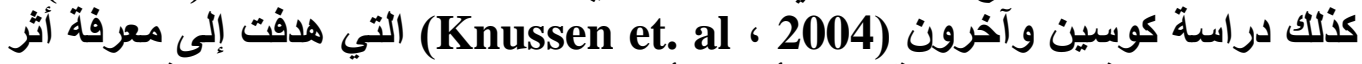

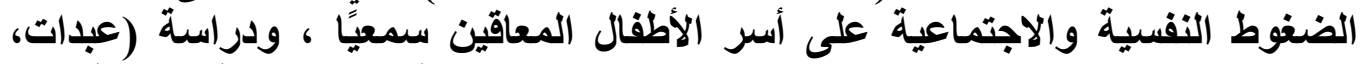

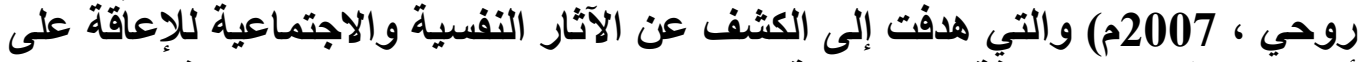

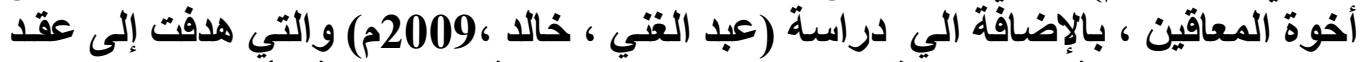

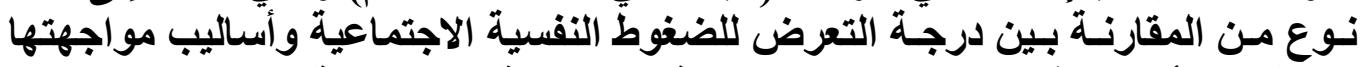

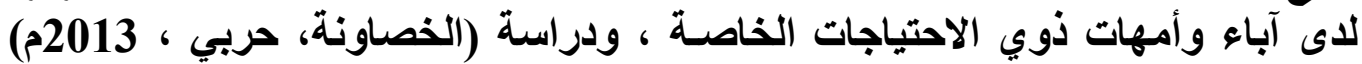

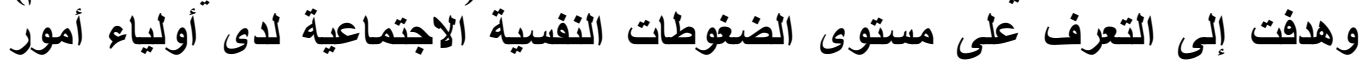

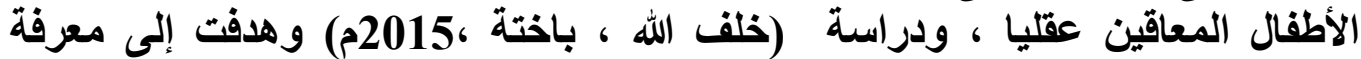

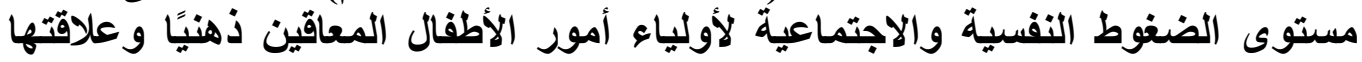

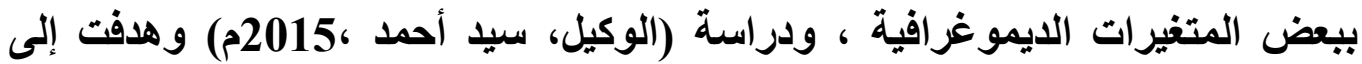

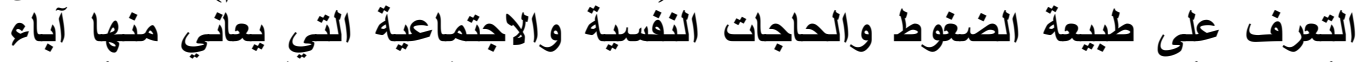

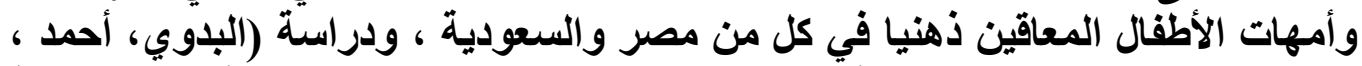

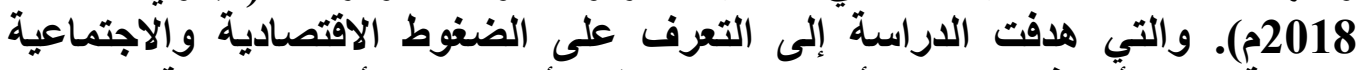

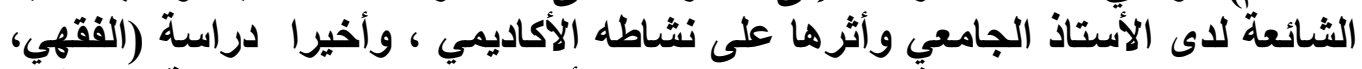

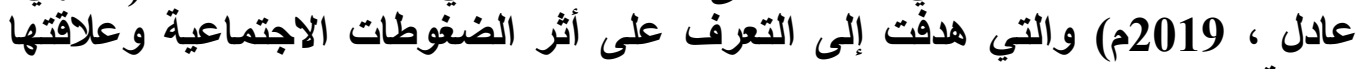
بعملية الاختيار والتعيين . 


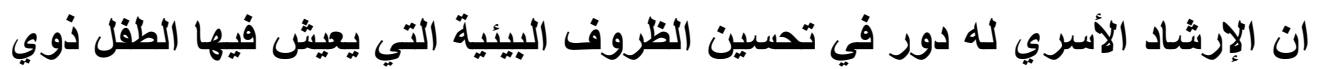

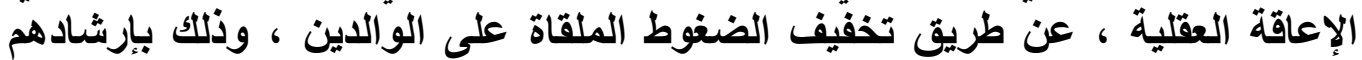

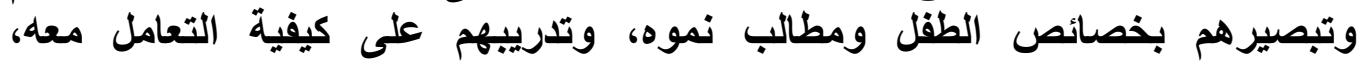

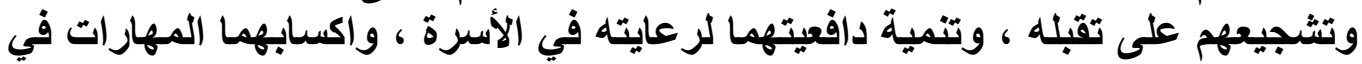

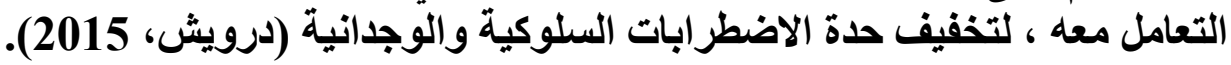

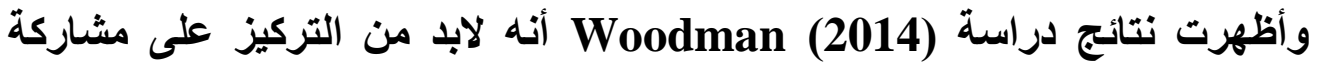

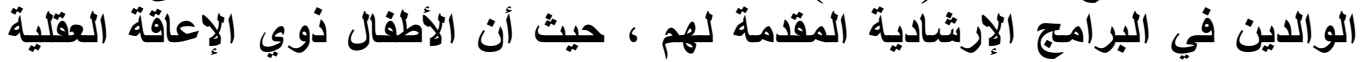

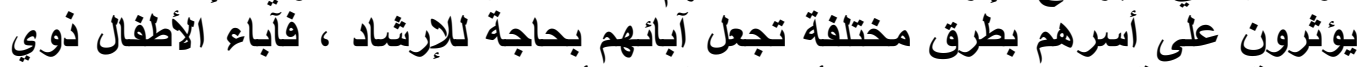

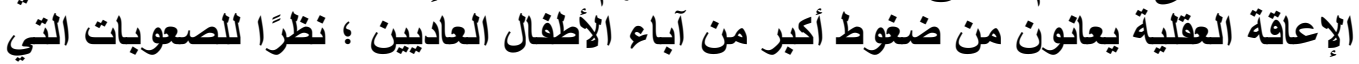
يواجهها آباء الأطفال ذوي الإعاقة من العقلية.

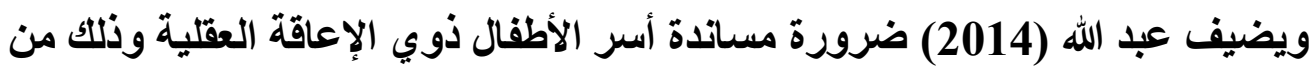

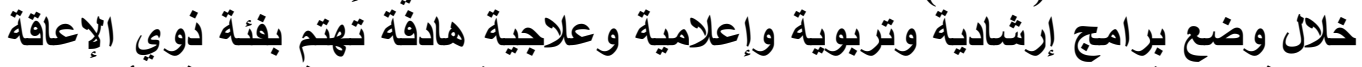

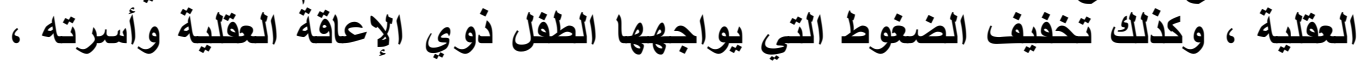

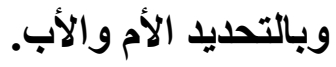

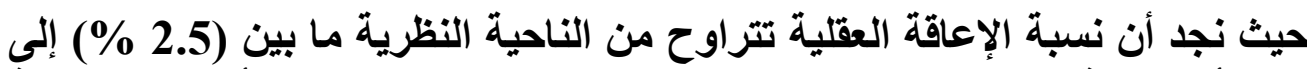

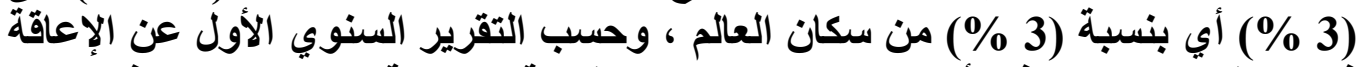

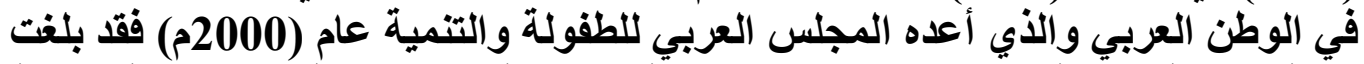

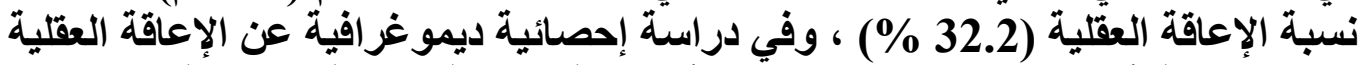

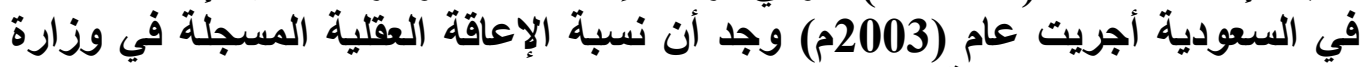

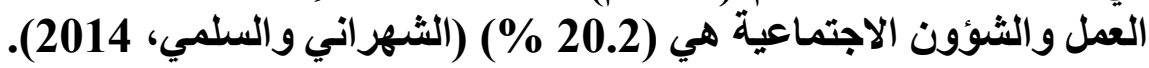

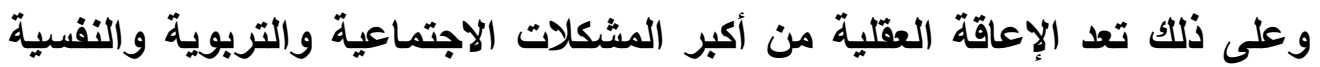

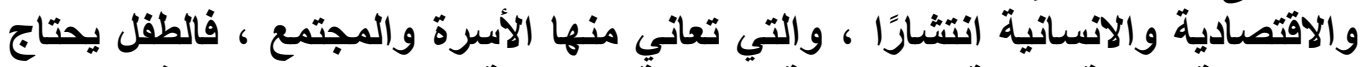

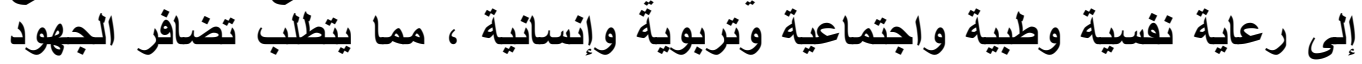

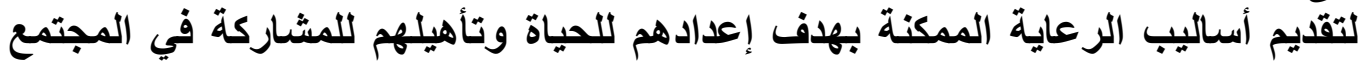
كغير هم من العاديين (حسين، 2009).

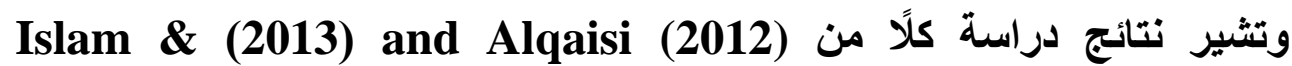
Shahnaz

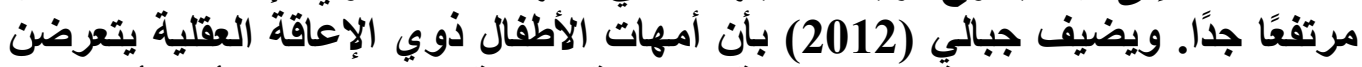

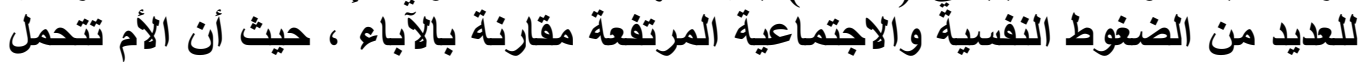

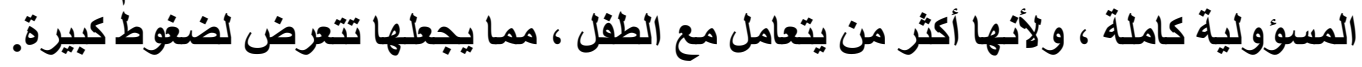


وقد بينت فرح (2005) من خلال نتائج دراستها إلى أن وجود طقل من ذوي الإعاقة

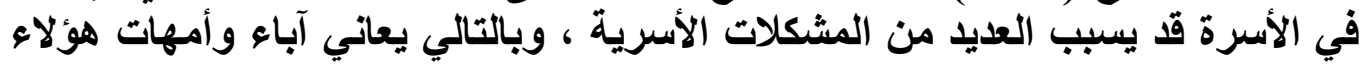

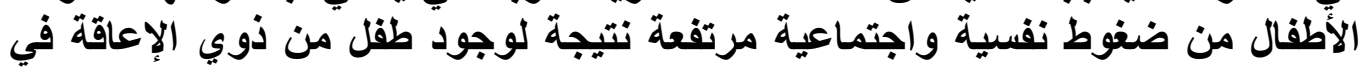

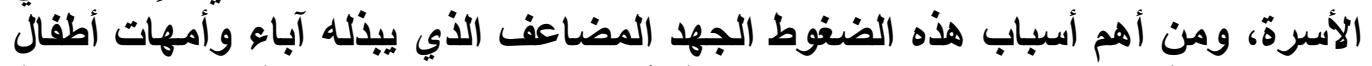

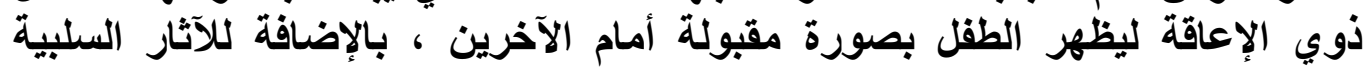

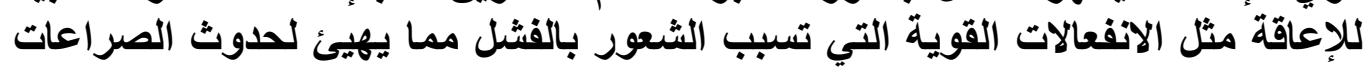
والمشكلات الأسرية.

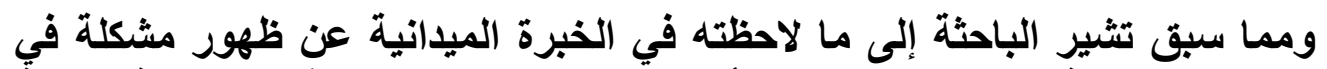

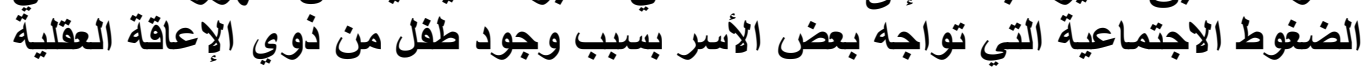

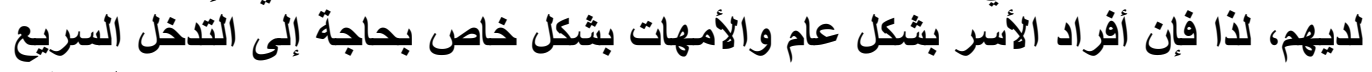

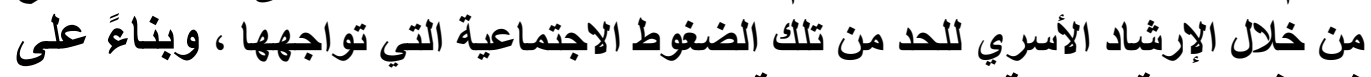

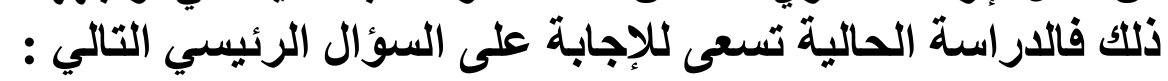

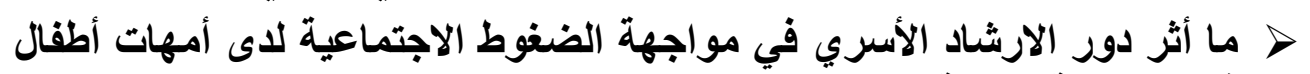

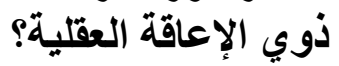
ويتفرع من السؤال الرئيسي الأسئلة الفرعية التالية :

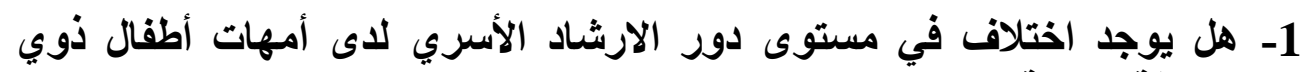
الإعاقة العقلية ؟ اجتئة 2- هل يوجد اختلاف في مستوى الضغوط الاجتماعية لاى أمهات أطفال ذوي الإعاقة العقلية ؟ ألوف 3- هل توجد فروق ذات دلالة إحصائية بين متوسط درجات أفراد العينة في الإرشاد

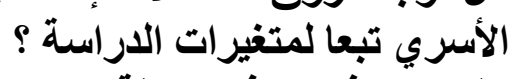

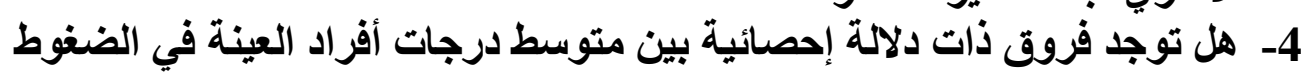

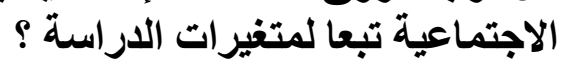

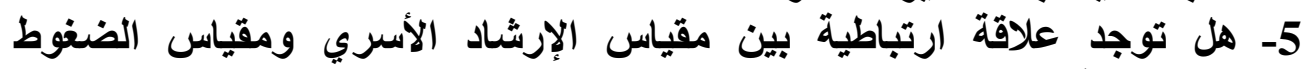
الاجتماعية ؟ أهداف البحث:

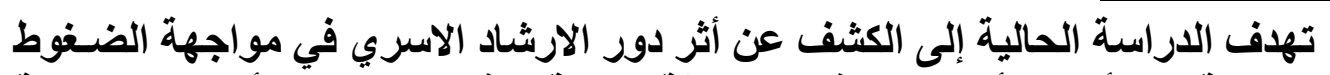

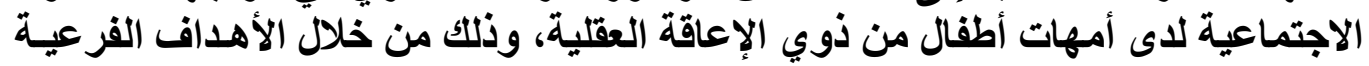
التالية : 1- يوجد اختلاف في مستوى دور الارشاد الأسري لاى أمهات أطفال ذوي الإعاقة 
2- يوجد اختلاف في مستوى الضغوط الاجتماعية لاى أمهات أطفال ذوي الإعاقة

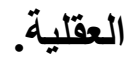
3- توجد فروق ذات دلالة إحصائية بين متوسط درجات أفراد العينة في الإرشاد

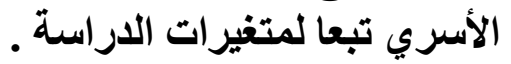
4- توجد فروق ذات دلالة إحصائية بين متوسط درجات أفراد العينة في الضغوط

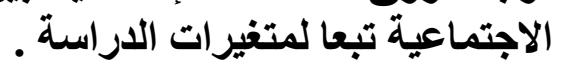
5- توجد علاقة ارتباطية بين مقياس الإرشاد الأسري ومقياس الضغوط الاجتماعية.

$$
\begin{aligned}
& \text { أهمية ألبحثة : ألبحث في : ألهية } \\
& \text { أ- الأهمية النظرية : }
\end{aligned}
$$

1- تسهم نتائج هذه الاراسة في إثراء البحث العلمي المعرفي والتطبيقي.

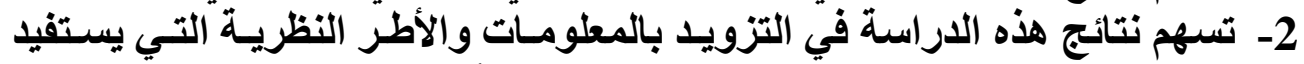

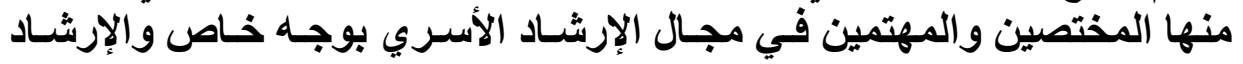
3- الاستفادة من نتائج هذه الاراسة في تعريف أسـر ذوي الإعاقـة العقليـة بأهميـة

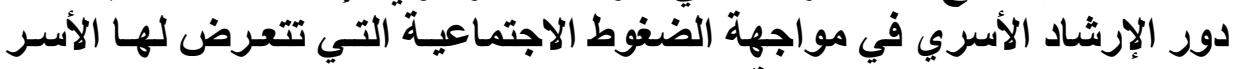
من مؤسسات المجتمع المختلفة. 4- تأتي أهمية هذه الاراسة في تناولها فئية من الفئات التي تزايد الاهتمسام بها في

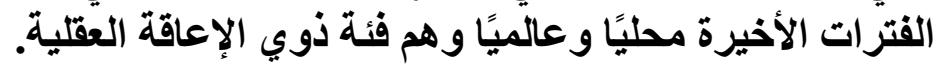

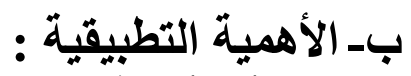

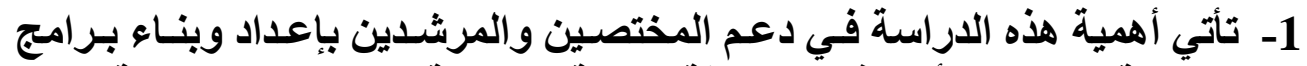

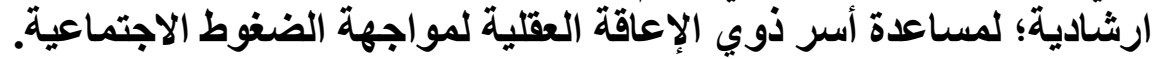

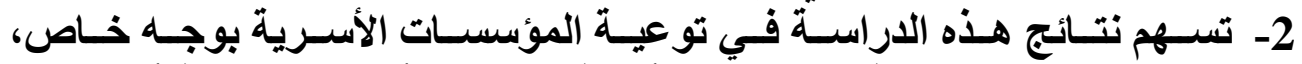

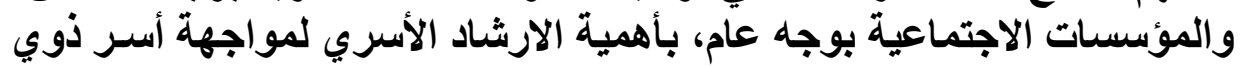

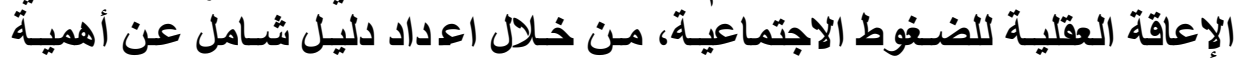

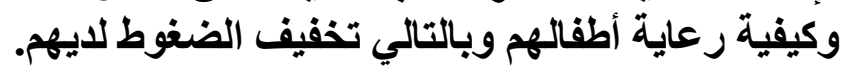

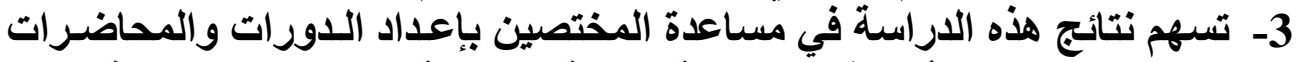

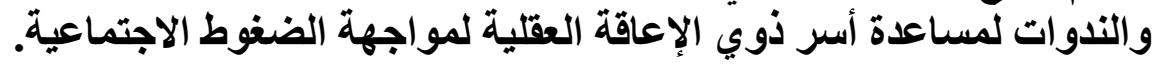

$$
\text { فروض البحث : الأسلوب : }
$$

1- - يوجد اختلاف في مستوى دور الارشاد الأسري لاى أمهات أطفال ذوي الإعاقة العقلية. 2- - يوجد اختلاف في مستوى الضغوط الاجتماعية لاى أمهات أطفال ذوي الإعاقة العقلية. 
3- توجد فروق ذات دلالة إحصائية بين متوسط درجات أفراد العينة في الإرشاد الأسري تبعا

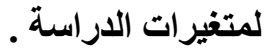
4- توجد فروق ذات دلالة إحصائية بين متوسط درجات أفراد العينة في الضغوط الاجتماعية تبعا لمتفيرات الار اسة . 5- توجد علاقة ارتباطية بين مقياس الإرشاد الأسري ومقياس الضغوط الاجتماعية.

$$
\text { ـ الإرشاد الأسري : البحث : }
$$

- هو احداث تغيير في عناصر الأنست الأسري ، وتعديل سلوكيات أعضاء الأسرة

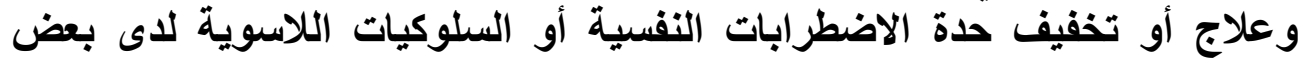

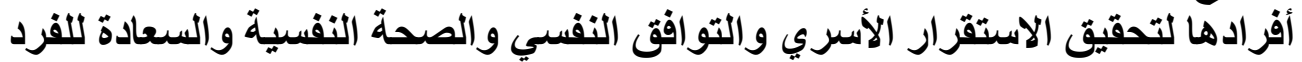

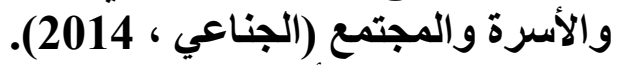

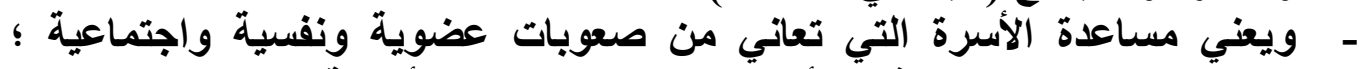

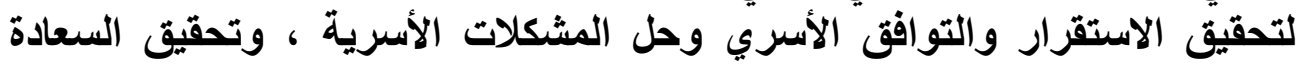

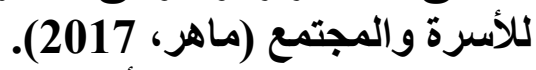

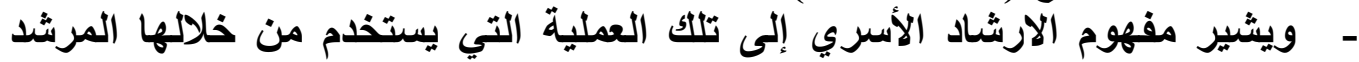

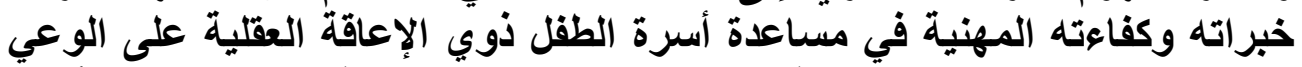

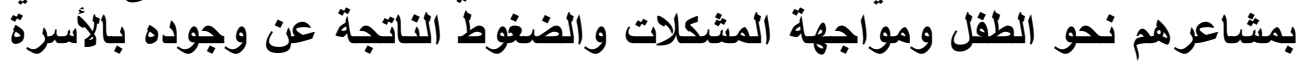

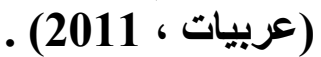

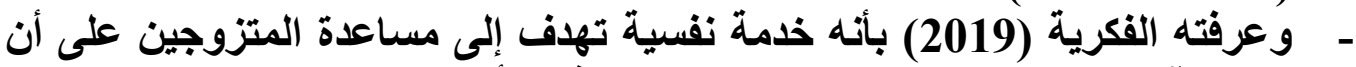
يكونوا آباء ناجحين ؛ لتحقيق الاستقرار والتوافت الأنه الأسري.

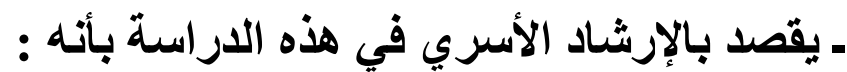

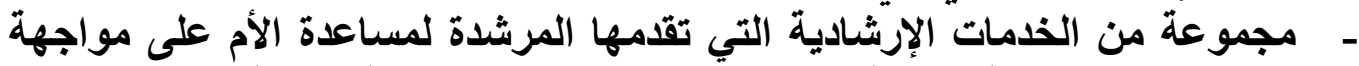

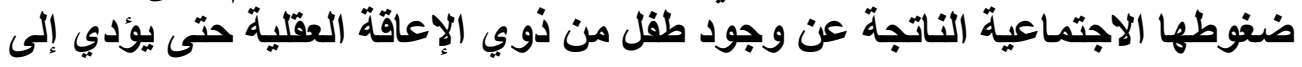

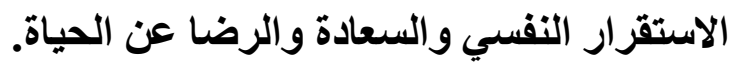

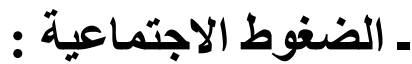

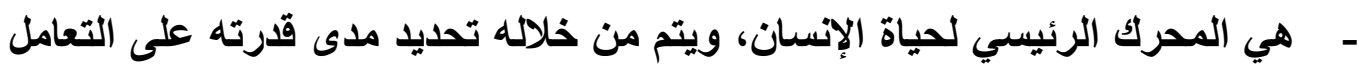

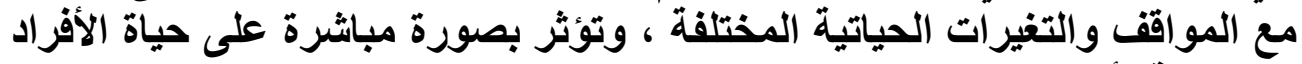

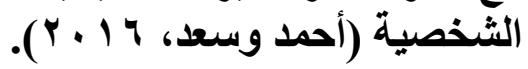

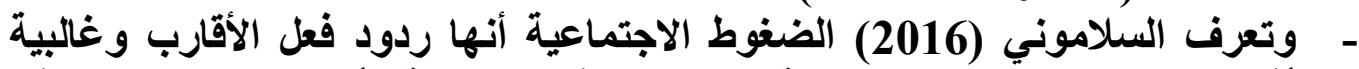

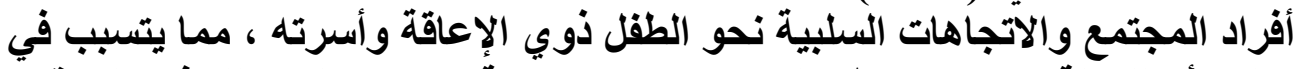

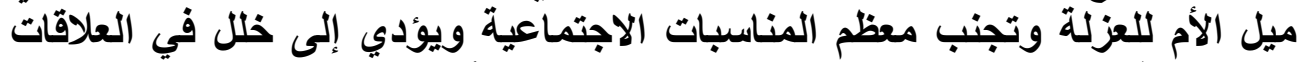

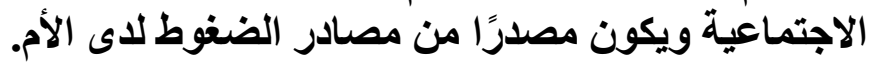




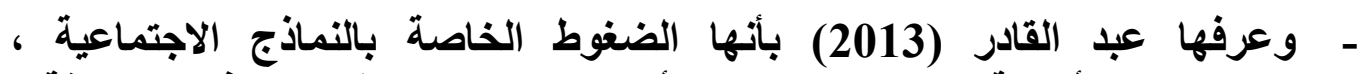

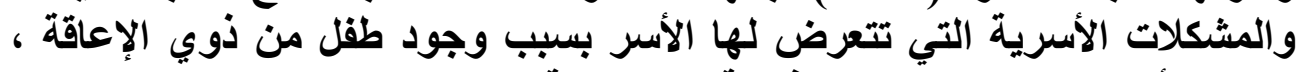
وكثرة الأبناء لايهم ، وانتعام الرفاهية الاجتماعية.

ـ يقصد بالضغوط الاجتماعية في هذه الاراسة بأنها :

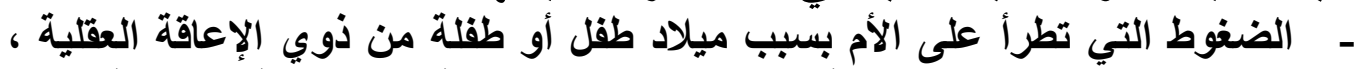

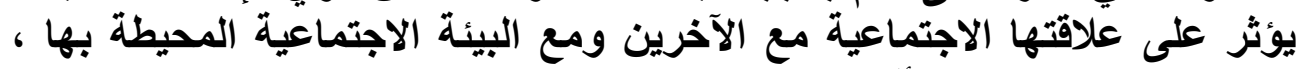

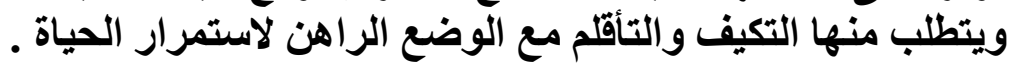

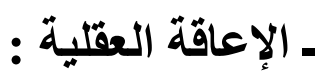

- - هي الإعاقة الناتجة عن أمراض نفسية أو أمراض وراثية أو شلل دماغي نتيجة لنقص الأكسجين أو نتيجة لأمراض جينية ، أو كل ما يعيق العقل عن القياض القيام بوظائفه

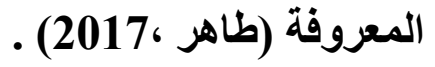

$$
\begin{aligned}
& \text { منهج البحث : }
\end{aligned}
$$

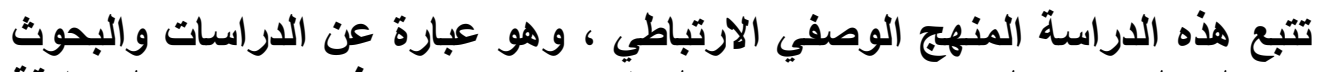

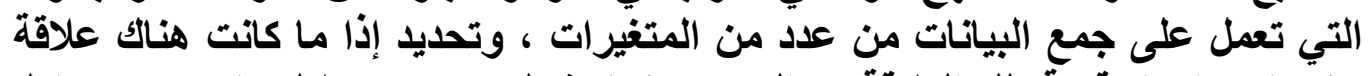

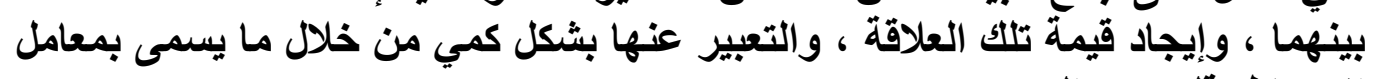

$$
\begin{aligned}
& \text { الارتباط (قليوبي والسيد ، 2020). } \\
& \text { حدود البحث : } \\
& \text { الحدود المكانية : }
\end{aligned}
$$

اقتصر المجال الجغرافي لعينة الاراسة على عينة عينة من الأمهات السعوديات لأطفال

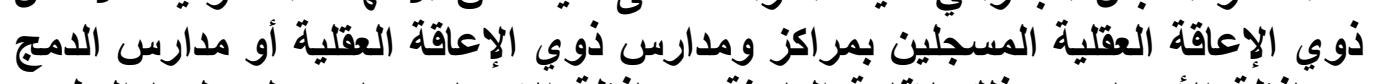

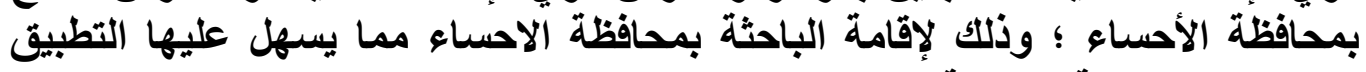
الميداني على عينة الدراسة.

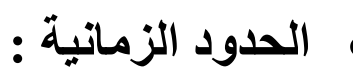

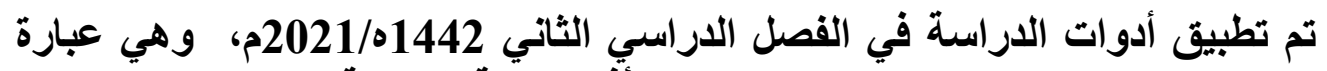
عن مقياس استقصاء تم توزيعها إلكترونيا على أُقراد عينة الداراسة.

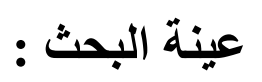

اثنتملت عينة الاراسة الأساسية على عينة قصدية قوامها (101) أم سعودية لائها

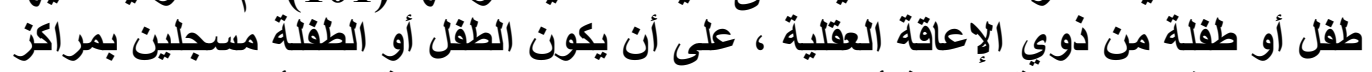

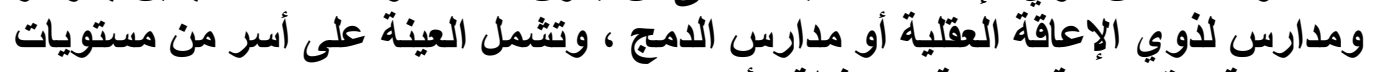
اجتماعية واقتصادية متباينة بمحافظة الأحساء. 


$$
\text { أدوات البحث : }
$$

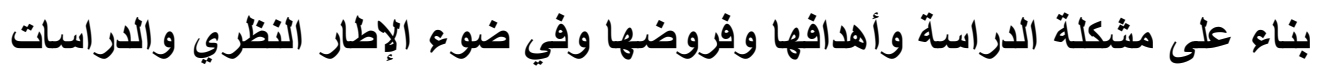

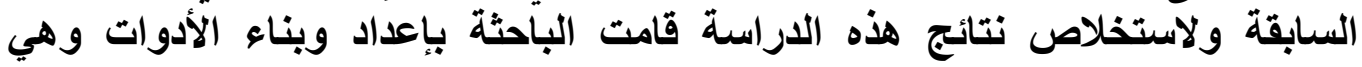
كالتالي:

$$
\text { 1. استمارة البيانات العامة (إعداد الباحثة) : }
$$

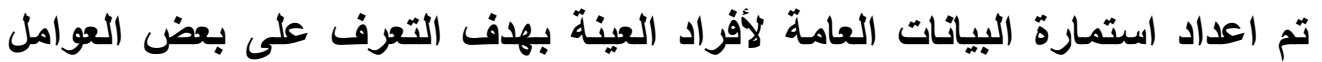
الايموغرافية والتي احتوت على (جنس الطفل ، عمر الطقل ، عمر الأم ، اجمالي الأل العل

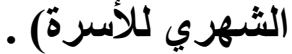

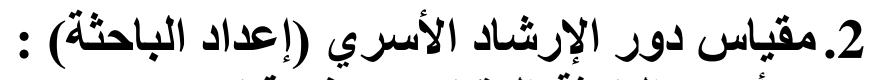

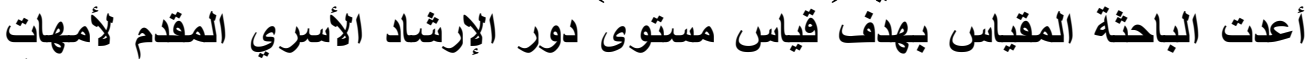

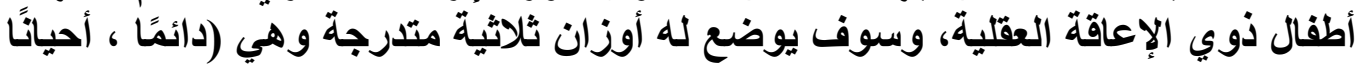

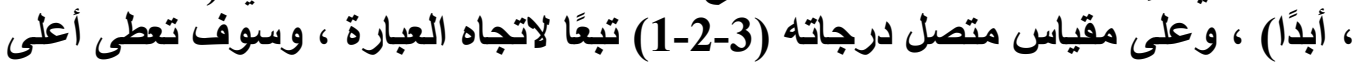

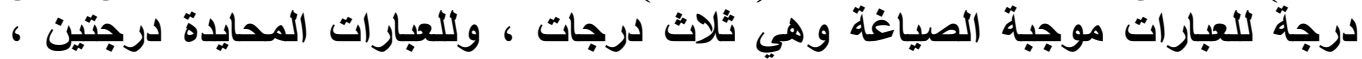

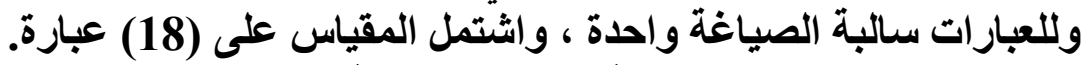
3. مقياس الضغوط الاجتماعية (إعداد الباحثة) :

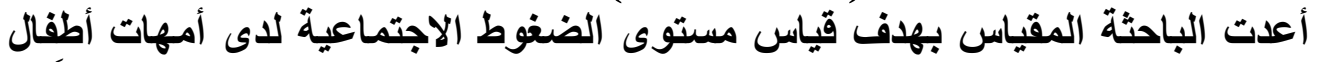

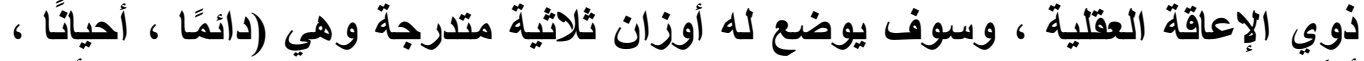

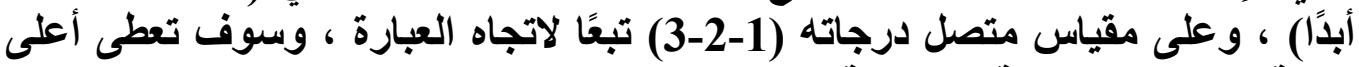

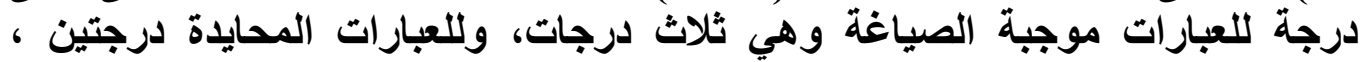
وللعبارات سالبة الصياغة واحدة ، واشتُمل المقياس على درجي (20) عبارة . الإطار النظري : الإبيات مفهوم الإرشاد النفسى الأسرى وأهميته :

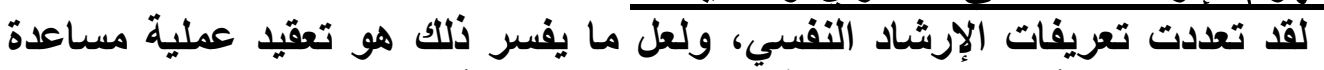

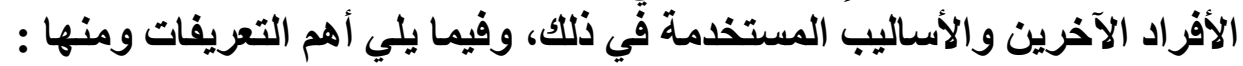

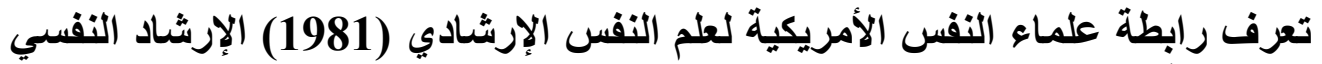

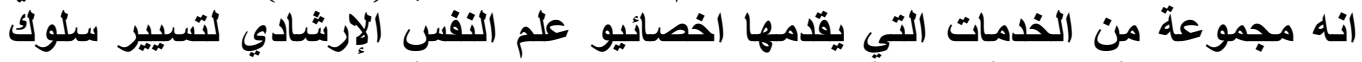

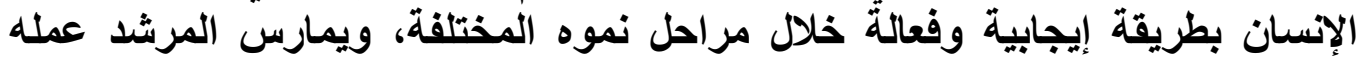

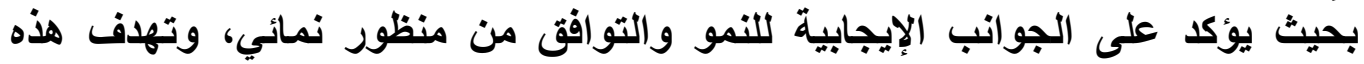

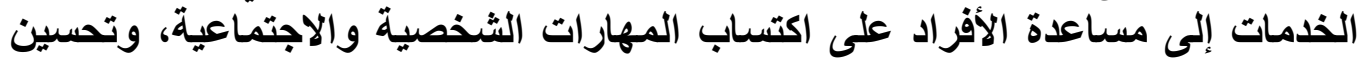

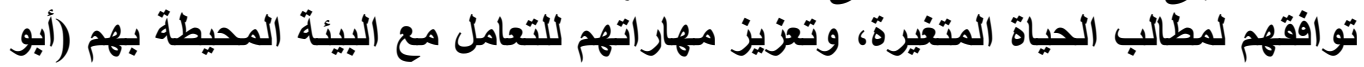

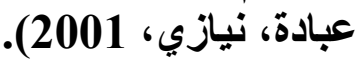


والإرشاد الأسري عبارة عن مجموعة من التوجيهات العملية التي تقام لأسرة الطقل

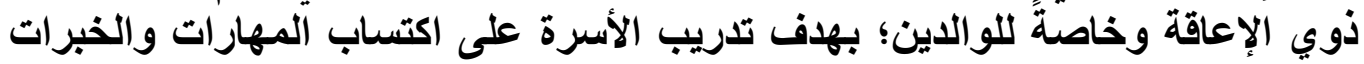

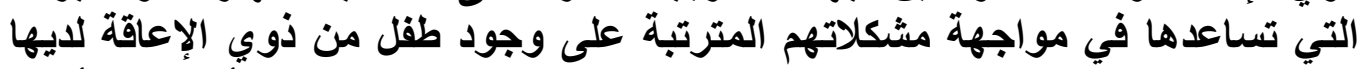

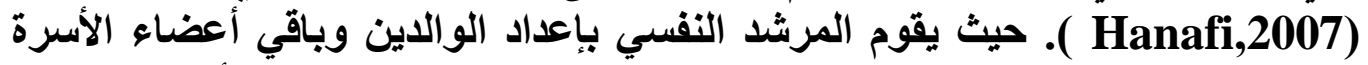

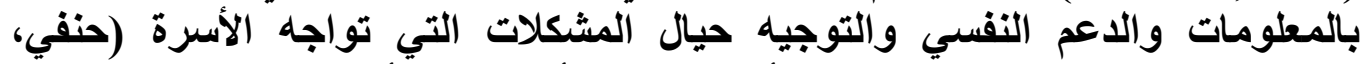

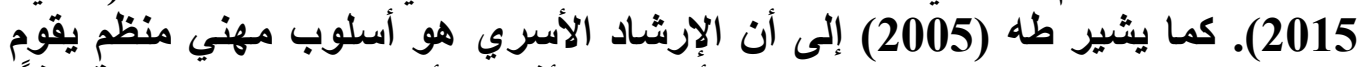

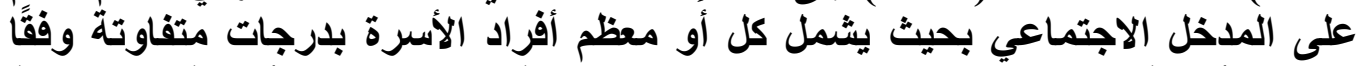

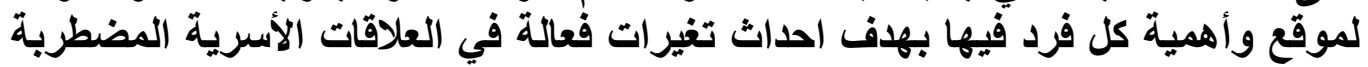
وتحقيق صور للتفاعل الإيجابي.

فالإرشاد النفسي الأسري يوضح كيفية تعامل الأسرة مع الطفل، ويوضح الإئ دور الأبناء،

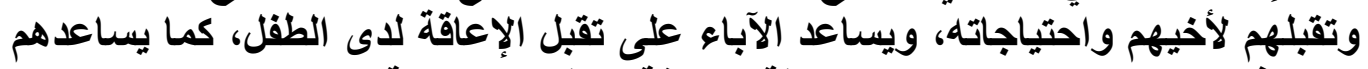

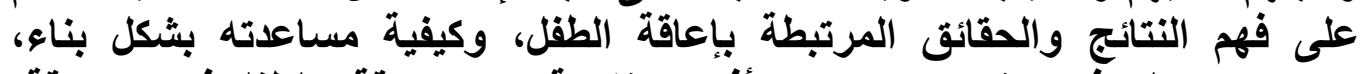

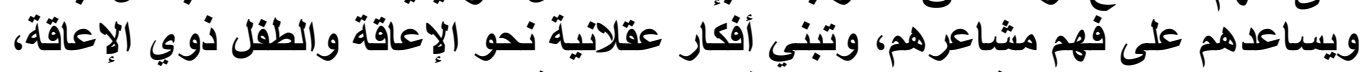

ويساعدهم على مواصلة تطوير تحقيق ذواتهم الخهم الخاصة (Saleh\& Shfi,2015).

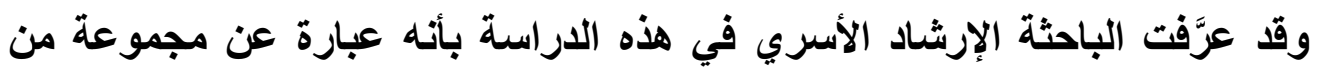

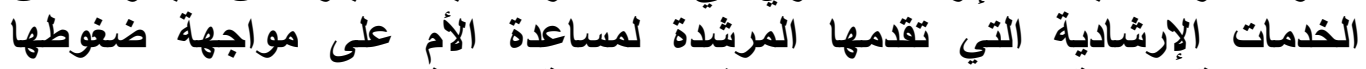

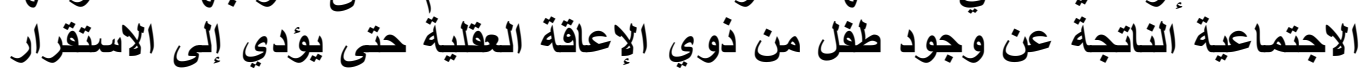
النفسي والسعادة والرضا عن العياة.

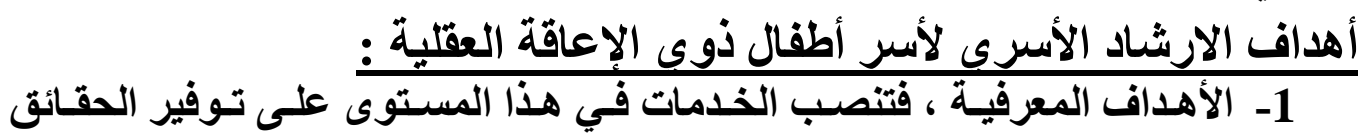

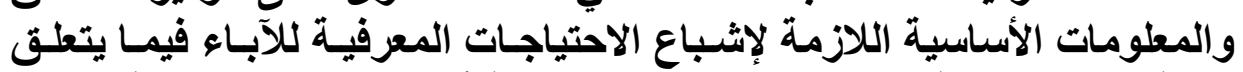

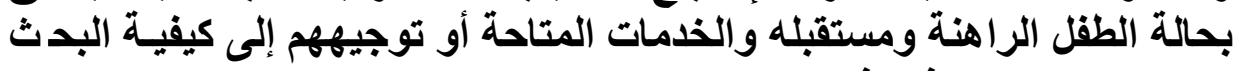
عن المصادر المتو افرة في المجتمع المحلئي.

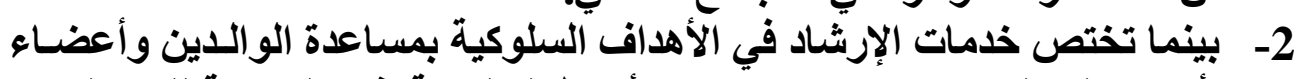

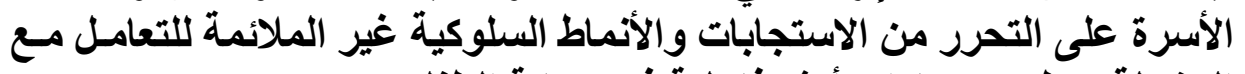
المشكلة وتطوير مهارات أكثر فاعلية في رعاية الطفلّ.

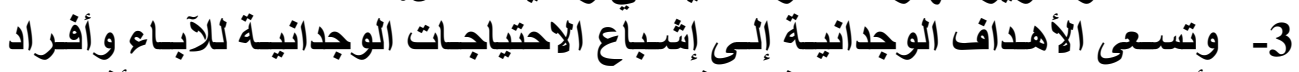

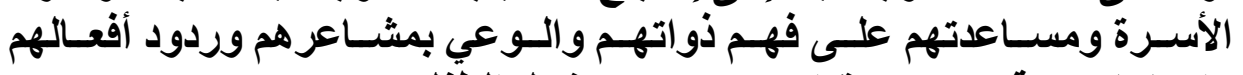

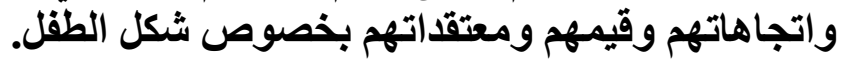

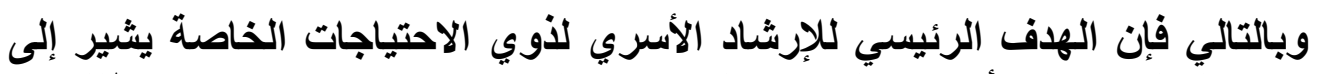

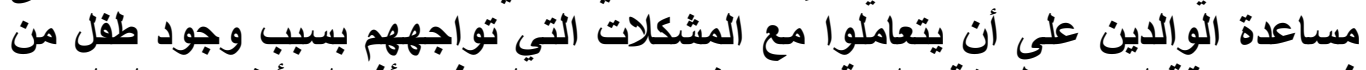

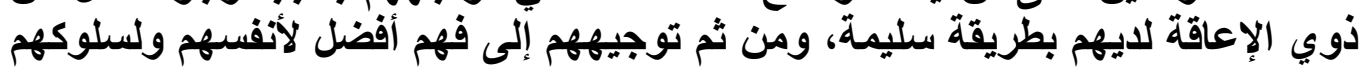
.(Iwaniec,2006) 
وتقوم العملية الإرشادية على مجموعة من مبادئ الإرشاد النفسي الأسري التي تعمل

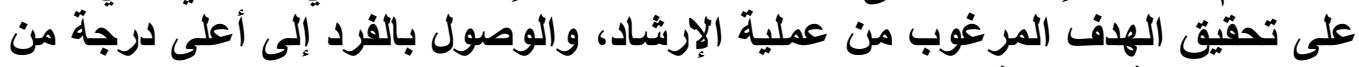

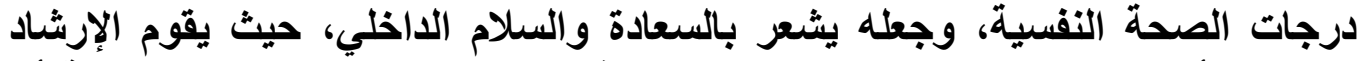

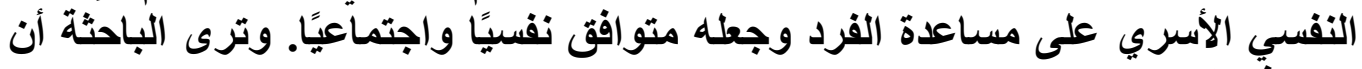

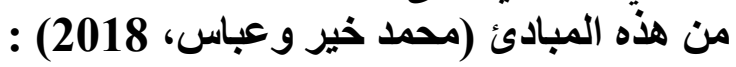

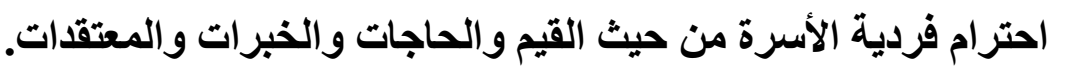

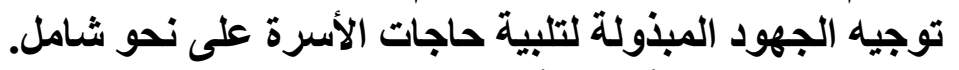

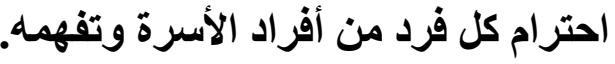

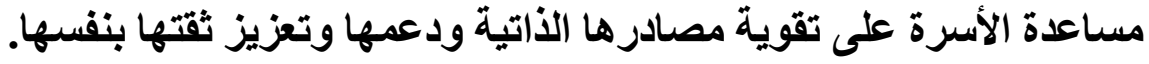

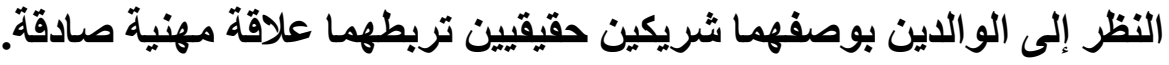

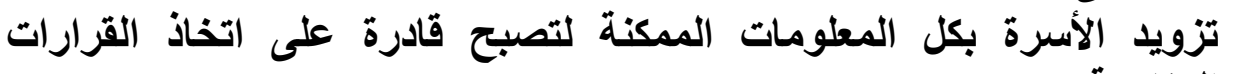
المناسبة. - مئ.

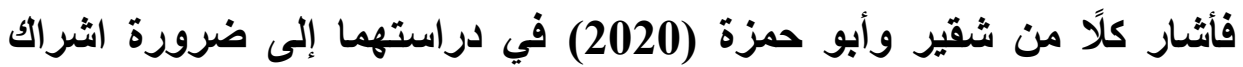

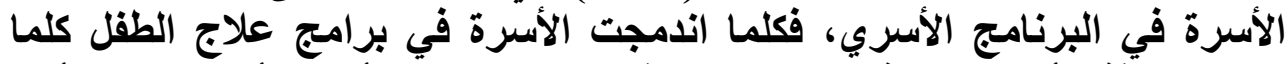

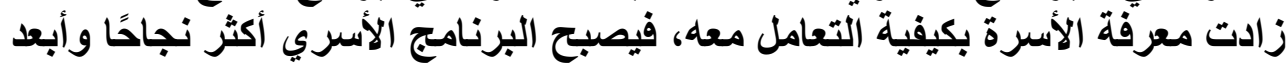

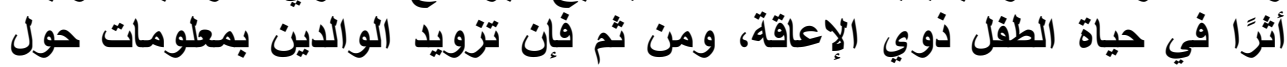

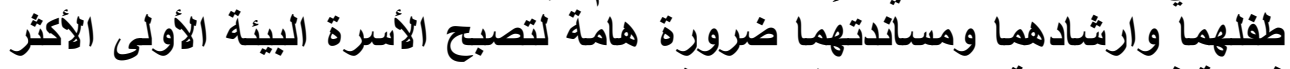

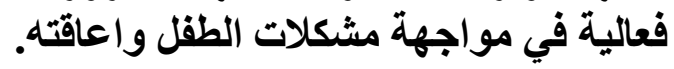

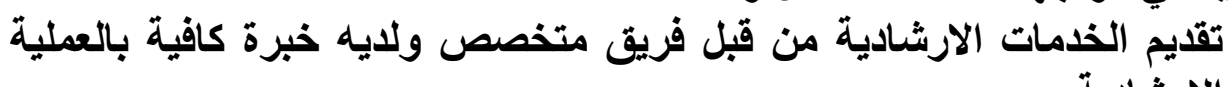
الارشادية.

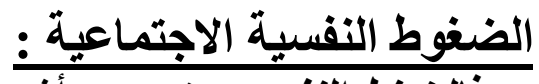

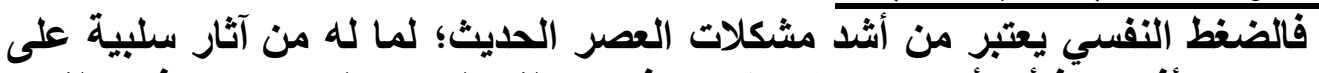

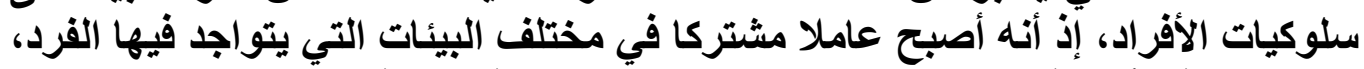
ومنها البيئة الأسرية التي يوجد بها طفل من ذوي الإعاقة العقلية (Sayiner, 2006).

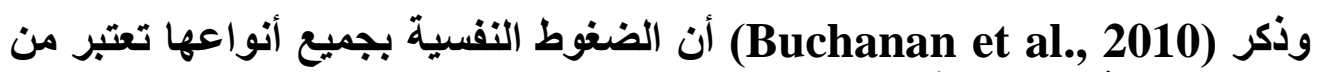

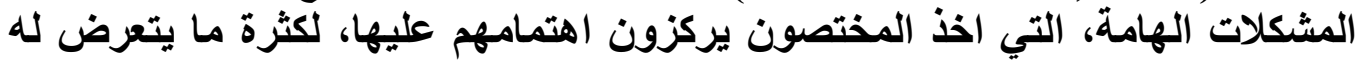

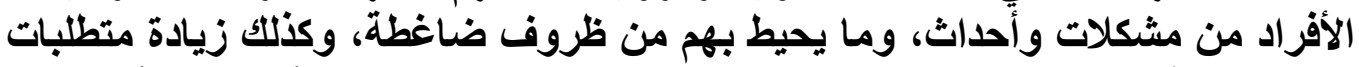

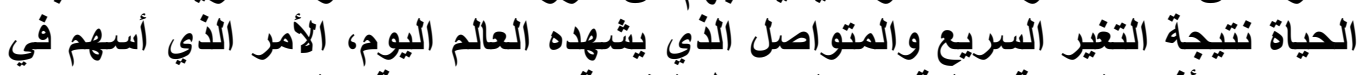

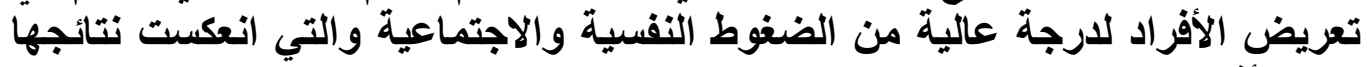

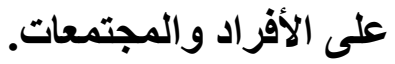




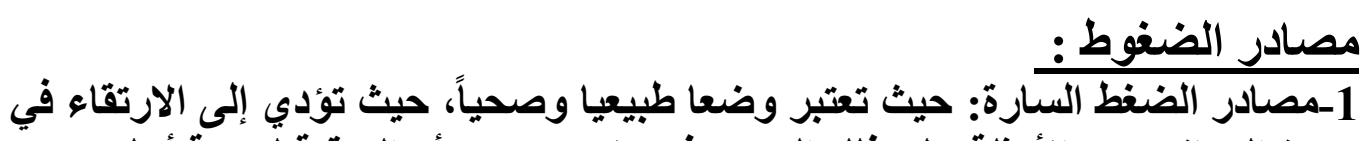

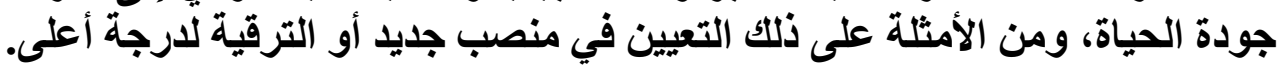

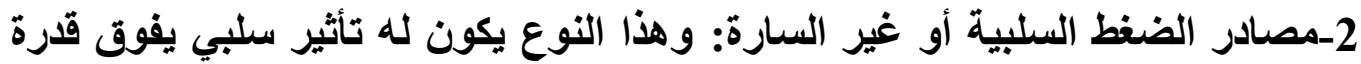

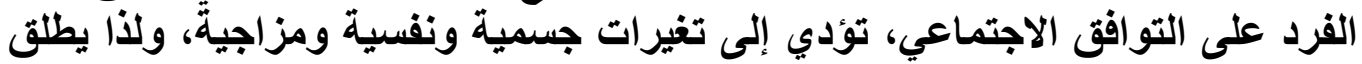

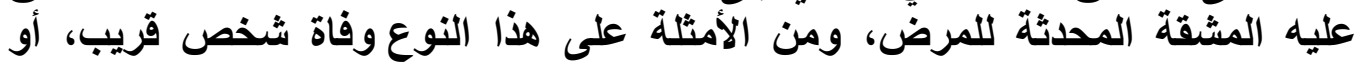

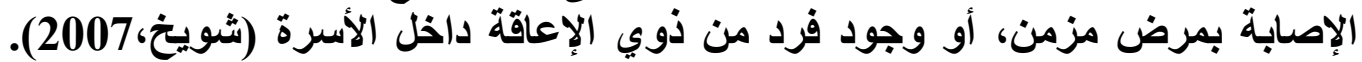

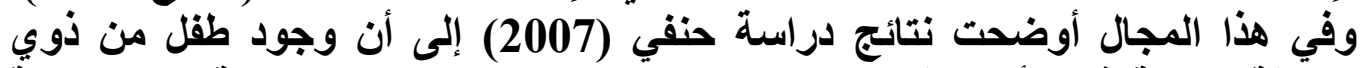

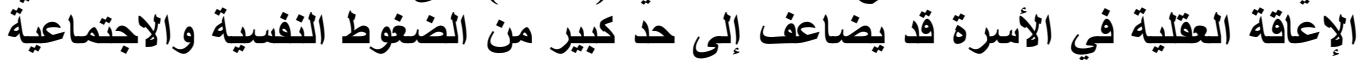

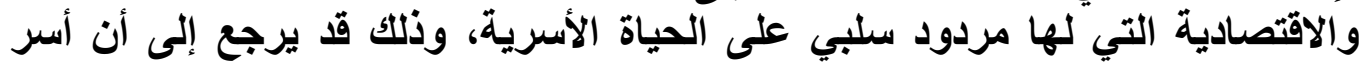

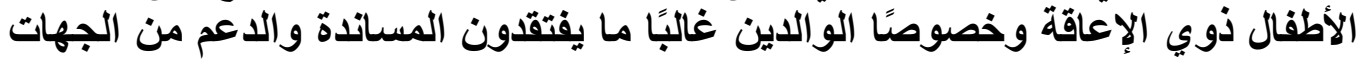

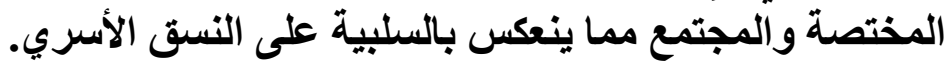

\section{أنواع الضغوط النفسية :}

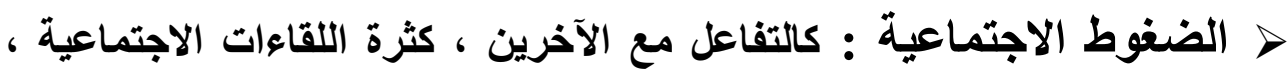

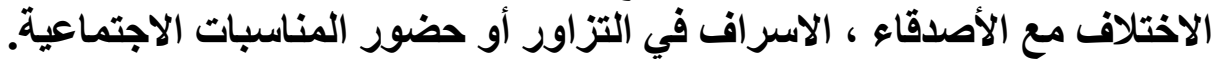

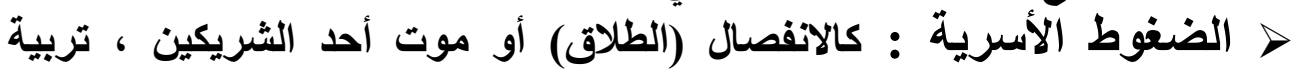

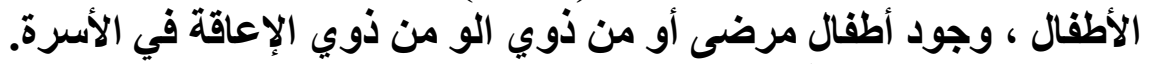

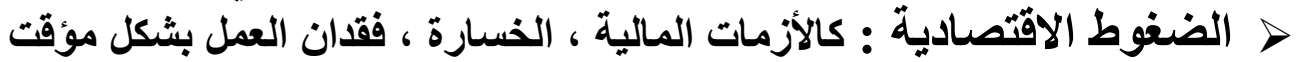

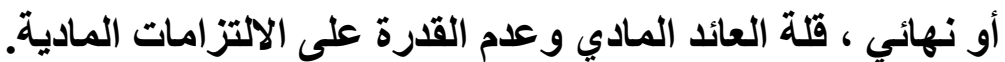

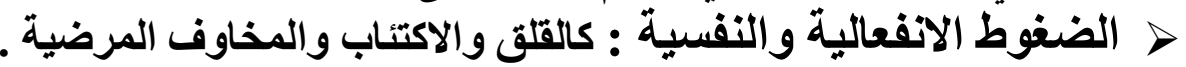

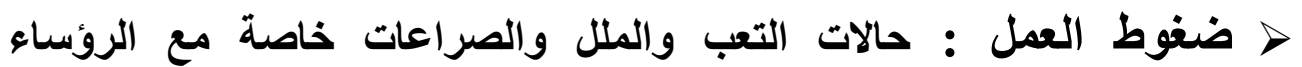

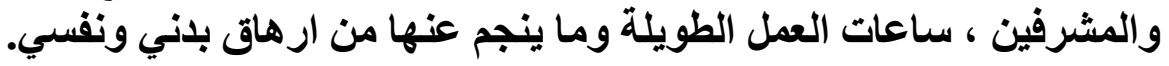

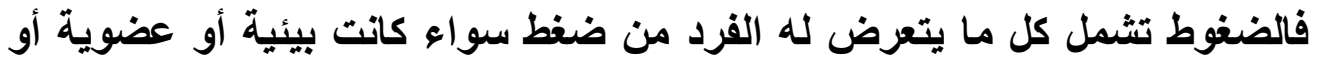

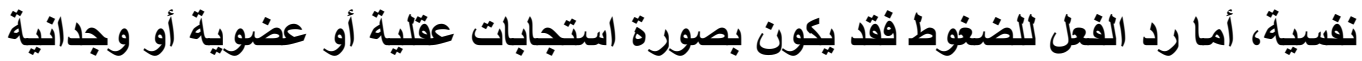

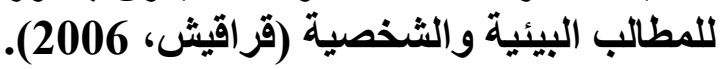

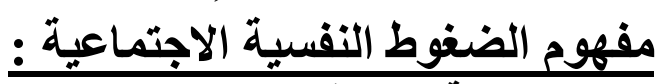

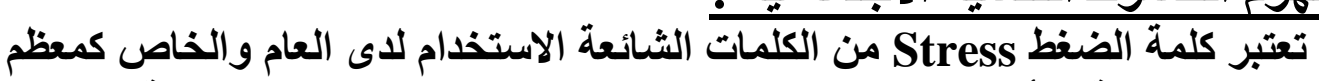

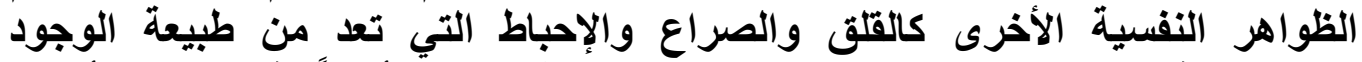

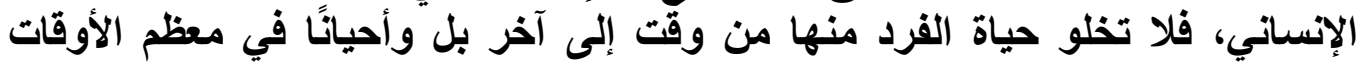

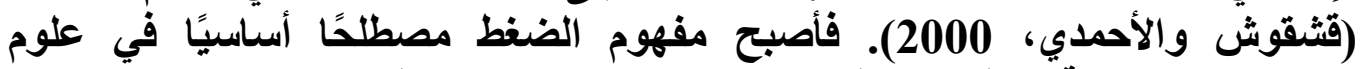

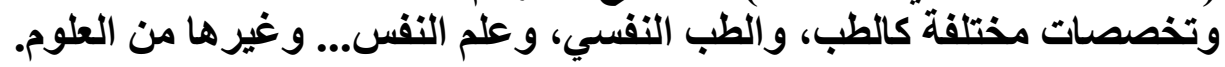


ورغم اهتمام الكثير من العلماء منذ أواخر القرن الثامن عثر من القرن الماضي الفئي

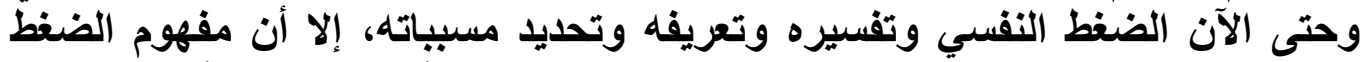

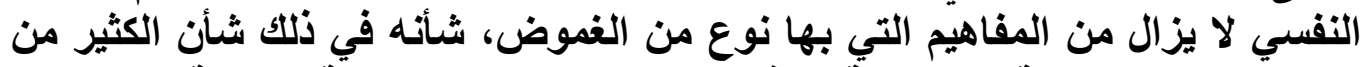

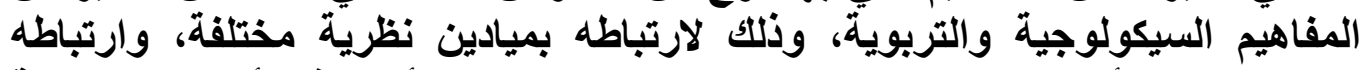

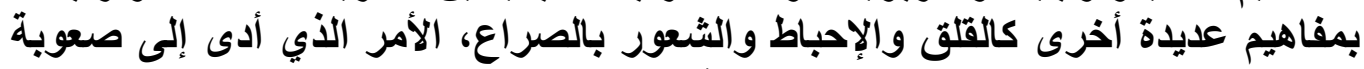

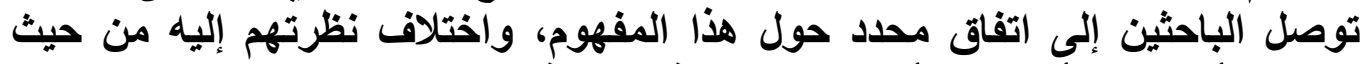

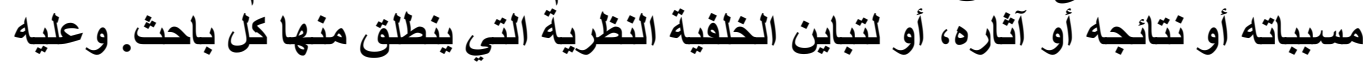
تعددث التعاريف المقدمة لمفهوم الضغط أنفار النفسي بشكل يُعكس هذا التباين في وجهات

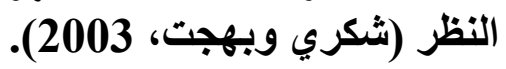

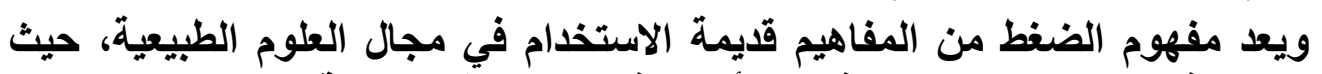

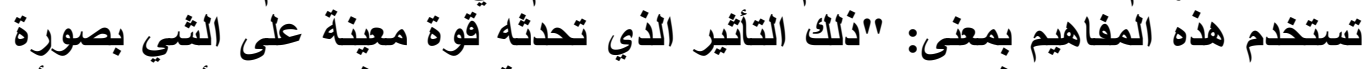

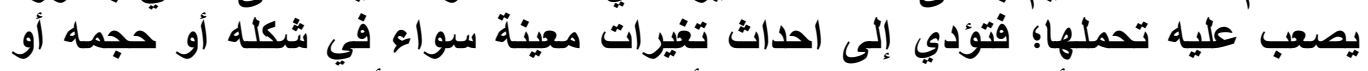

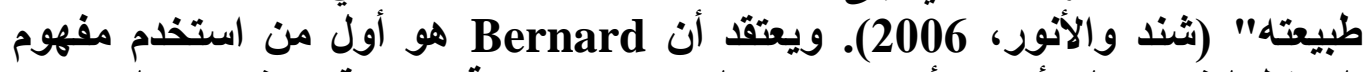

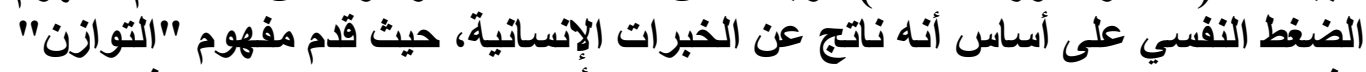

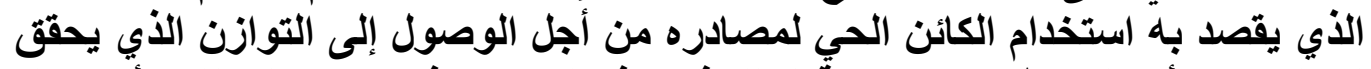

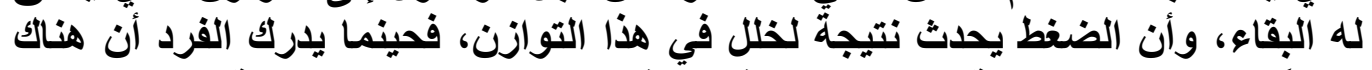

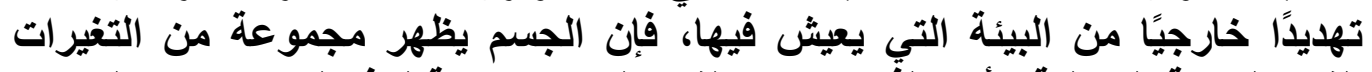

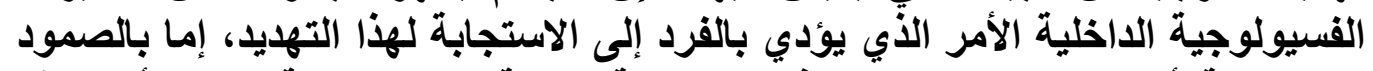

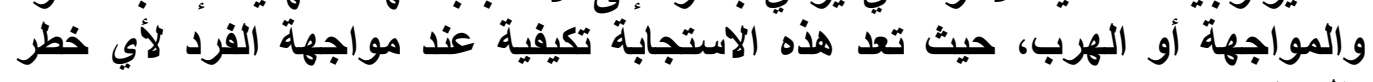

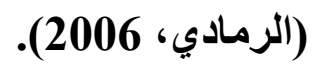

أما بالنسبة للضغوط النفسية الاجتماعية فهي المحرك الرئيسي لحياة الإنسان، ويتم

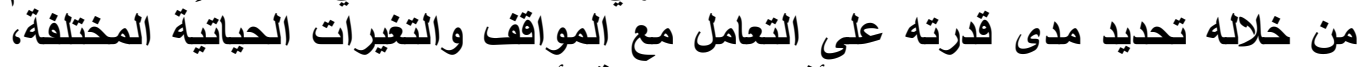

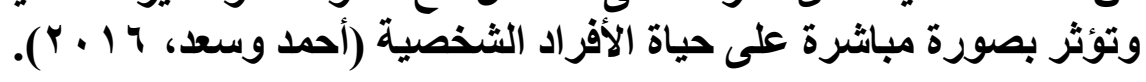

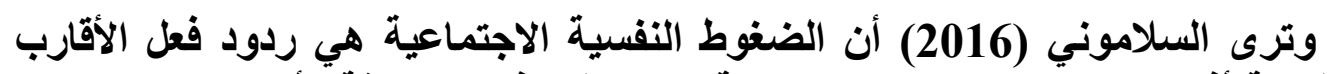

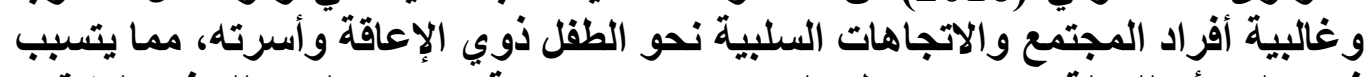

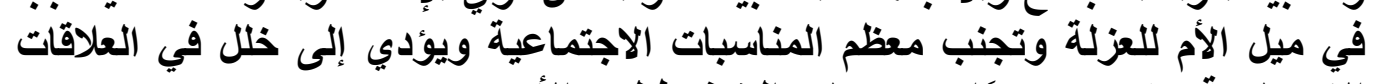

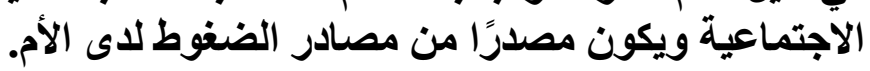

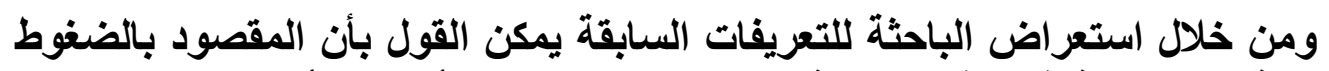

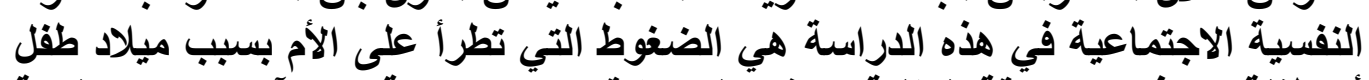

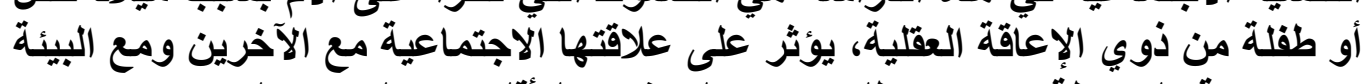

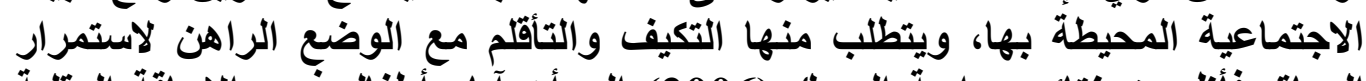

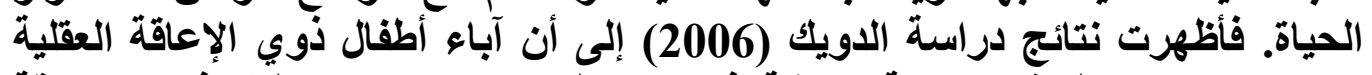

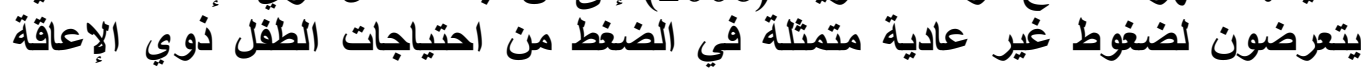




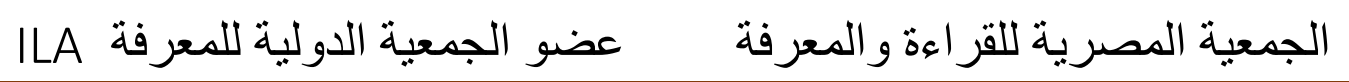

العقلية، وصعوبة العناية به ومثاكله السلوكية، كما أن هناك صراعات تواجه الآباء

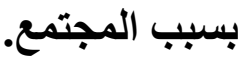

صدق وثبات أدوات البحث :

مقياس الإرشاد الأسرى: مئي:

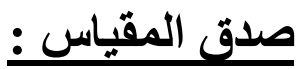

يقصد به قدرة المقياس على قياس ما وضع لقياسه.

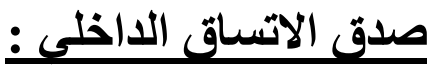

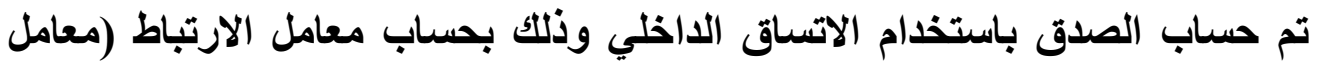
ارتباط بيرسون) بين درجة كل عبارة والدرجة الكلية للمقياس، والجدول التالي يوضح

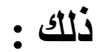

جدول (1) قيم معاملات الارتباط بين درجة كل عبارة والدرجة الكلية لمقياس الإرشاد الأسري

\begin{tabular}{|c|c|c|c|c|c|}
\hline الالالة & الارتباط & p & الدلالة & الارتباط & b \\
\hline 0.01 & 0.713 & 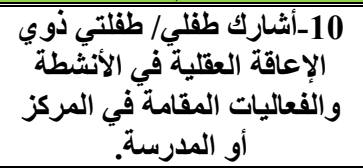 & 0.01 & 0.787 & 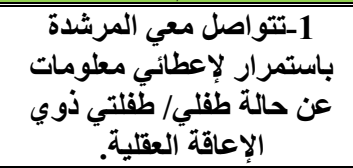 \\
\hline 0.01 & 0.807 & 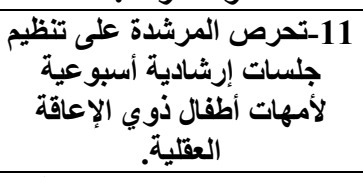 & 0.01 & 0.848 & 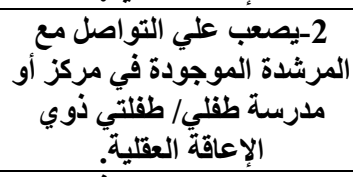 \\
\hline 0.05 & 0.641 & 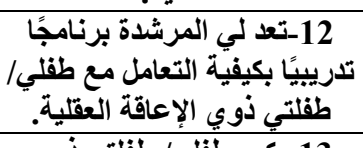 & 0.01 & 0.944 & 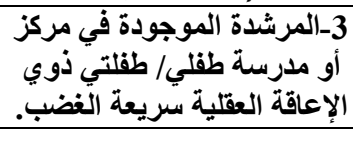 \\
\hline 0.05 & 0.619 & 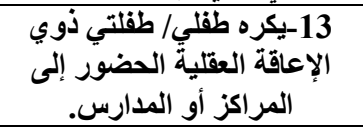 & 0.01 & 0.903 & 4-تقوم المرشتدرة بتو عيني ثقافيًا \\
\hline 0.01 & 0.921 & 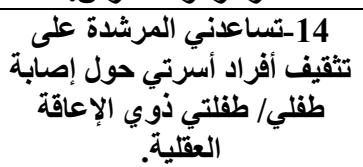 & 0.01 & 0.755 & الاتسجام في علاقلتي معد أفراد \\
\hline 0.01 & 0.812 & 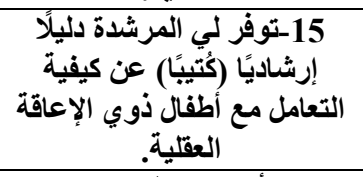 & 0.01 & 0.871 & التكيف مساعع الضني المرط الخدارجية. \\
\hline 0.01 & 0.776 & 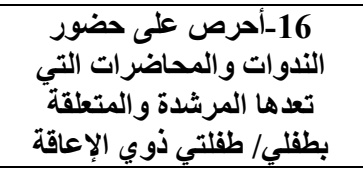 & 0.05 & 0.637 & 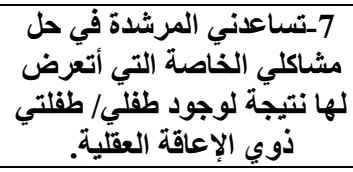 \\
\hline
\end{tabular}


الجمعية المصرية للقر اعة والمعرفة عضو الجمعية الدولية للمعرفة

\begin{tabular}{|c|c|c|c|c|c|}
\hline & & العقلية. & & & \\
\hline 0.01 & 0.865 & 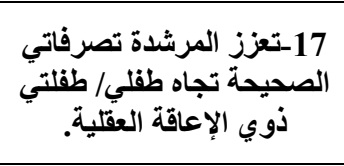 & 0.05 & 0.602 & 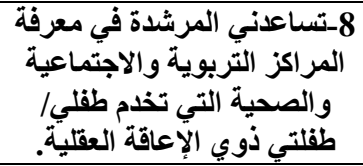 \\
\hline 0.01 & 0.711 & 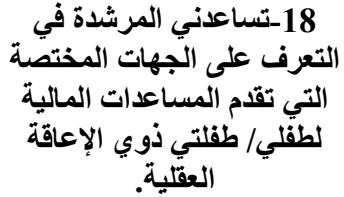 & 0.01 & 0.729 & 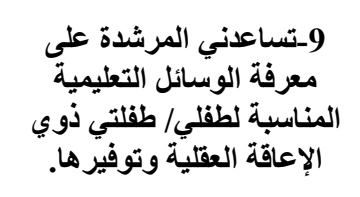 \\
\hline
\end{tabular}

يتضح من الجدول أن معاملات الارتباط كلها دالة عند مستوى (0.01 - 0.05 )

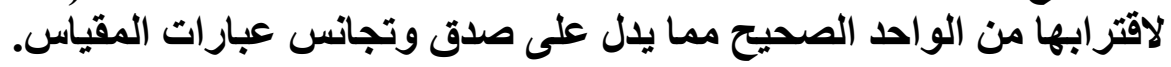

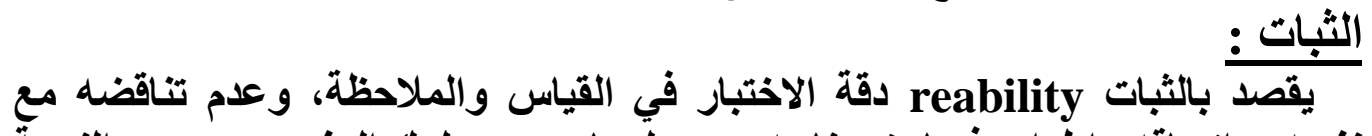

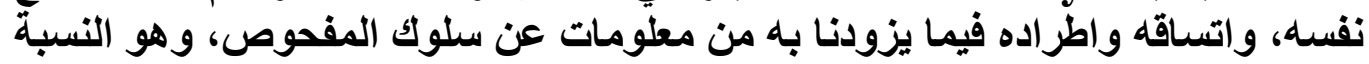

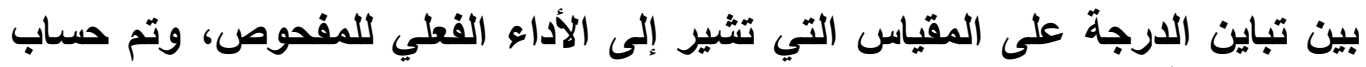

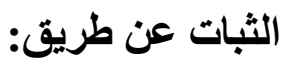

Alpha Cronbach معامل الفا كرونباخ: 1

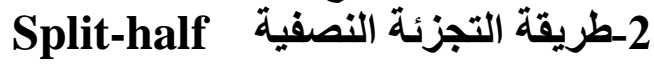
3uttman جيوتمان

جدول (2) قيم معامل الثبات لمقياس الإرشاد الأسري

\begin{tabular}{|c|c|c|c|}
\hline جيوتمان & التجزئة النصفية & معامل & \\
\hline 0.850 & $0.894-0.811$ & 0.862 & ثبات مقياس الإرشاد الأسري ككل \\
\hline
\end{tabular}

يتضح من الجدول السابق أن جميع قيم معاملات الثبات: معامل الفان الفان التجزئة النصفية، جيوتمان دالة عند مستوى (0.01) مما يال على على ثبات المات المقياس.

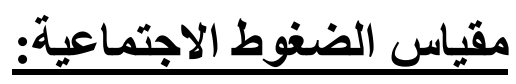

يقصد به المقرة المقياس:

صدق الاتساق الداخلى : تابل تم حساب الصدق باستخذام الاتساق الأخلي وذللك بحساب معامل الارتباط (معامل

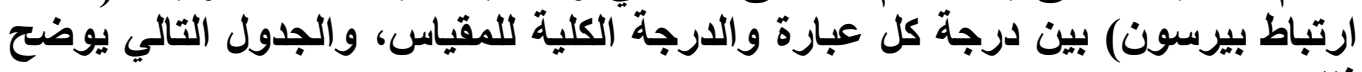


جدول (3) قيم معاملات الارتباط بين درجة كل عبارة والارجة الكلية لمقياس الضغوط

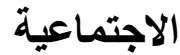

\begin{tabular}{|c|c|c|c|c|c|}
\hline الدلالة & الارتباط & م & الدلالة & الارتباط & م \\
\hline 0.01 & 0.793 & 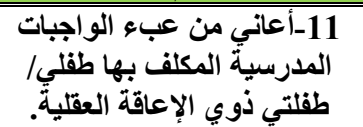 & 0.01 & 0.762 & 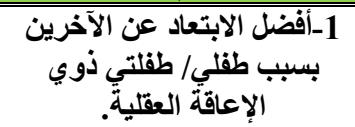 \\
\hline 0.05 & 0.631 & 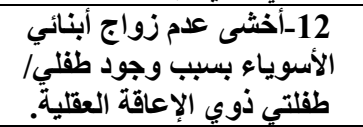 & 0.01 & 0.851 & 2-2ينتابني الثلعور بأنتي سبب \\
\hline 0.01 & 0.862 & علي 13-ازبب وجود الأعمال المنزلية طلتية & 0.01 & 0.915 & 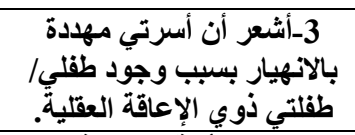 \\
\hline 0.01 & 0.748 & 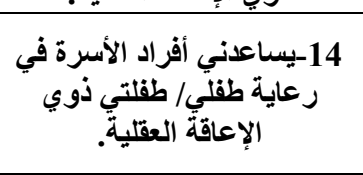 & 0.01 & 0.737 & 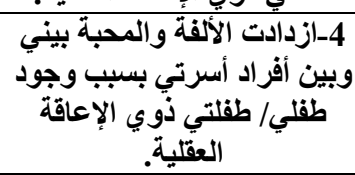 \\
\hline 0.01 & 0.895 & 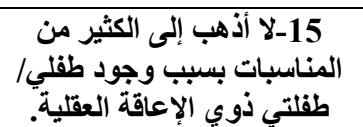 & 0.05 & 0.628 & 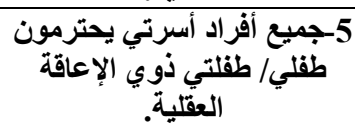 \\
\hline 0.01 & 0.957 & 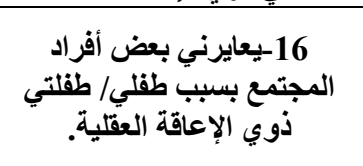 & 0.01 & 0.823 & 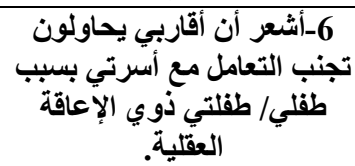 \\
\hline 0.05 & 0.616 & 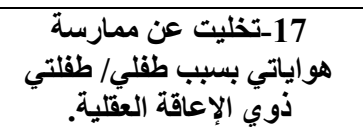 & 0.01 & 0.889 & 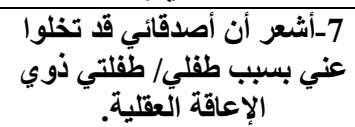 \\
\hline 0.01 & 0.774 & 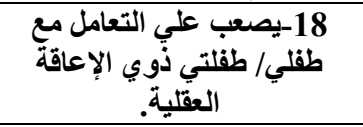 & 0.01 & 0.948 & 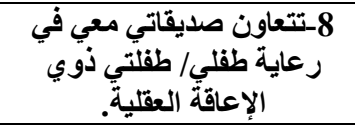 \\
\hline 0.01 & 0.936 & 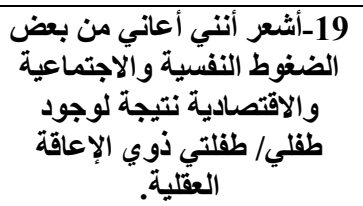 & 0.05 & 0.606 & 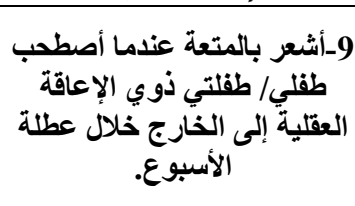 \\
\hline 0.01 & 0.838 & 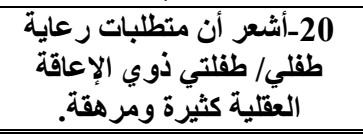 & 0.01 & 0.706 & 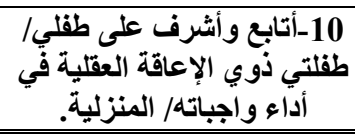 \\
\hline
\end{tabular}

يتضح من الجدول أن معاملات الارتباط كلها دالة عند مستوى (0.01 0.05 - 0.05 ) لاقترابها من الواحد الصحيح مما يدل على صدق وتجانس الأنساط عبار دات المقياس.

الثبات :

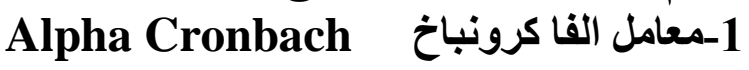




\section{ILA الجمعية المصرية للقر اعة والمعرفة عضو الجمعية الدولية للمعرفة}

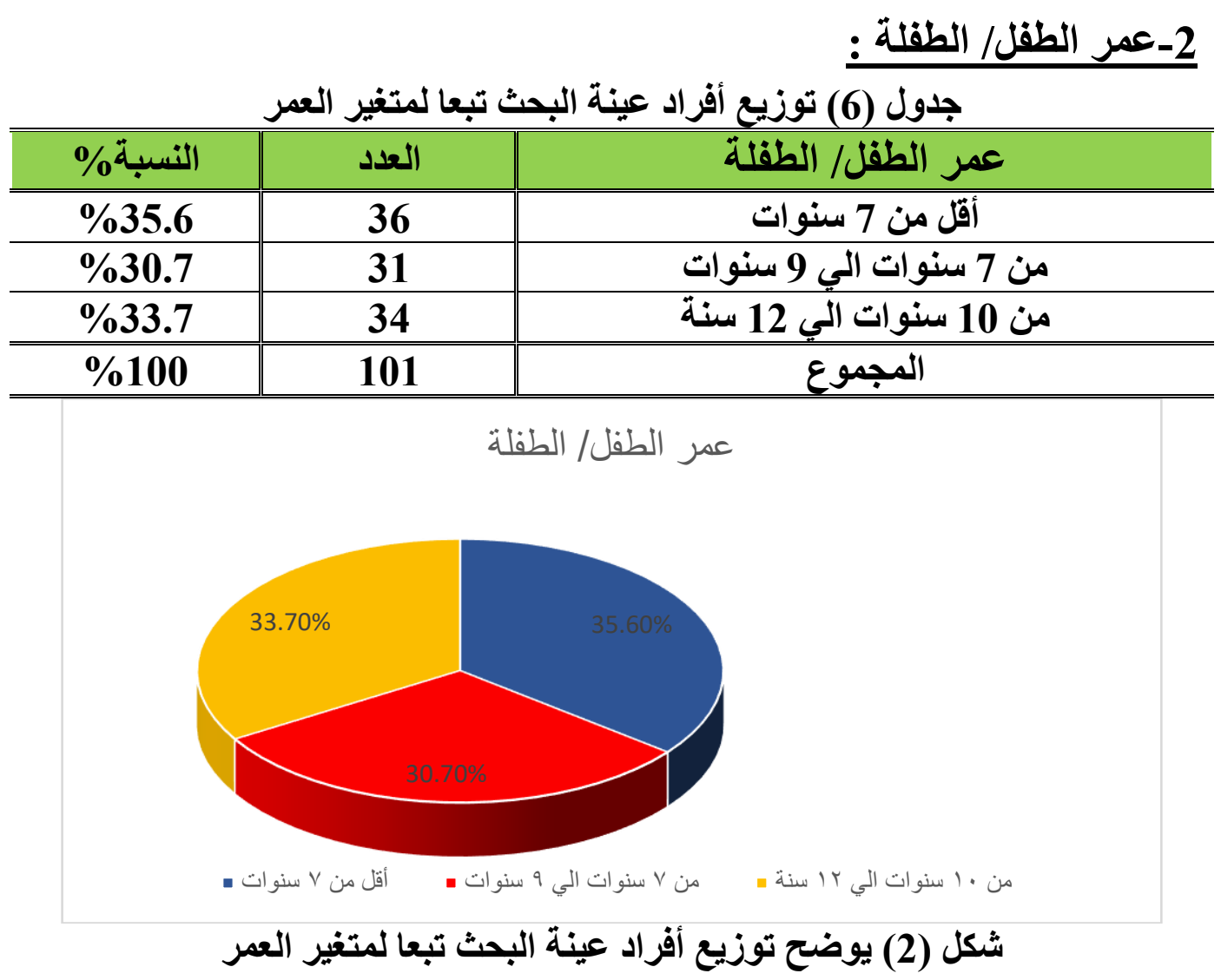

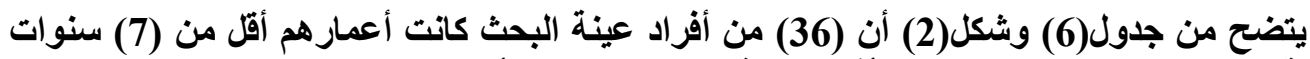

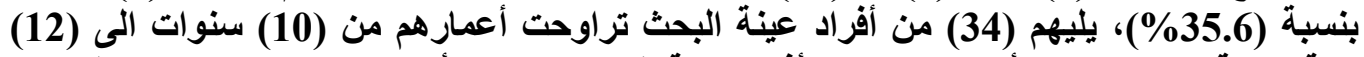

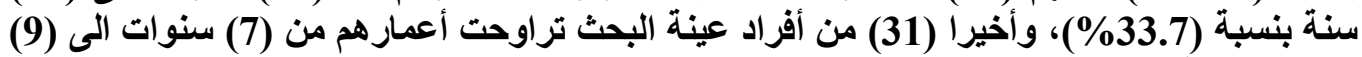

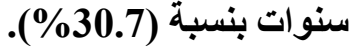

:3

جدول (7) توزيع أفراد عينة البحث تبعا لمتغير عمر الأم

\begin{tabular}{|c|c|c|}
\hline النسبة\%\% & 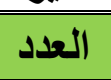 & عمر الأم \\
\hline$\% 36.6$ & 37 & أقل من 35 سنة \\
\hline$\% 40.6$ & 41 & من35 سنة لأقلّ من 45سنة \\
\hline$\% 22.8$ & 23 & من 45 سنة فأكثر \\
\hline$\% 100$ & 101 & المجموع \\
\hline
\end{tabular}




\section{الجمعية المصرية للقر اءة والمعرفة عضو الجمعية الدولية للمعرفة المي}

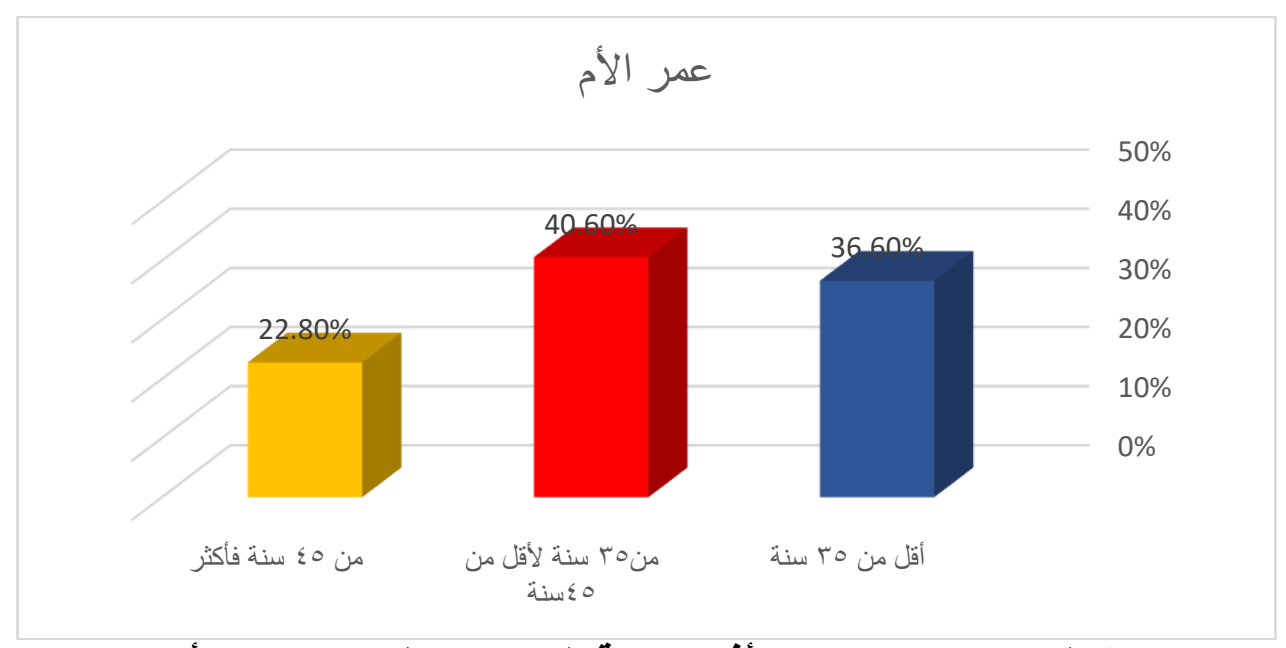

شكل (3) يوضح توزيع أفراد عينة البحث تبعا لمتغير عمر الأم

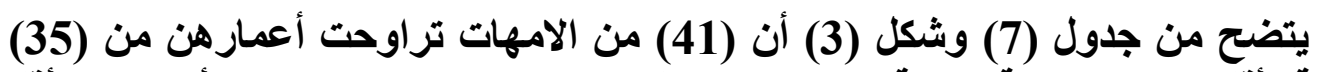

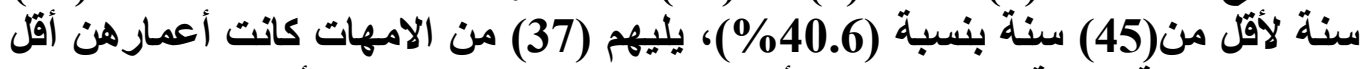
من (35) سنة بنسبة (36.6\%))، وأخيرا (23) من الامهات كانت أعمارهن من (45) (35)

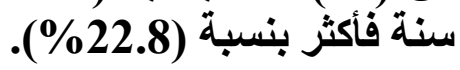

\begin{tabular}{|c|c|c|}
\hline \multicolumn{3}{|c|}{ جدول (8) توزيع أسر عينة البحث وفقا لفئات الدخل المختلفة } \\
\hline 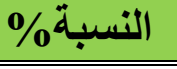 & العدد & الاخل الشهري \\
\hline$\% 31.7$ & 32 & أقل من 10000 ريال \\
\hline$\% 47.5$ & 48 & من 10000 ريال لأقل من 15000 ريال \\
\hline$\% 20.8$ & 21 & من 15000 ريال فأكثر \\
\hline$\% 100$ & 101 & 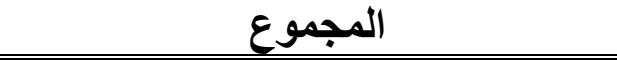 \\
\hline
\end{tabular}

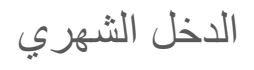

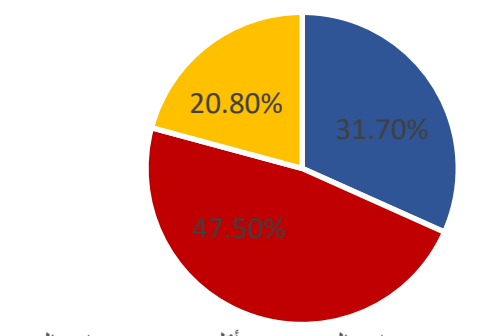

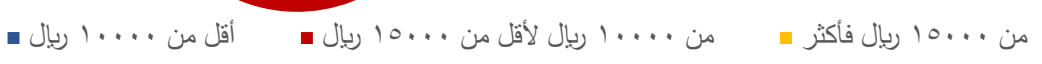


شكل (4) يوضح توزيع أسر عينة البحث وفقا لفئات الاخل المختلفة

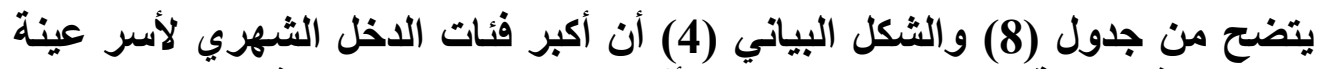

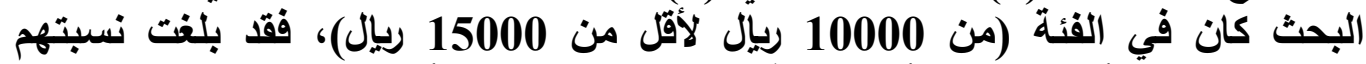

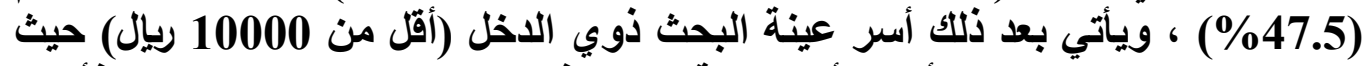

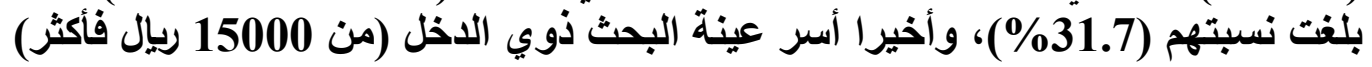

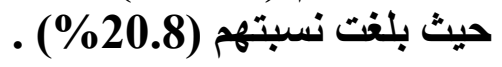

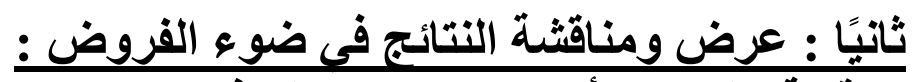

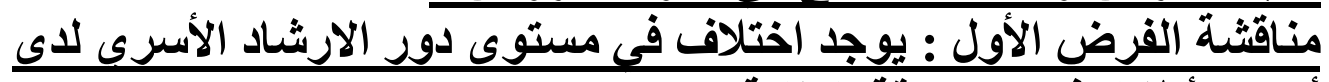

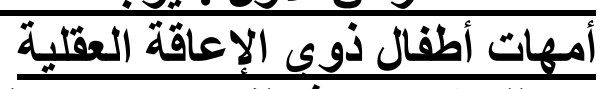

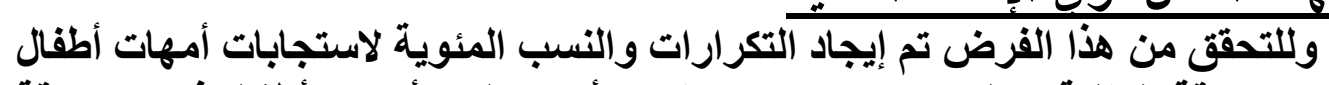

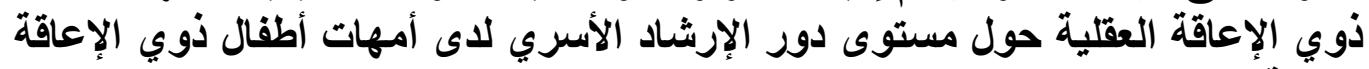
العقلية

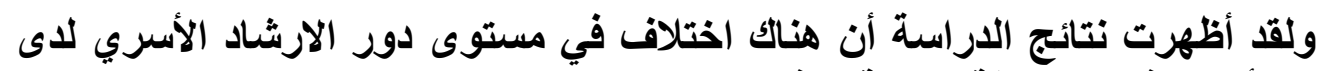

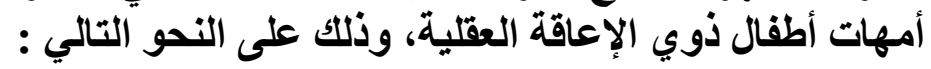

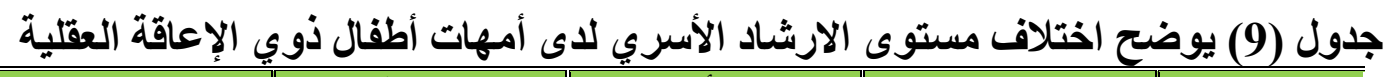

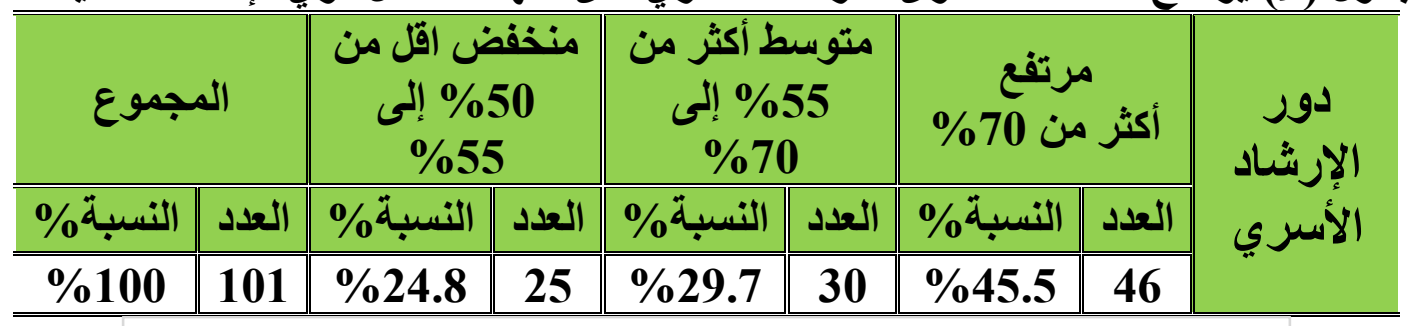
دور الإرشاد الأسري

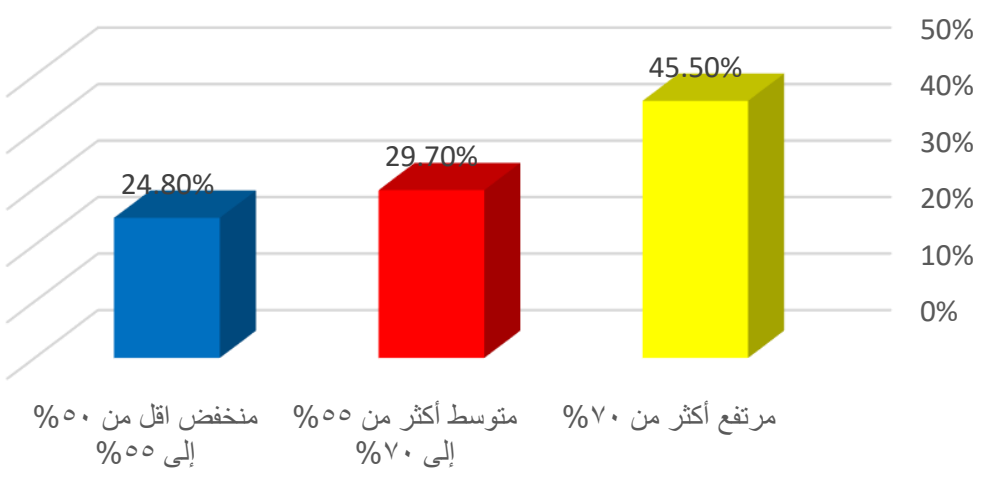

شكل (5) يوضح اختلاف مستوى الارشاد الأسري لاى أمهات أطفال ذوي الإعاقة العقلية 
يتضح من الجدول (9) وشكل (5) أن مستوى الارشاد الأسري المرتفع لاى أمهات

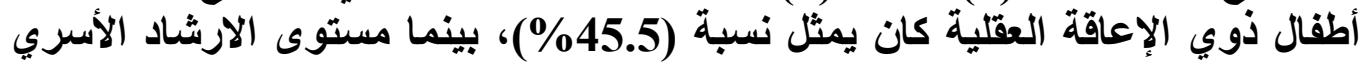

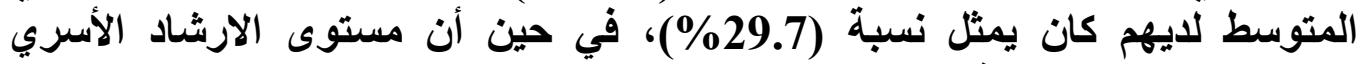
المنخفض كان يمثل نسبة (24.8\%)

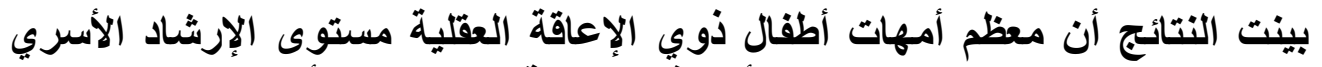

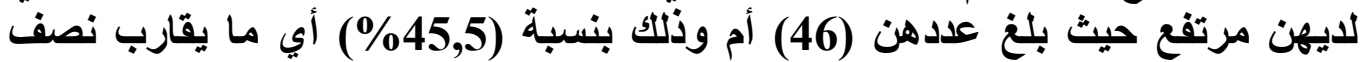

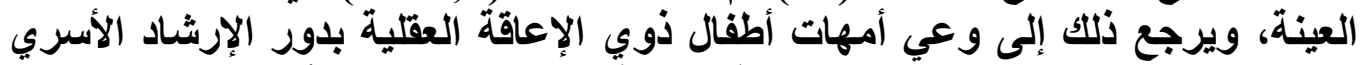

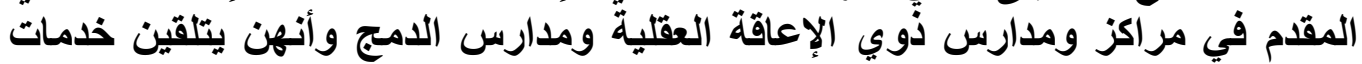

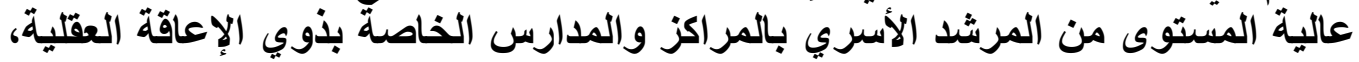

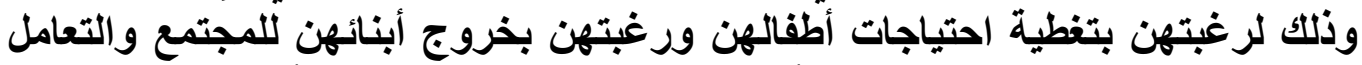

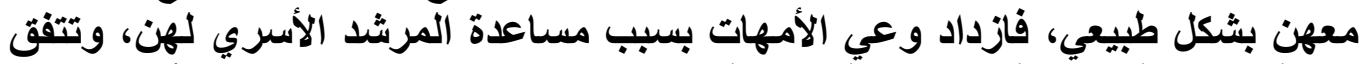

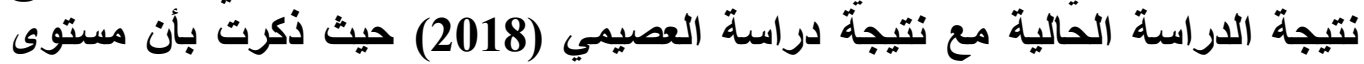

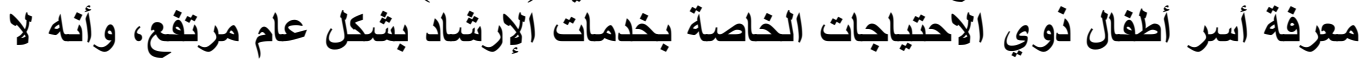

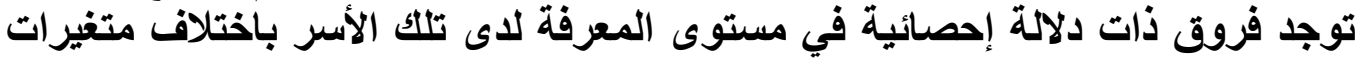

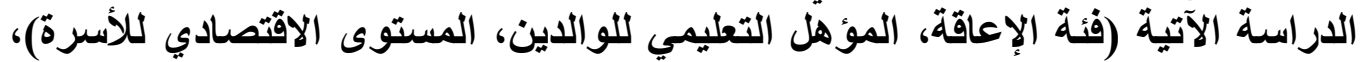

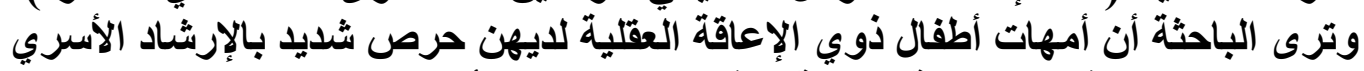

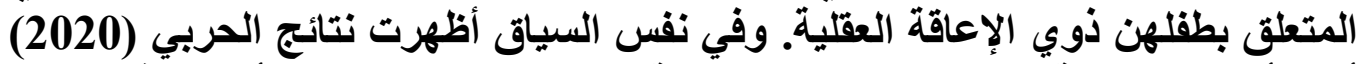
أن الأسر السعودية يملكون اتجاهات إيجابية نحو خدمات الإنة الإشاد الأسري في في جميع المر احل بمستوى مرتفع.

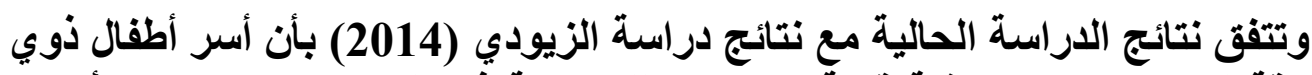

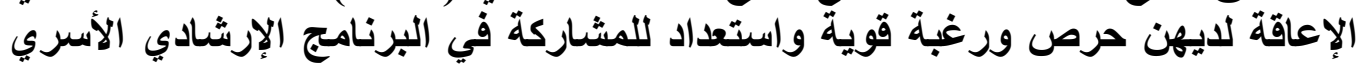

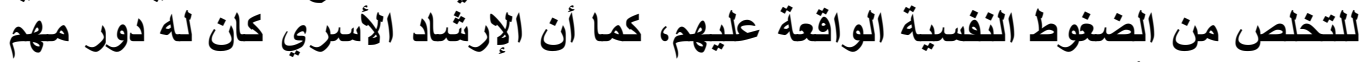

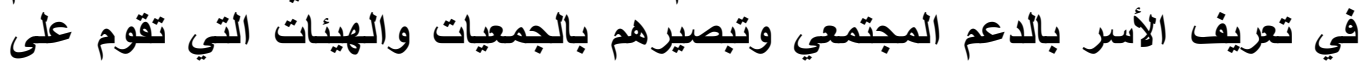

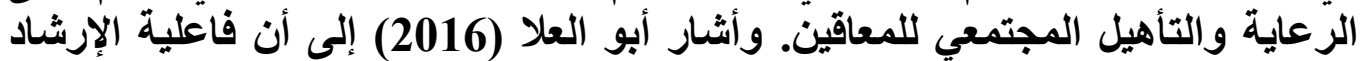

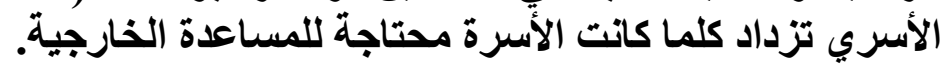

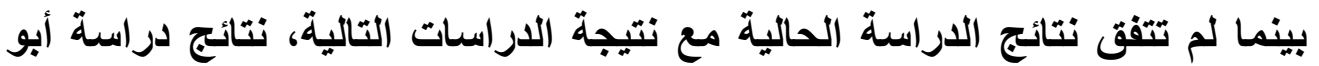

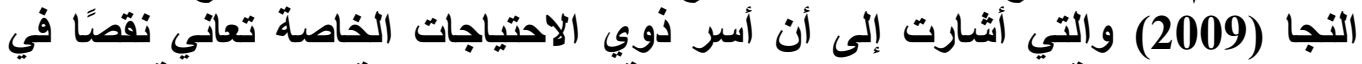

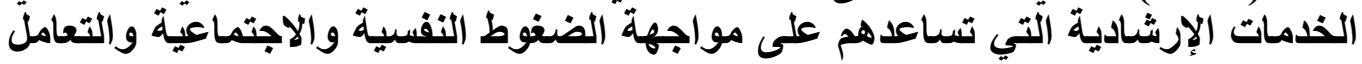

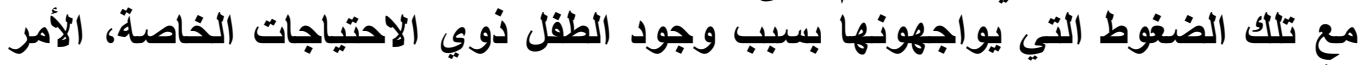

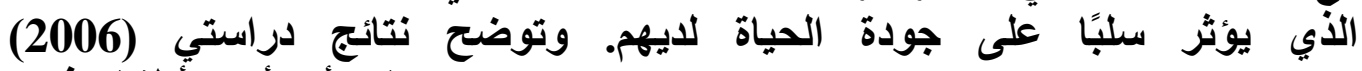
Hintermair

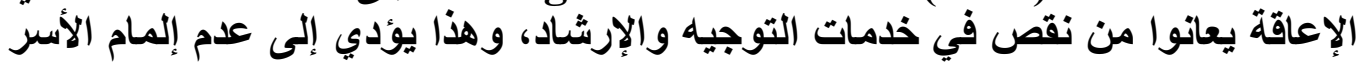

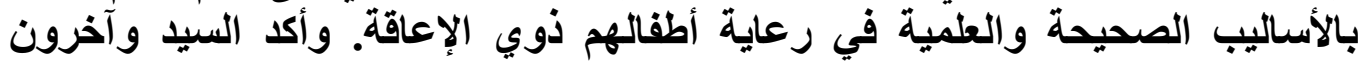


(2016) على أن الأسرة تعاني من بعض المشكلات والضغوط النفسية التي لا تجد سبيلًا

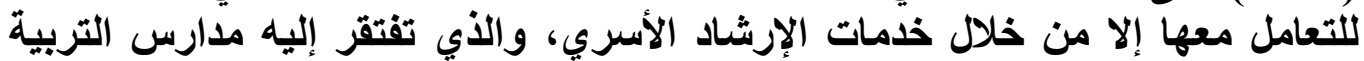

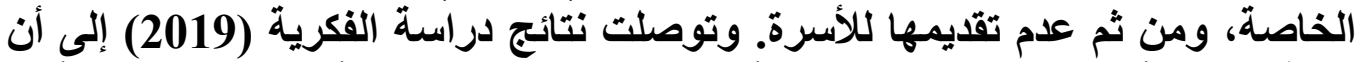

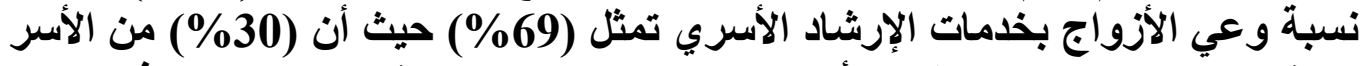

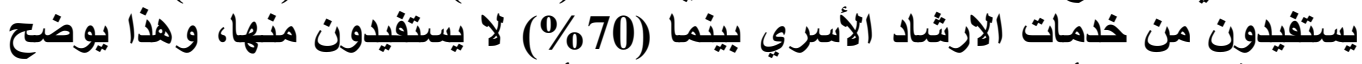
قصور في وعي الأزواج بخدمات وبرات الارئ الارشاد الأسري.

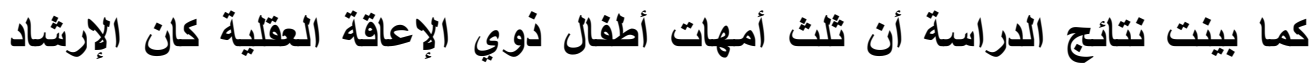

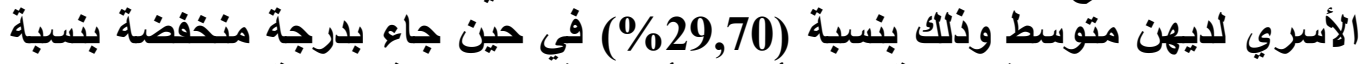

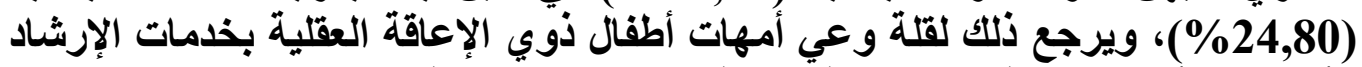

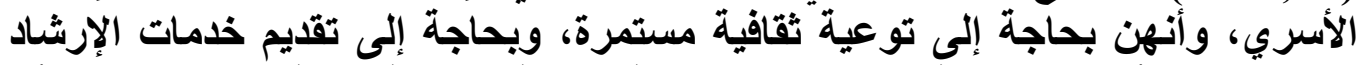

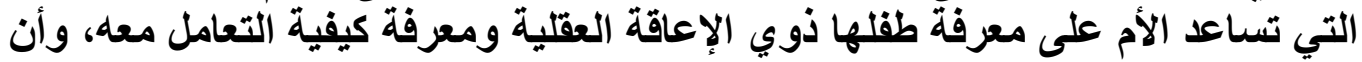

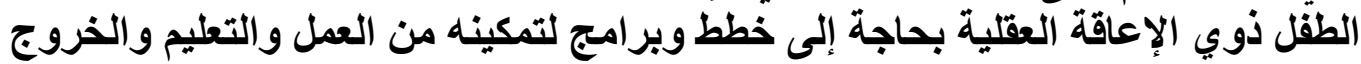

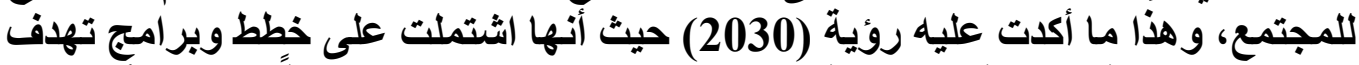

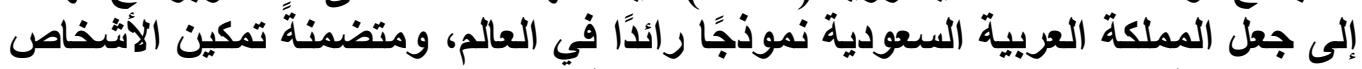

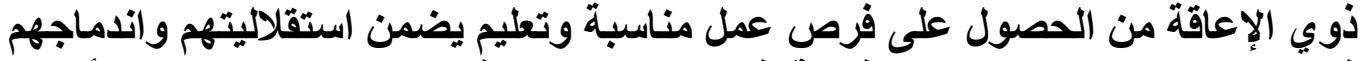

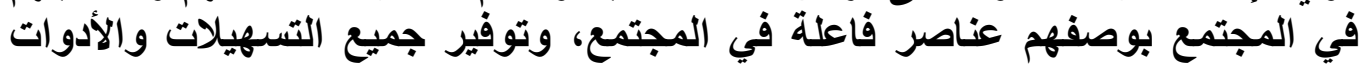
التي تساعدهم على تحقيق هذا النجاح.

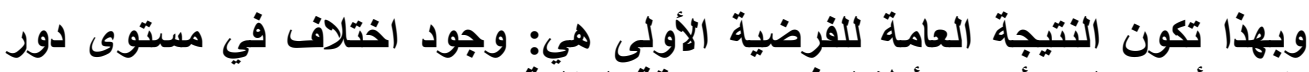
الإرشاد الأسري لاى أمهات أطفال ذوي الإعاقة العقلئية.

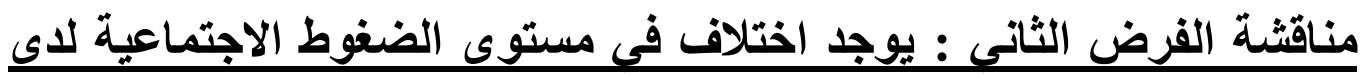

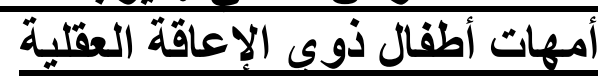

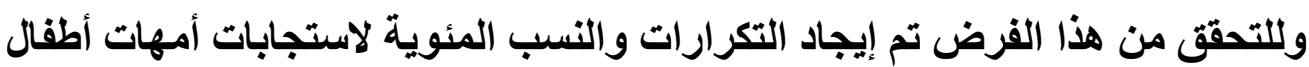

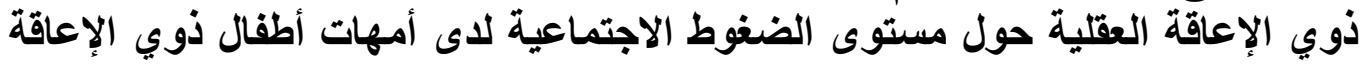

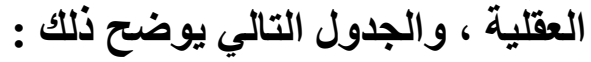

جدول (10) يوضح اختلاف مستوى الضغوط الاجتماعية لاى أمهات أطفال ذوي الإعاقة العقلية

\begin{tabular}{|c|c|c|c|c|c|c|c|c|}
\hline \multicolumn{2}{|c|}{ المجموع } & \multicolumn{2}{|c|}{ 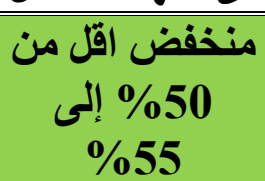 } & \multicolumn{2}{|c|}{ 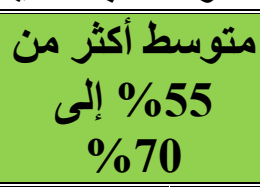 } & \multicolumn{2}{|c|}{ أكثر من مرتفع \% } & \multirow{3}{*}{ الاجتماعي } \\
\hline النسبة & الد & $\begin{array}{c}\text { النسبة } \\
\text { \% }\end{array}$ & العد & $\begin{array}{l}\text { النسبة } \\
\text { \% }\end{array}$ & العد & أنسبة & العد & \\
\hline$\% 100$ & $\begin{array}{c}10 \\
1\end{array}$ & $\% 21.8$ & 22 & $\% 41.6$ & 42 & $\% 36.6$ & 37 & \\
\hline
\end{tabular}


الجمعية المصرية للقر اءة والمعرفة عضو الجمعية الدولية للمعرفة المي

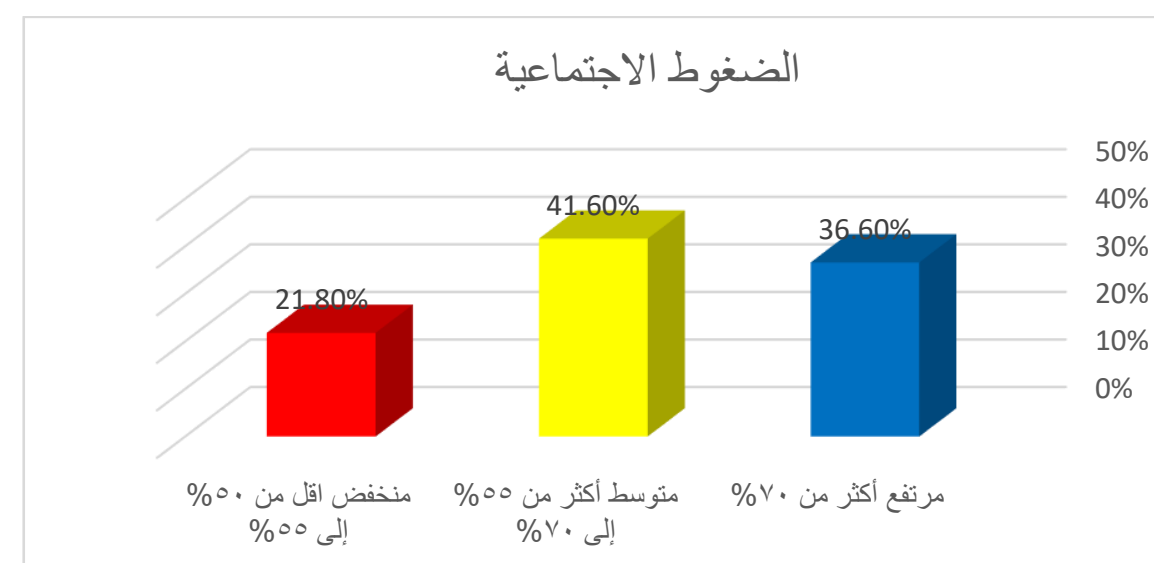

شكل (6) يوضح اختلاف مستوى الضغوط الاجتماعية لاى أمهات أطفال ذوي الإعاقة العقلية

يتضح من الجدول (10) وشكل (6) أن مستوى الضغوط الاجتماعية المرتفع لدى الدئ

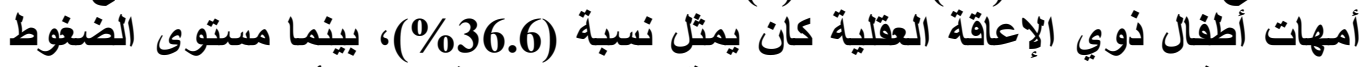

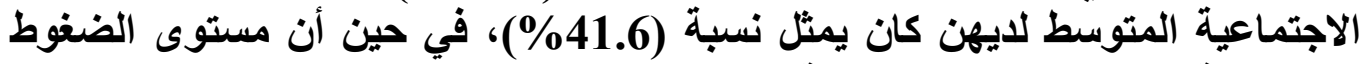

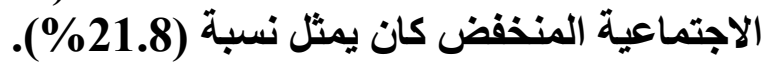

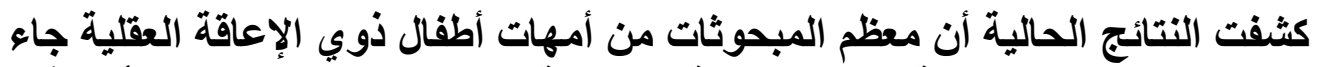

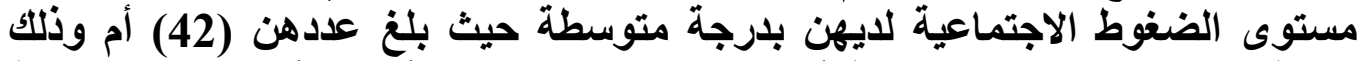

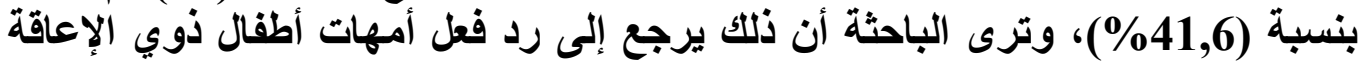

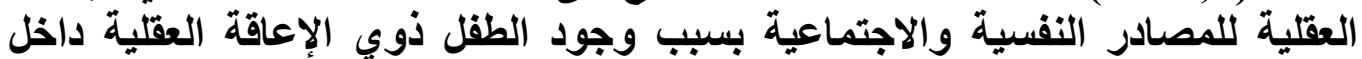

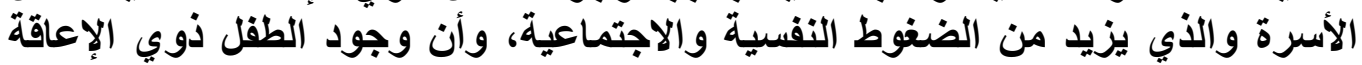

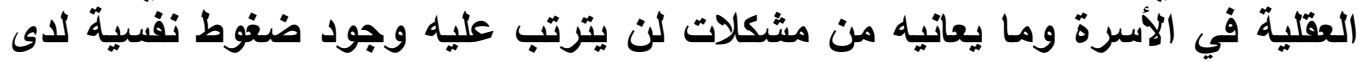

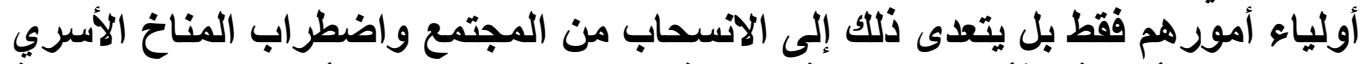

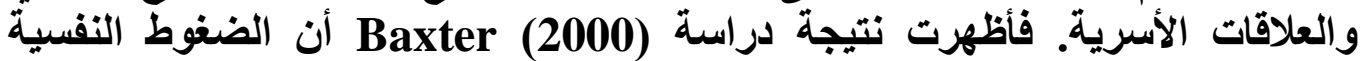

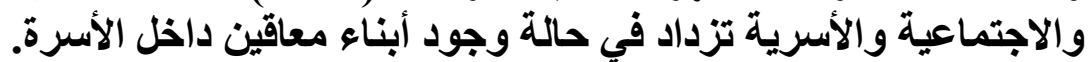

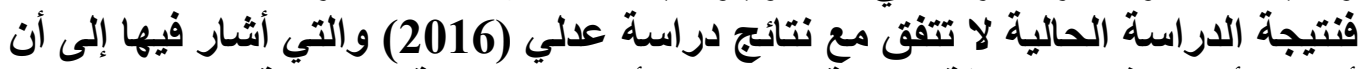

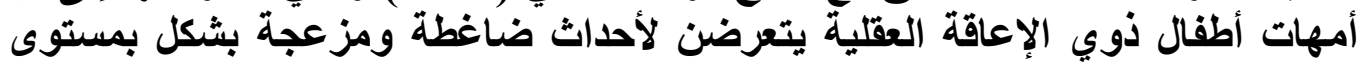

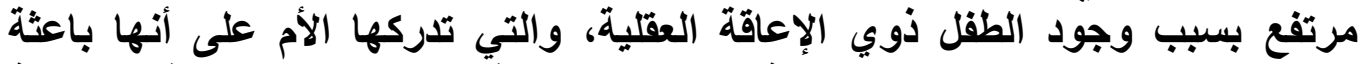

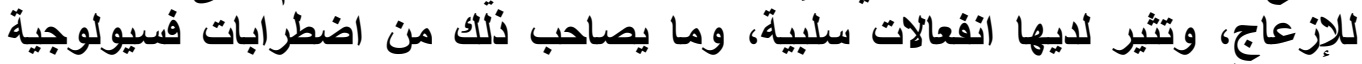

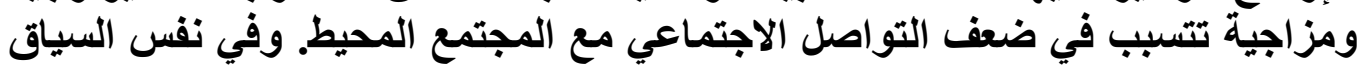

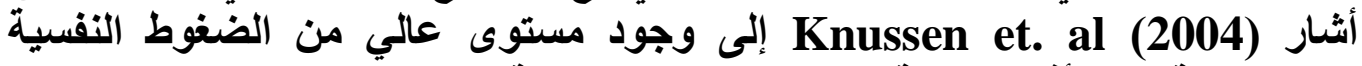

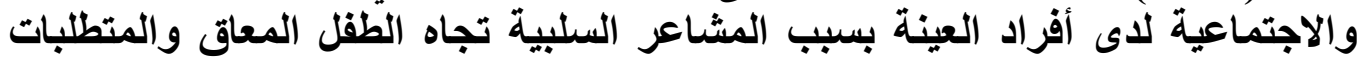

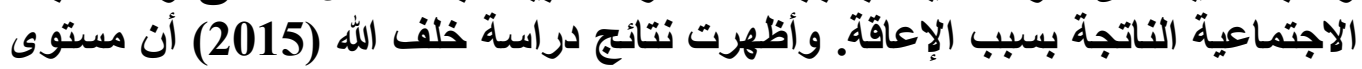




\section{ILA الجمعية المصرية للقر اءة والمعرفة عضو الجمعية الدولية للمعرفة}

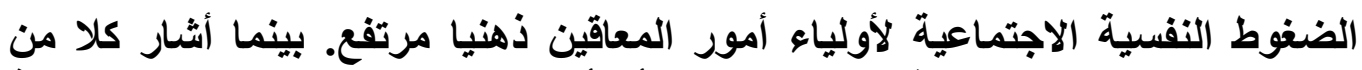

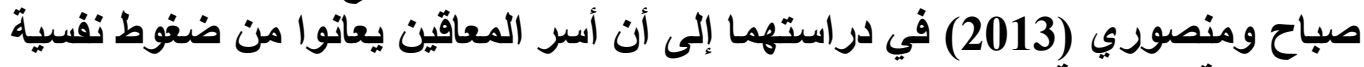
واجتماعية منخفضة.

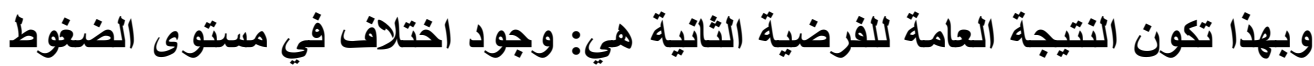
الاجتماعية لاى أمهات أطفال ذونة العامة للفري الإعاقة العقلية.

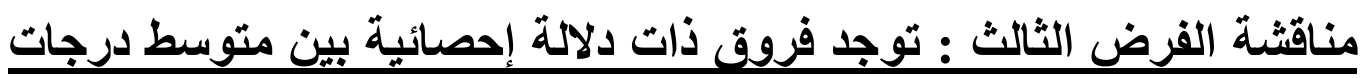

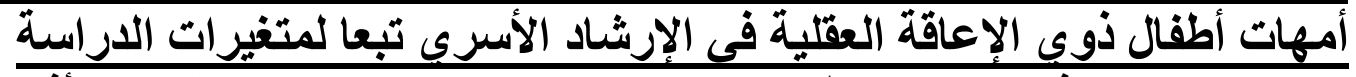

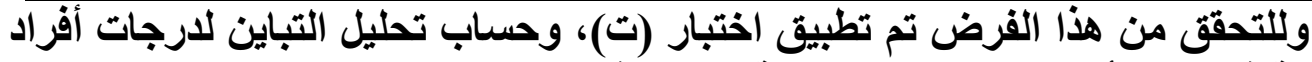

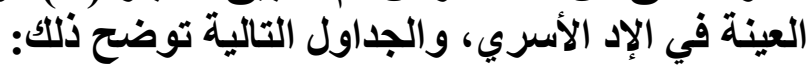
جدول (11) الفروق في متوسط درجات أفراد العينة في الإرشاد الأسري تبعا لمتغير الجنس

\begin{tabular}{|c|c|c|c|c|c|c|}
\hline الدلالة & 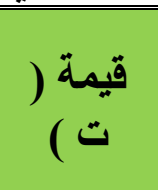 & الحرية & العينة & الالمعرافي & الحستابي & الطفل الطقلة \\
\hline \multirow{2}{*}{ دال عند 0.01} & \multirow{2}{*}{15.527} & \multirow{2}{*}{99} & 53 & 3.074 & 30.159 & ذكر \\
\hline & & & 48 & 4.521 & 46.670 & أنثي \\
\hline
\end{tabular}

\section{جنس الطقل/ الطفلة}

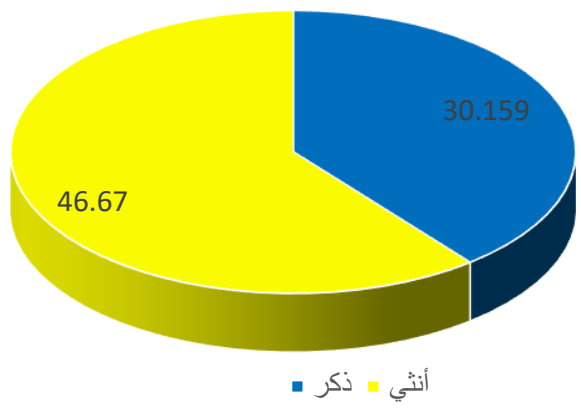

شكل (7) الفروق في متوسط درجات أفراد العينة في الإرشاد الأسري تبعا لمتغير الجنس

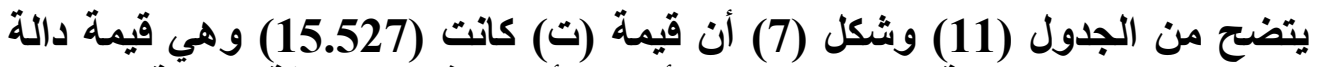

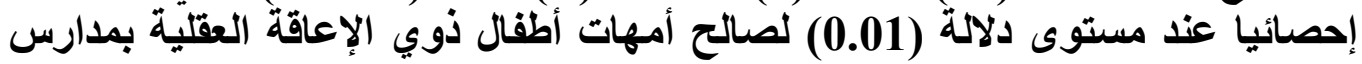

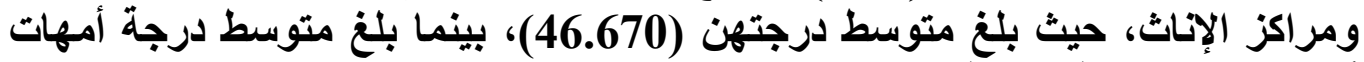
أطفال ذوي الإعاقة العقلية بمدارس ومراكز الأنكور درن (30.159). 
وترى الباحثة أن ذلتك يدل على أن مدارس ومراكز الإناث كان الإششاد الأسري لايهه

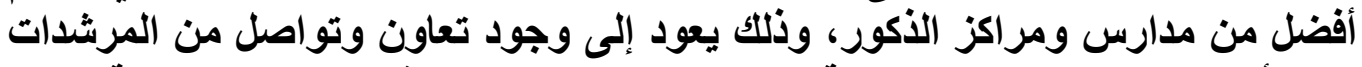

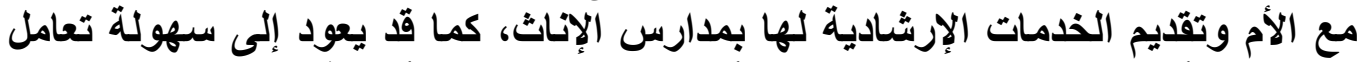

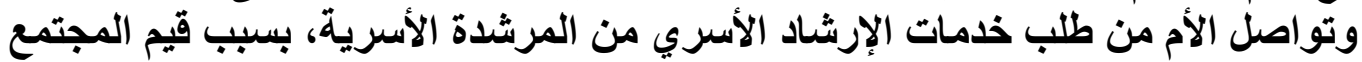

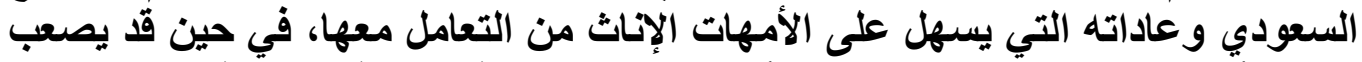

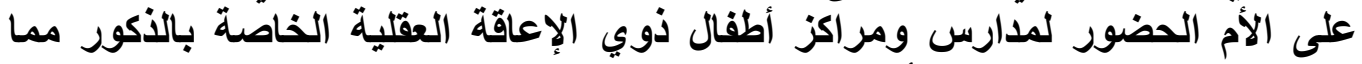
يعوق تلقي خدمات الإرشاد الأسري. ويوضح السلامة (2003) أن أداء المرشد في المدارس العارئ الحكومية يختلف تبعًا لمتغير الجنس، ولُصالح مدارس الإناث في جميع المجالات.

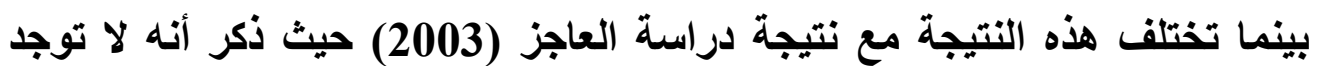

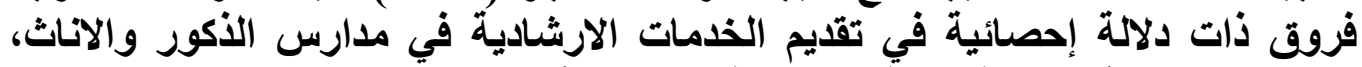

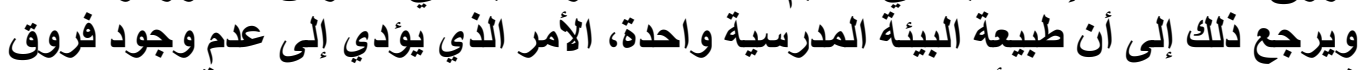

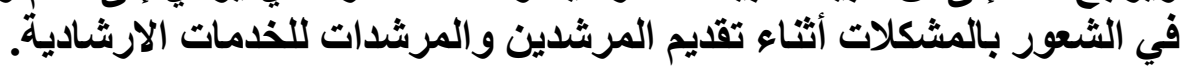

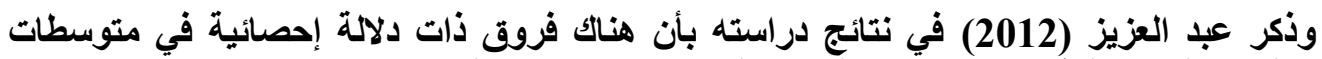

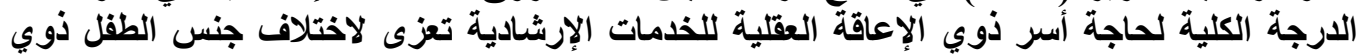

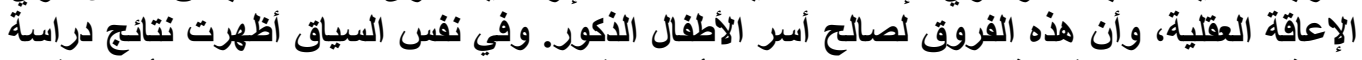

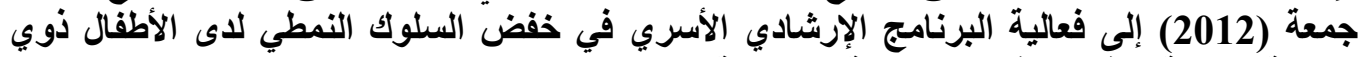
الإعاقة الفكرية (الذكور) في المجموعة التجرية التجريبية. جدول (12) تحليل التباين لارجات أفراد العينة في الإرشاد الأسري تبعا لمتغير عمر الطقل/ الطقلة في الإلة

\begin{tabular}{|c|c|c|c|c|c|}
\hline الدلالة - مالة & قفيمة & الدرجية & متروسط & المربعاتٍ & عمر الطقل/ الطقلة \\
\hline \multirow{2}{*}{0.01} & \multirow{2}{*}{$\mathbf{5 7 . 2 9 0}$} & 2 & 2638.716 & 5277.432 & بين المجموعات \\
\hline & & 98 & 46.059 & 4513.792 & داخل المجموعات \\
\hline & & 100 & & 9791.224 & |لהבת ع \\
\hline
\end{tabular}

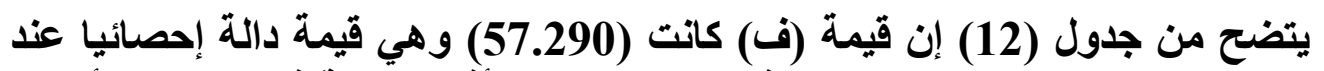

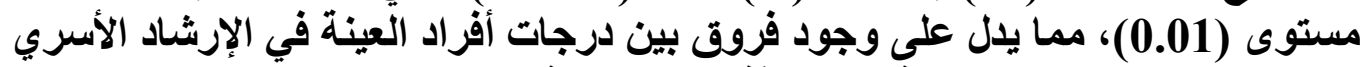

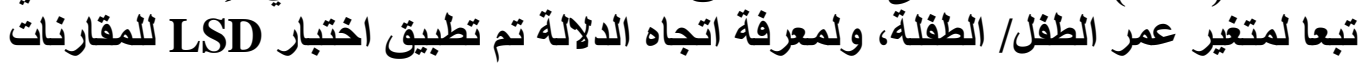
المتعدة و الجدول التالي يوضح الطلك : 
الجمعية المصرية للقر اءة والمعرفة عضو الجمعية الدولية للمعرفة المي

جدول (13) اختبار LSD للمقارنات المتعددة

\begin{tabular}{|c|c|c|c|}
\hline من 10 سنوات 12 سنة & من 7 سنوات الي 9 سنوات 39.463 & أقل من 7 سنوات & عمر الطقل/ الطقلة \\
\hline & & - & أقل من 7 سنوات \\
\hline & - & $* * 8.277$ & من 7 سنوات الي 9 سنوات \\
\hline - & $* 7.936$ & $* * 16.213$ & من 10 سنوات الّي 12 سنة \\
\hline
\end{tabular}

عمر الطفل/ الطفلة

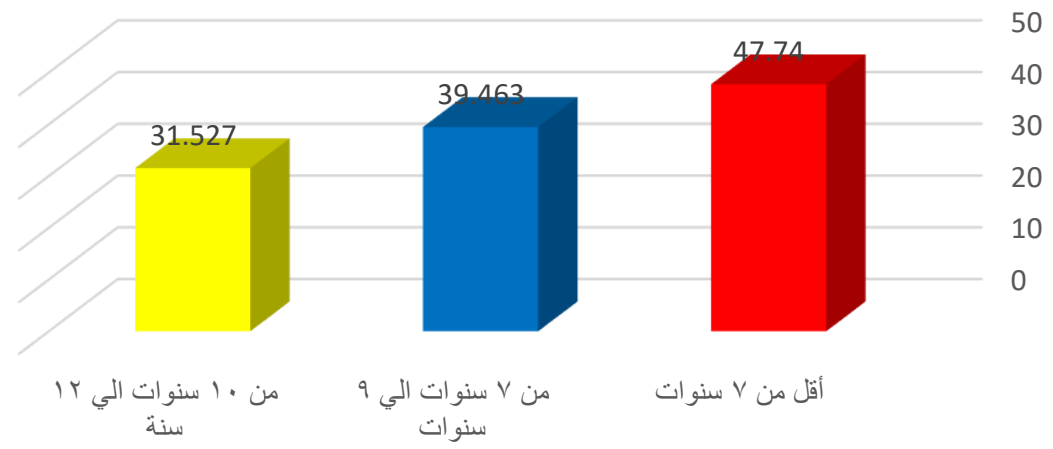

شكل (8) فروق درجات العينة في الإرشاد الأسري تبعا لمتفير عمر الطفل/ الطفلة

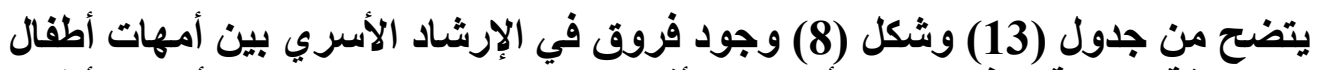

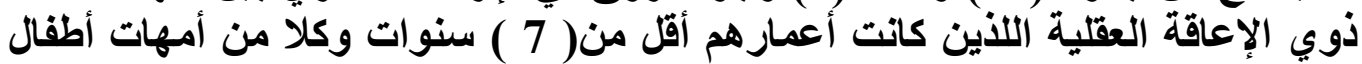

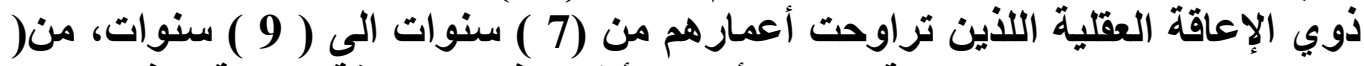

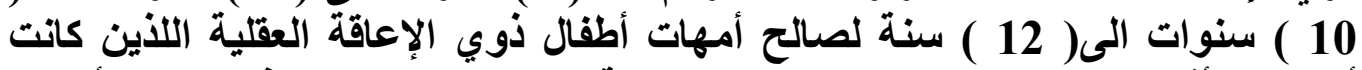

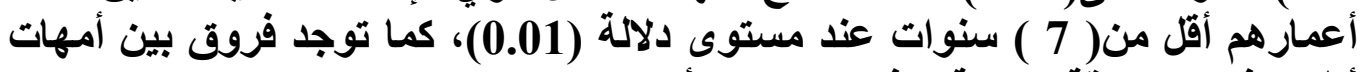

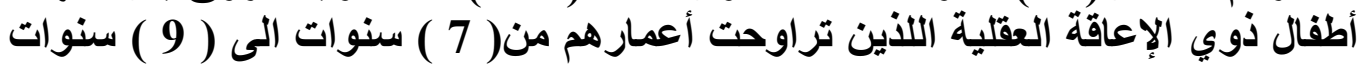

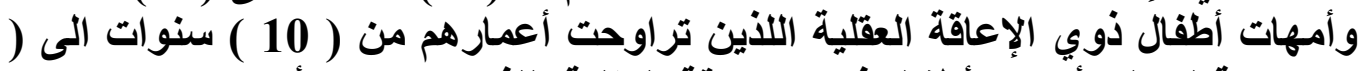

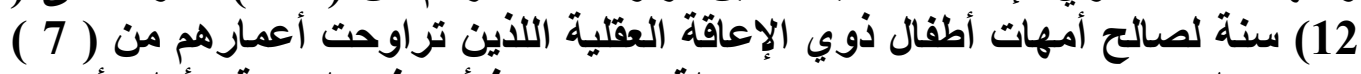

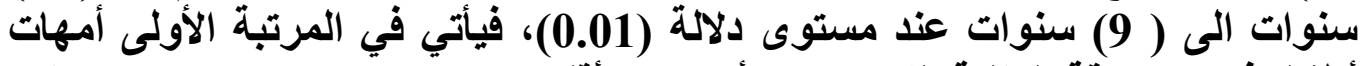
أطفال ذوي الإعاقة العقلية اللاتي كانت أعمار هم أقل من (

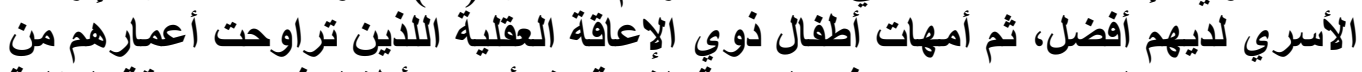

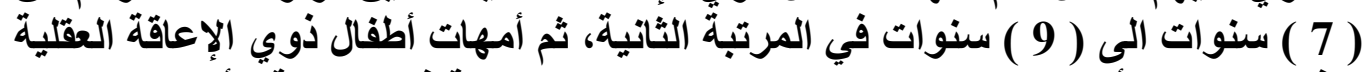
اللذين تراوحت أعمار هم من ( 10 ) سنوات الى ( 12 ) سنة في المرتبة الأخيرة . 
بينت النتائج أن أمهات الأطفال اللاتي أعمارهن أقل من (7) سنوات كان الإرشاد

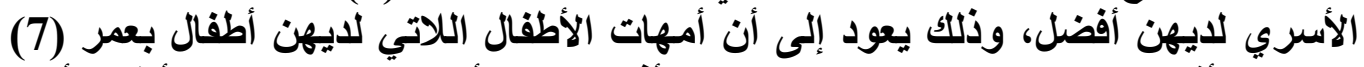

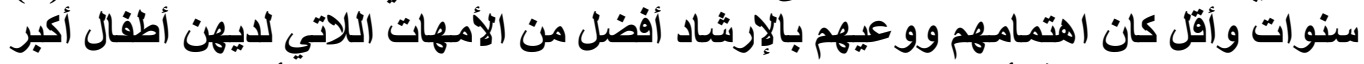

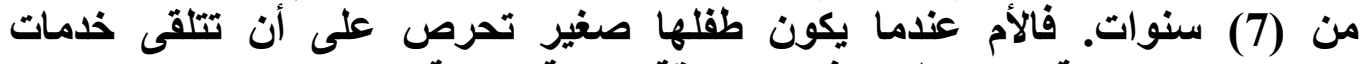

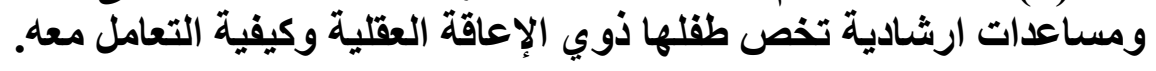

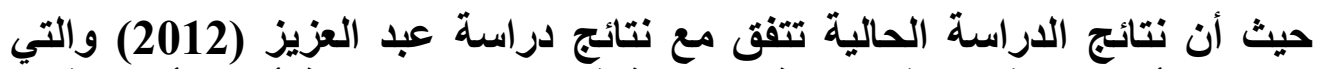

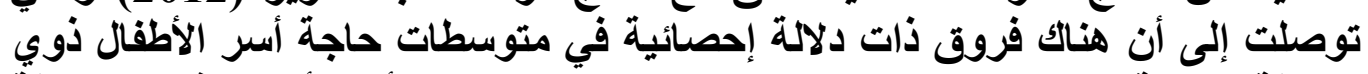

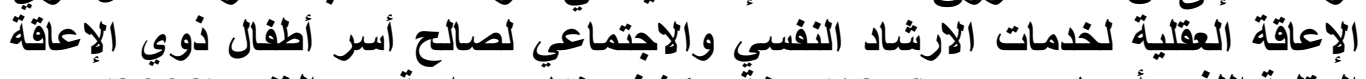

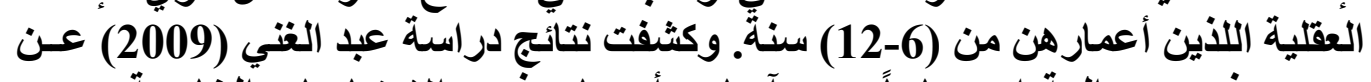

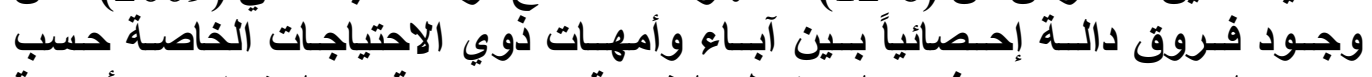

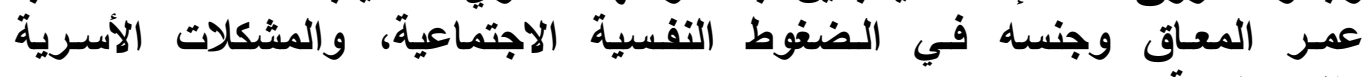
و والاجتماعيـة.

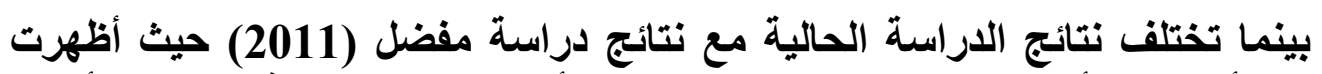

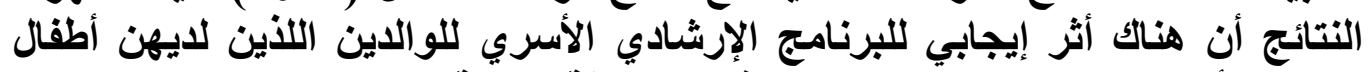

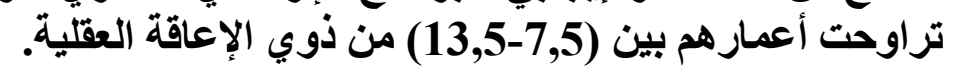

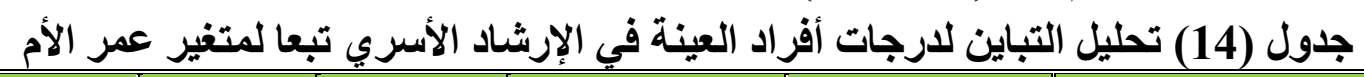

\begin{tabular}{|c|c|c|c|c|c|}
\hline الدلالة & قيمة & الحرية & المربعات & المربعات & عمر الأم \\
\hline \multirow{3}{*}{0.01 دال } & \multirow{3}{*}{36.504} & 2 & 2505.828 & 5011.656 & بين المجموعات \\
\hline & & 98 & 68.646 & 6727.320 & داخل المجموعات \\
\hline & & 100 & & 11738.976 & المجموع \\
\hline
\end{tabular}

يتضح من جدول (14) إن قيمة (ف) كاتت (36.504) وهي قيمة دالة إحصائيا عند

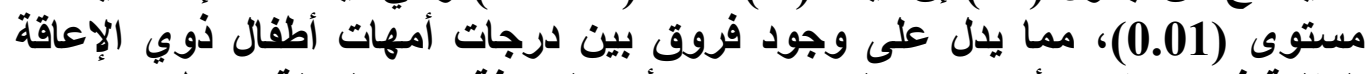

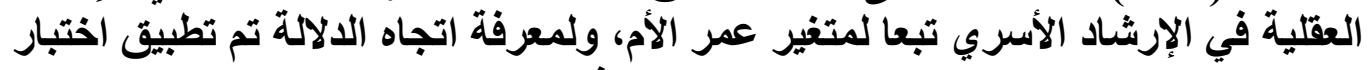

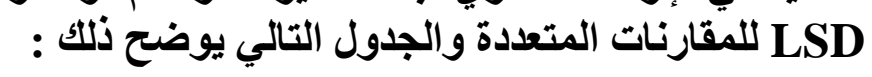
جدول (15) اختبار LSD للمقارنات المتعددة

\begin{tabular}{|c|c|c|c|}
\hline 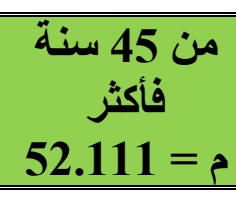 & من35 من 45سنة لأقل & أق = من 35 سنة 42.883 & عمر الأم \\
\hline & & - & أقل من 35 سنة \\
\hline & - & $* 2.074$ & من35 سنة لأقَل من 45سنة \\
\hline - & $* * 7.154$ & $* * 9.228$ & من 45 سنة فأكثر \\
\hline
\end{tabular}


الجمعية المصرية للقر اءة والمعرفة عضو الجمعية الدولية للمعرفة

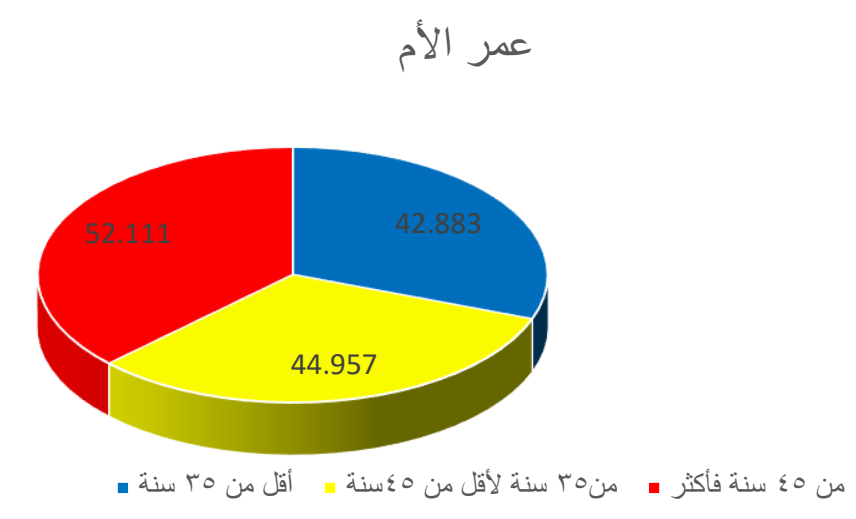

شكل (9) فروق درجات العينة في الإرشاد الأسري تبعا لمتغير عمر الأم

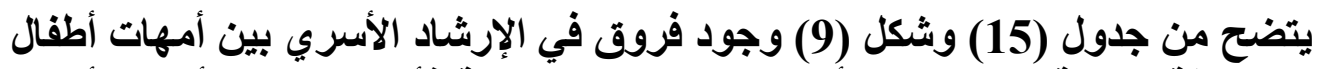

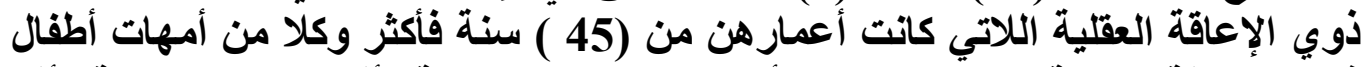

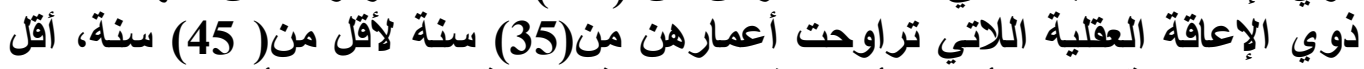

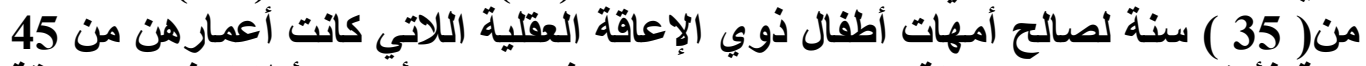

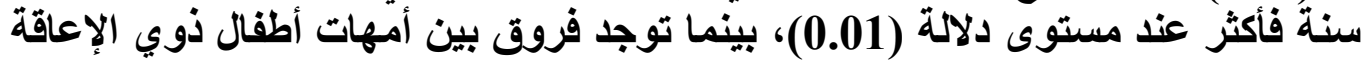

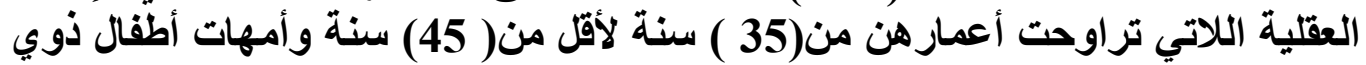

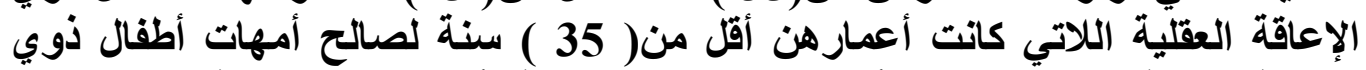

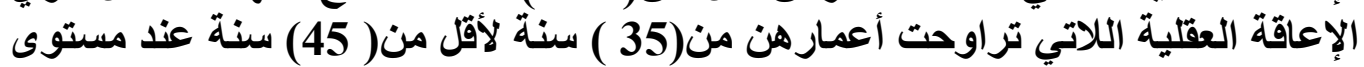

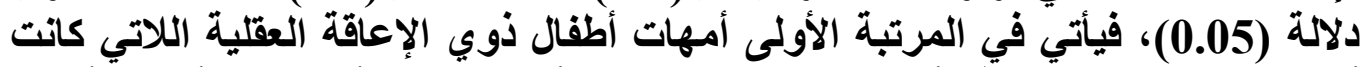

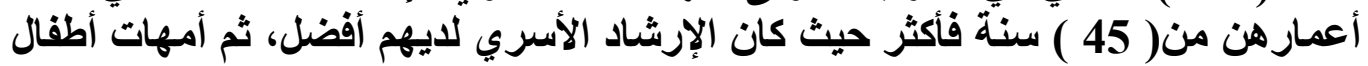

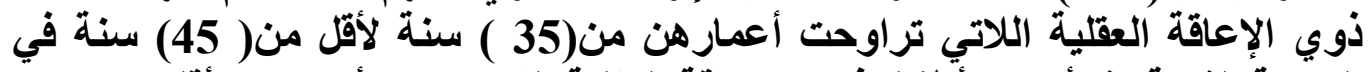

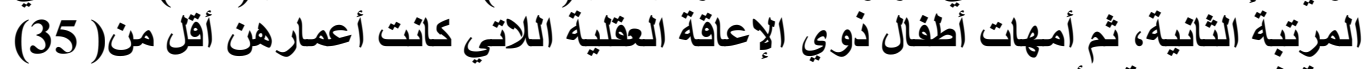
سنة في المرتبة الأخيرة.

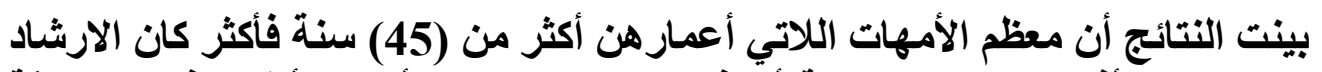

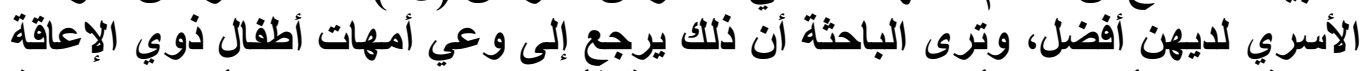

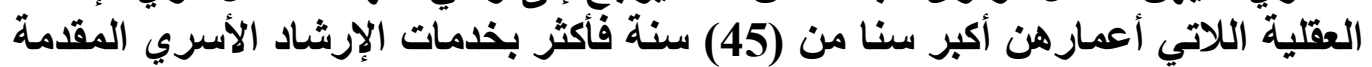

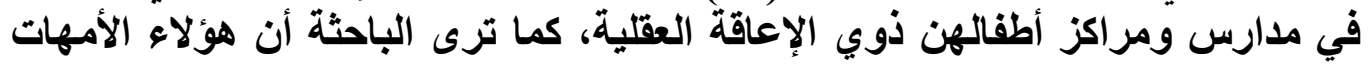

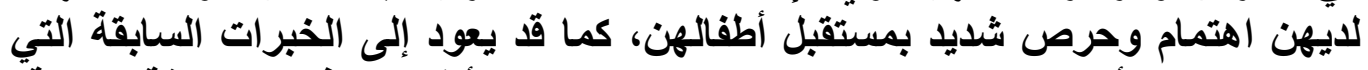

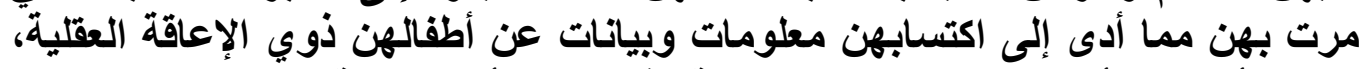

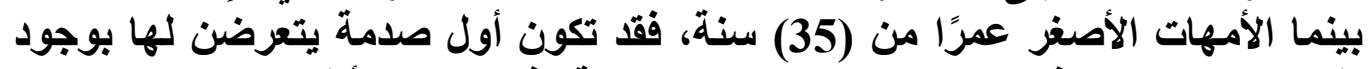

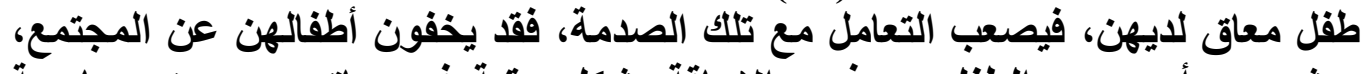

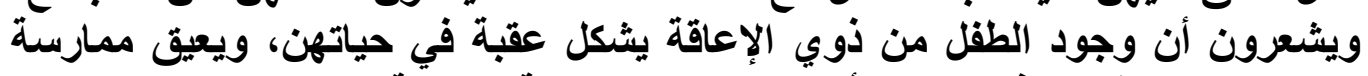

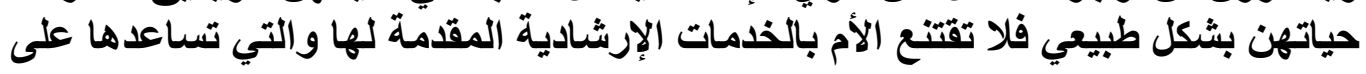


تجاوز تلكت الأفكار وتغيير نظرتها نحو طقلها ذوي الإعاقة، فهي بحاجة إلى ندوات

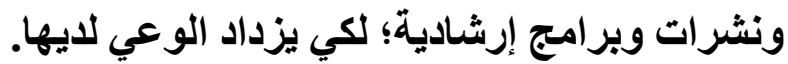

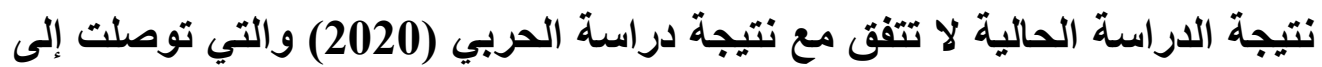

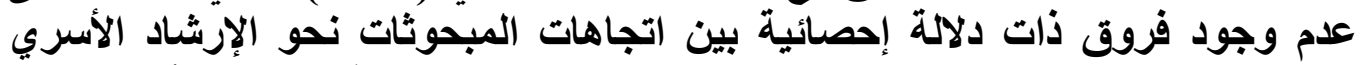

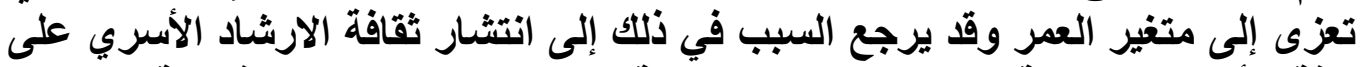

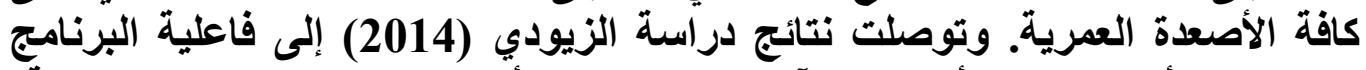

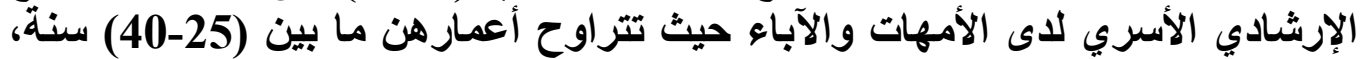

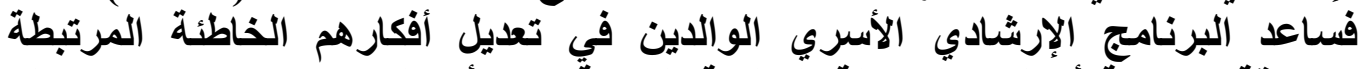

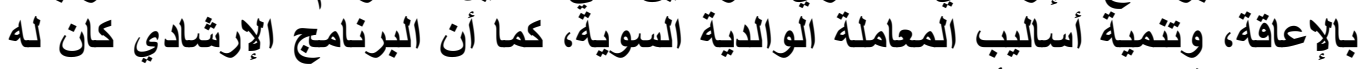

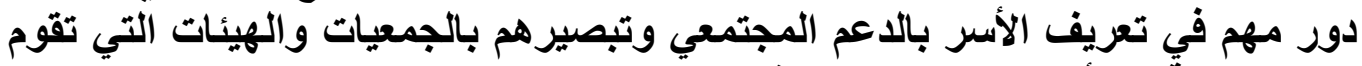
على الرعايةً والتأهيل المجتمعي للمعاقين.

جدول (16) تحليل التباين لارجات أفراد العينة في الإرشاد الأسري تبعا لمتنير الدخل الثهري للأسرة

\begin{tabular}{|c|c|c|c|c|c|}
\hline الدلالة & قيمة (ف) & الحرية & متوسط المربعات & المربعوع & الشأسري \\
\hline \multirow{3}{*}{ دال } & \multirow[b]{2}{*}{46.828} & 2 & 2581.536 & 5163.072 & بين المجموعات \\
\hline & & 98 & 55.128 & 5402.562 & المجموعات \\
\hline & & 100 & & 10565.634 & المجموع \\
\hline
\end{tabular}

يتضح من جدول (16) إن قيمة (ف) كانت (46.828) وهي قيمة دالة إحصائيا عند

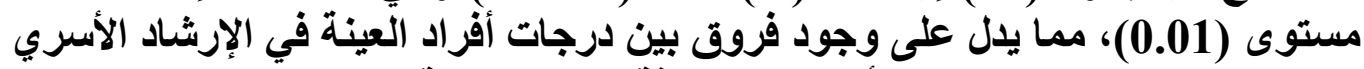

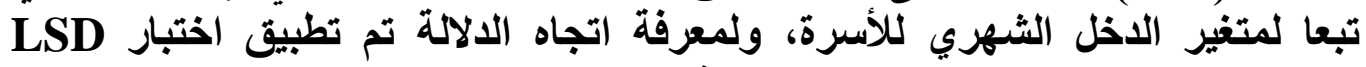

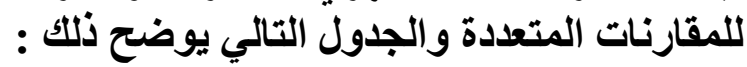
جدول (17) اختبار LSD للمقارنات المتعددة

\begin{tabular}{|c|c|c|c|}
\hline من فأكثر 1500 ريال & 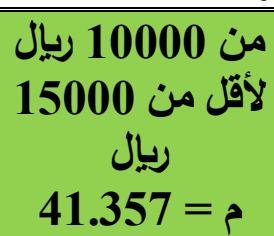 & 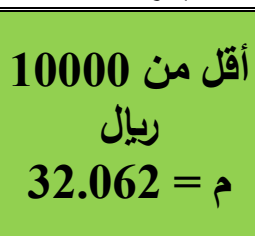 & الاخل الشهري للأسرة \\
\hline & & - & أقلّ من 10000 ريال \\
\hline & - & $* * 9.295$ & من 10000 ريال لأقلّ \\
\hline - & $* * 8.584$ & $* * 17.879$ & من 15000 ريال فأكثر \\
\hline
\end{tabular}




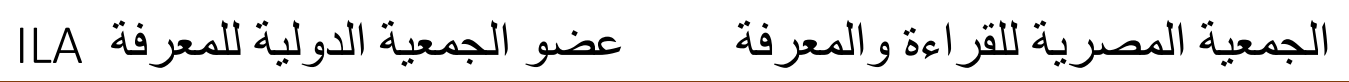

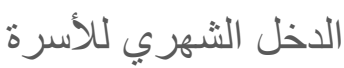

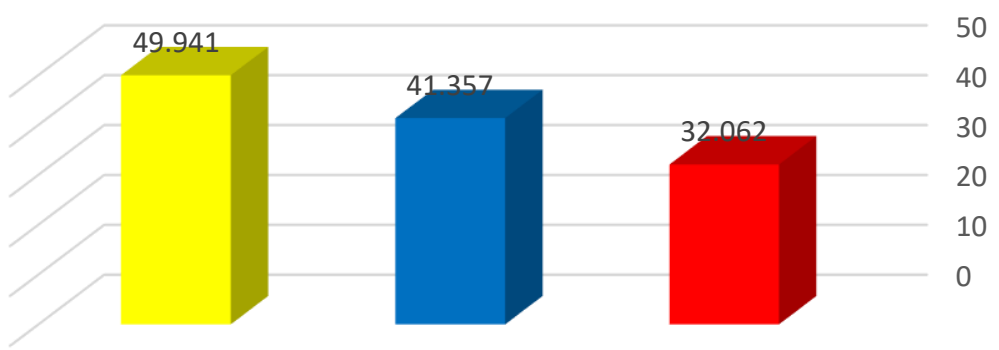

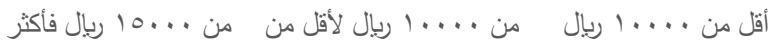

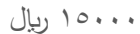

شكل (10) فروق درجات أفراد العينة في الإرشاد الأسري تبعا لمتغير الاخل الثهري لكلأسرة

يتضح من جدول (17) وشكل (10) وجود فروق في الإرشاد الأسري بين أمهات

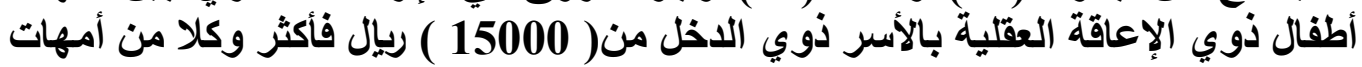

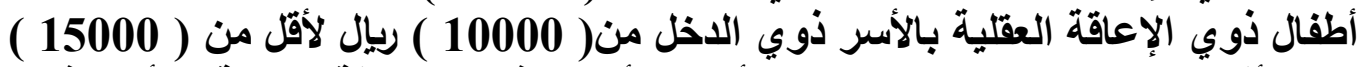

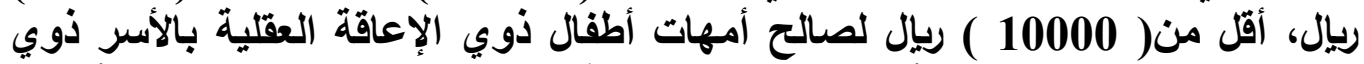

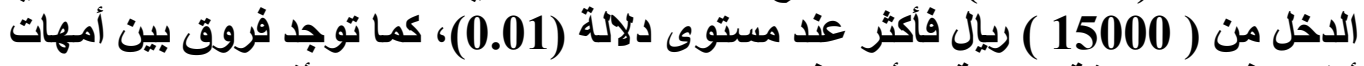

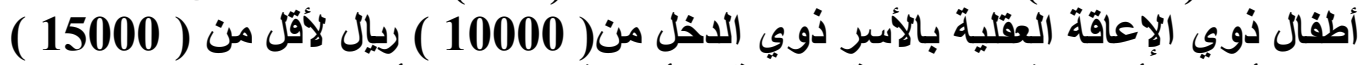

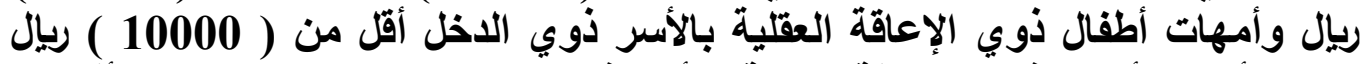

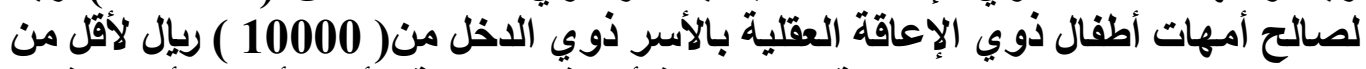

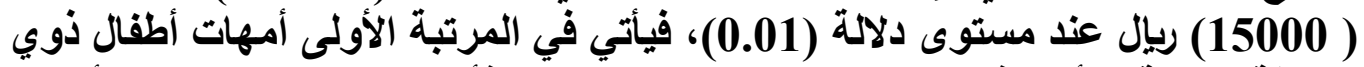

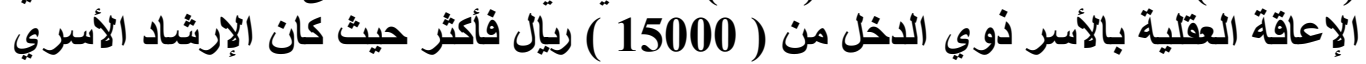

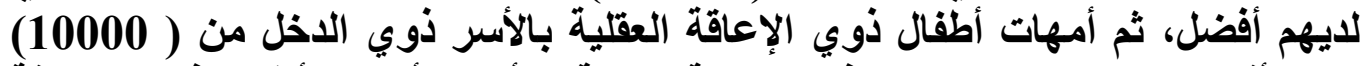

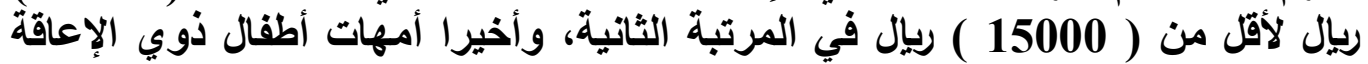

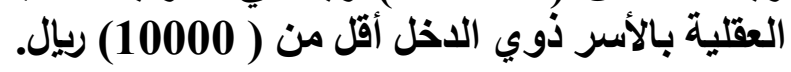

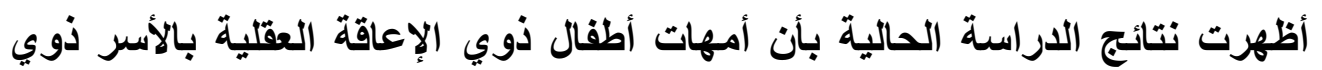

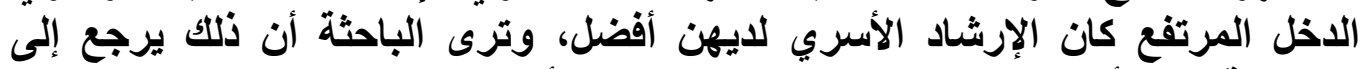

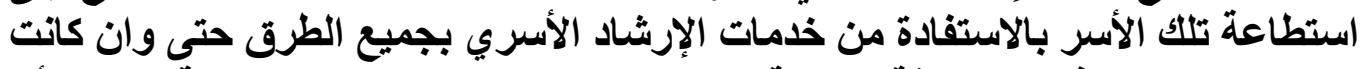

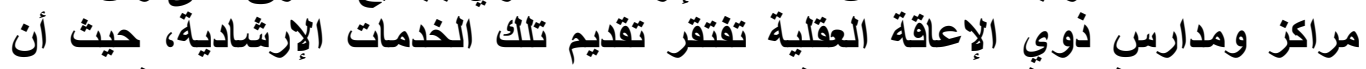

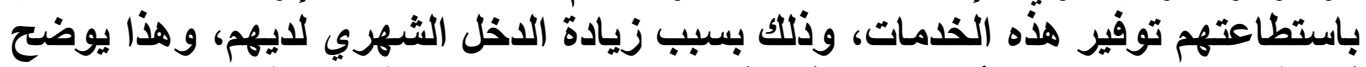

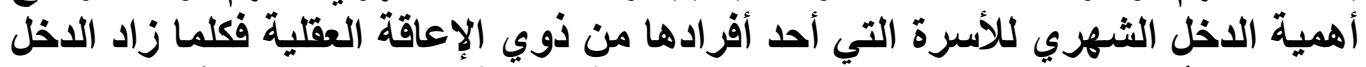
الثهري للأسرة زاد الهتمامهم بالطقل ذوي الإعاقة العقلية، وزاد الإرشاد الأسري المقام 


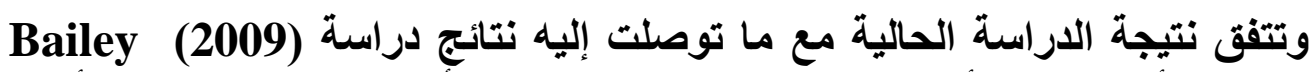

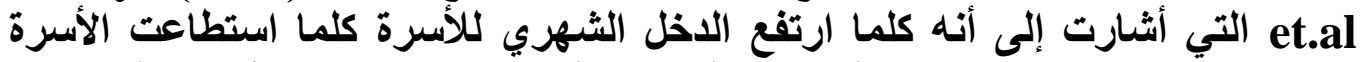

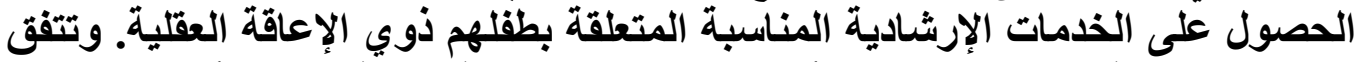

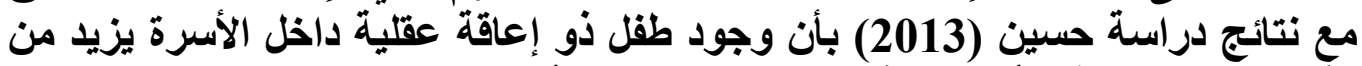

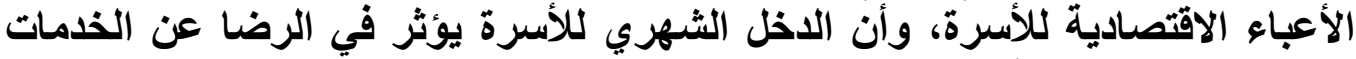

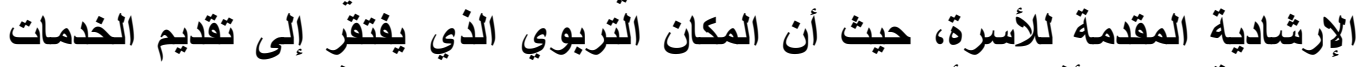

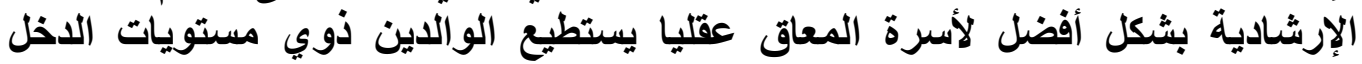

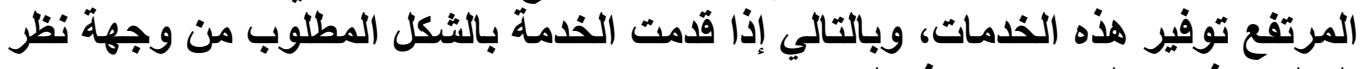

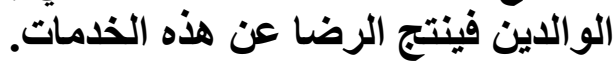

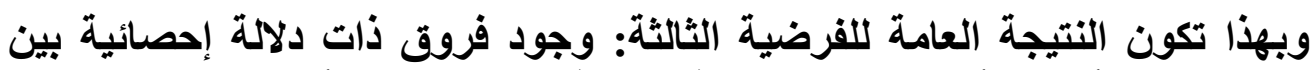

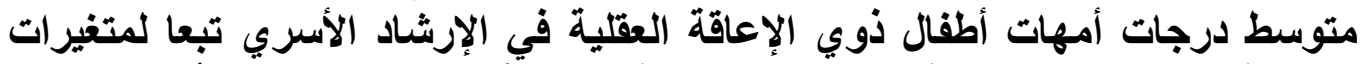

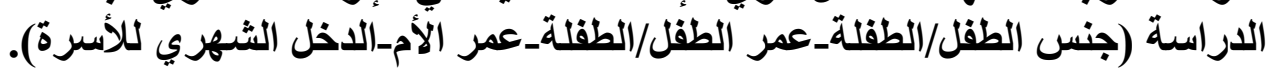

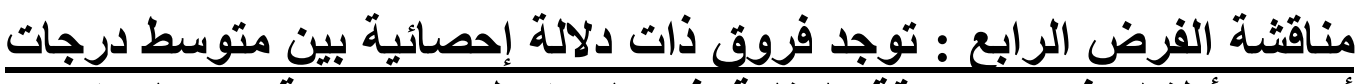

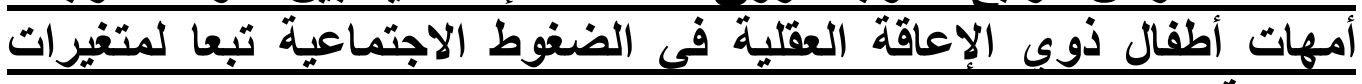
الألمراسة

وللتحقق من هذا الفرض تم تطبيق اختبار (ت)، وحساب تحليل التباين لارجات أمهات

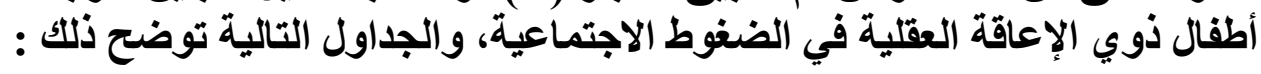

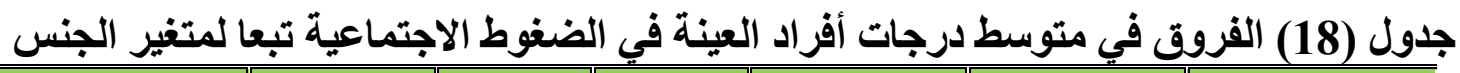

\begin{tabular}{|c|c|c|c|c|c|c|}
\hline الدلالة & قيمة (ت & الدرية & العينة & الالحعراف & الحستوسط المسي & الطفلة \\
\hline \multirow{2}{*}{ لصالح عند 0.01} & \multirow{2}{*}{9.820} & \multirow{2}{*}{99} & 53 & 4.827 & 53.671 & ذكر \\
\hline & & & 48 & 3.994 & 41.025 & أنثي \\
\hline
\end{tabular}


الجمعية المصرية للقر اءة والمعرفة عضو الجمعية الدولية للمعرفة المي

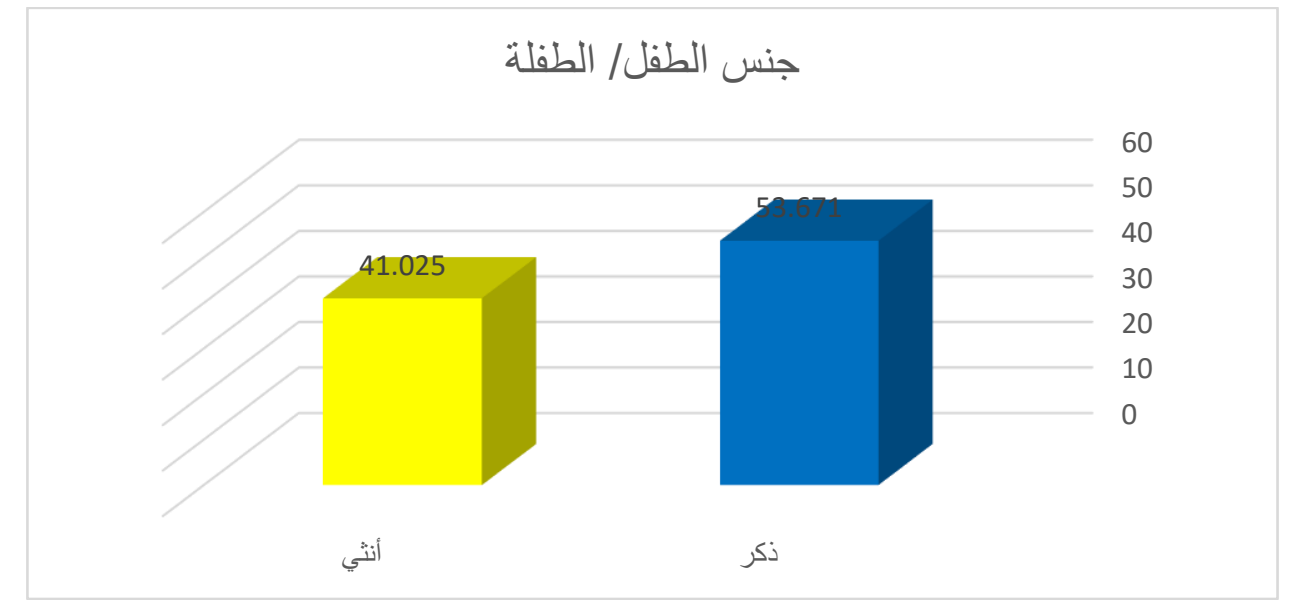

شكل (11) الفروق في متوسط درجات أفراد العينة في الضغوط الاجتماعية تبعا لمتغير الجنس

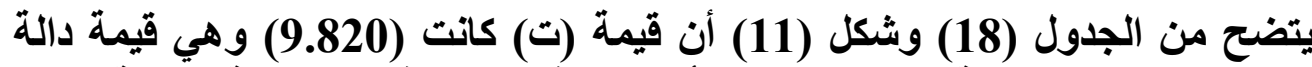

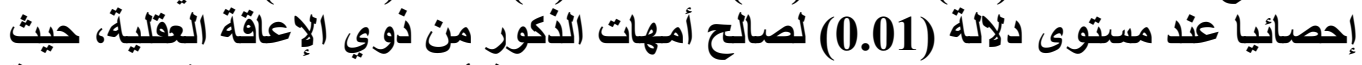

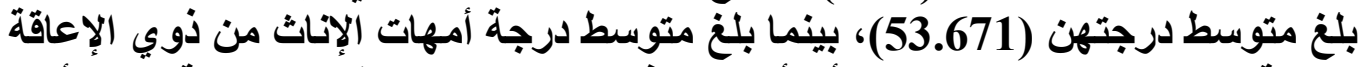
العقلية (41.025)، مما يدل على أن أمهات الذكور كانت الضغوط الاجتماعية لايهم أكثر الأر

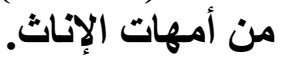

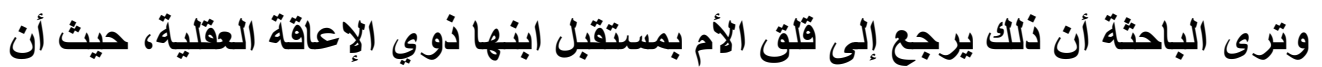

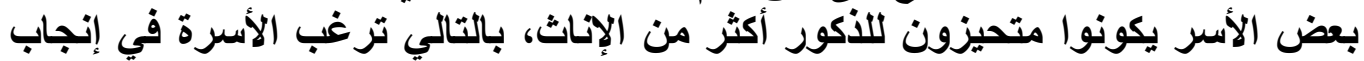

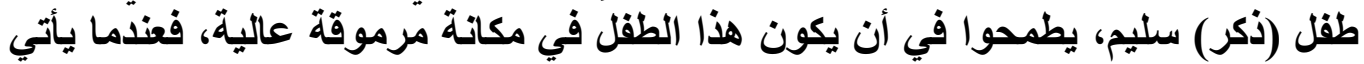

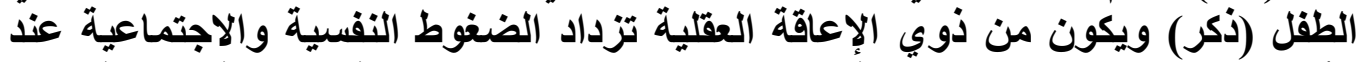

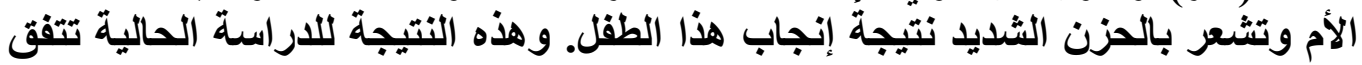

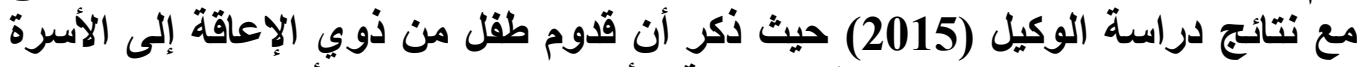

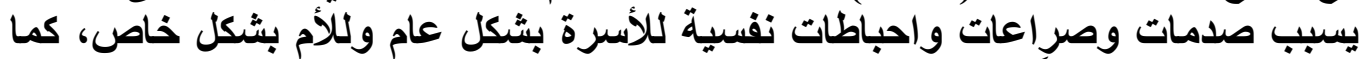

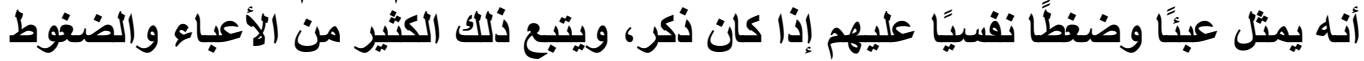

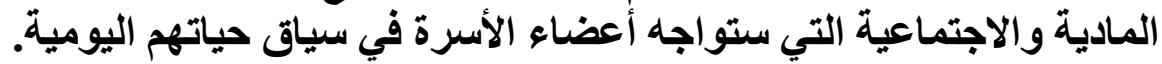

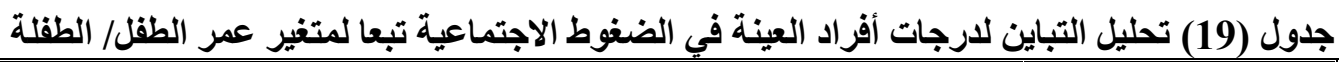

\begin{tabular}{|c|c|c|c|c|c|}
\hline الدلالة & قيمة (ف) & الحرجية & متوبطات & مجموعاع & عمر الطفلة \\
\hline \multirow{3}{*}{ בدال } & \multirow{2}{*}{34.566} & 2 & 2488.492 & 4976.985 & بين المجموعات \\
\hline & & 98 & 71.993 & 7055.277 & داخل المجموعات \\
\hline & & 100 & & 12032.262 & المجموع \\
\hline
\end{tabular}




\section{الجمعية المصرية للقر اعة والمعرفة عضو الجمعية الدولية للمعرفة ال}

يتضح من جدول (19) إن قيمة (ف) كانت (34.566) وهي قيمة دالة إحصائيا عند

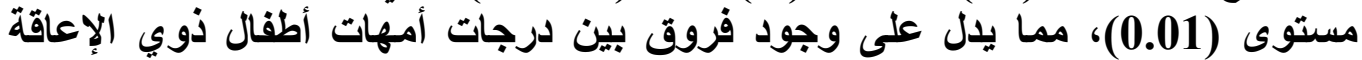

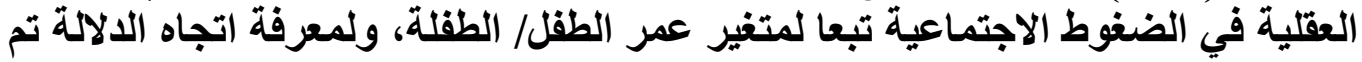

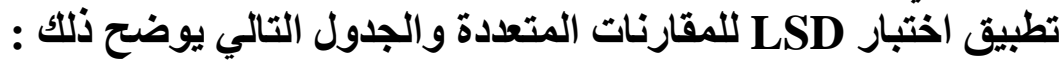
جدول (20) اختبار LSD للمقارنات المتعددة

\begin{tabular}{|c|c|c|c|}
\hline من 10 سنوات 12 سنة & 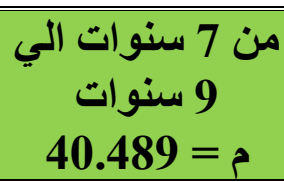 & أقل من 7 سنوات & عمر الطقل/ الطقلة \\
\hline & & - & أقلّل من 7 سنوات \\
\hline & - & $* 2.402$ & من 7 سنوات الي 9 سنوات \\
\hline- & $* * 9.957$ & $* * 12.359$ & من 10 سنوات الَي 12 سنة \\
\hline
\end{tabular}

عمر الطفل/ الطفلة

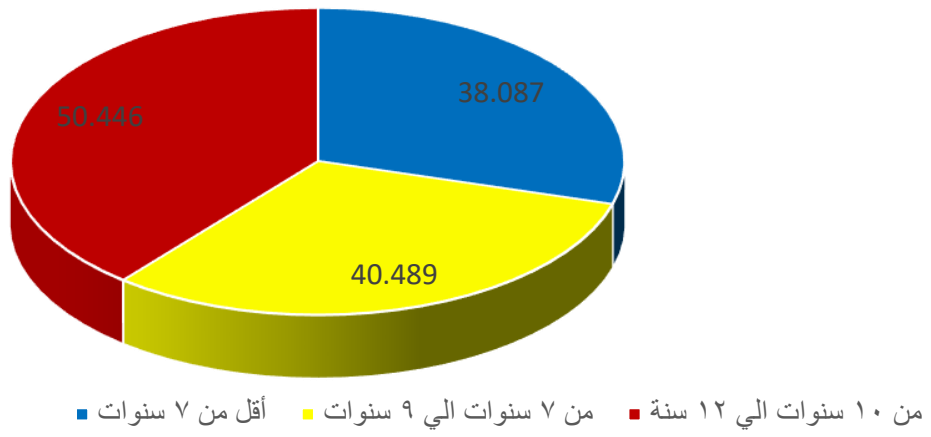

شكل (12) فروق درجات العينة في الضغوط الاجتماعية تبعا لمتغير عمر الطقل/ الطقلة

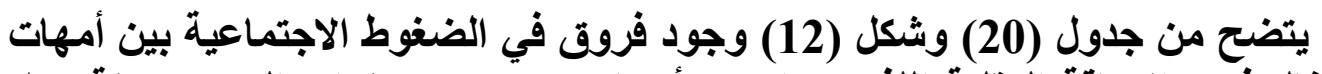

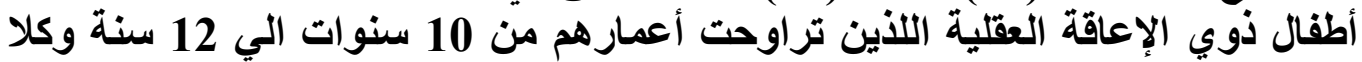

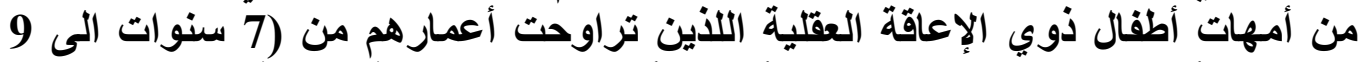

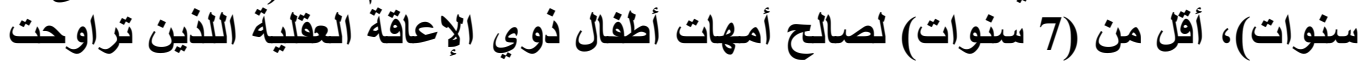

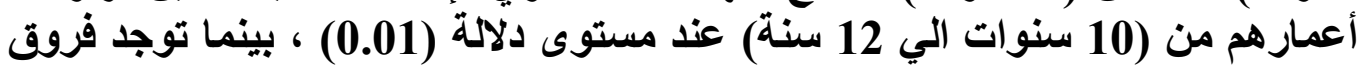

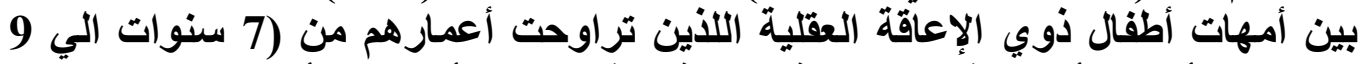

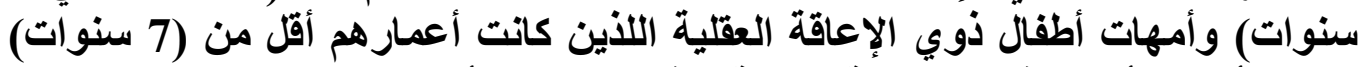

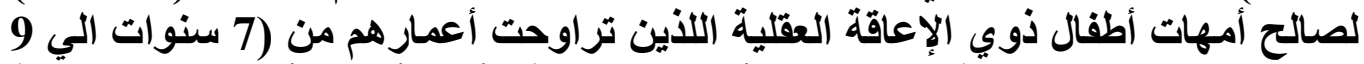

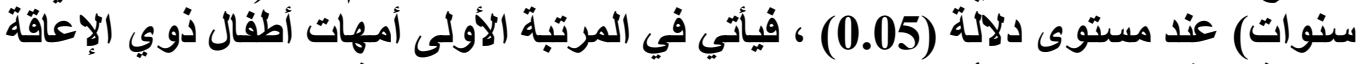

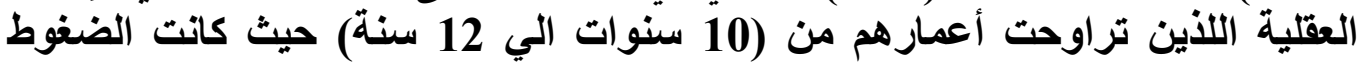




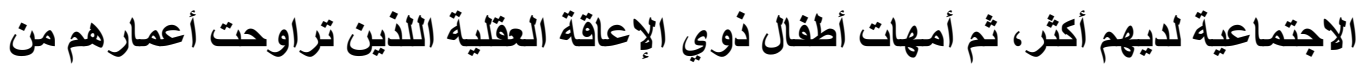

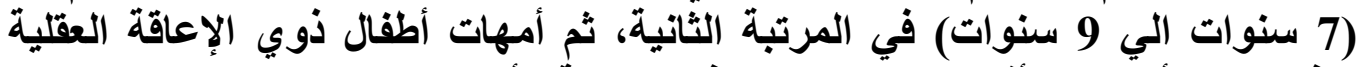

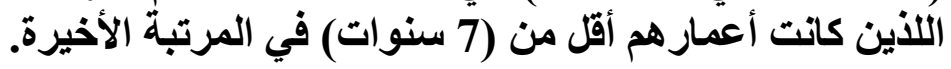

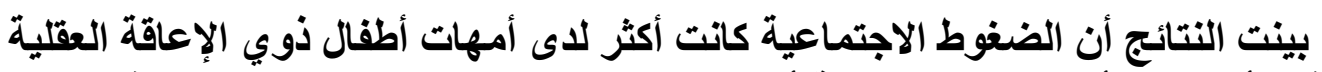

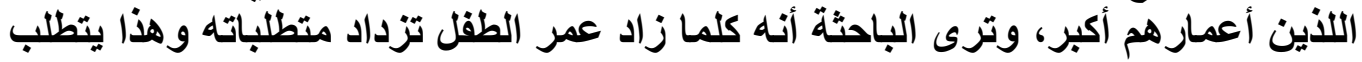

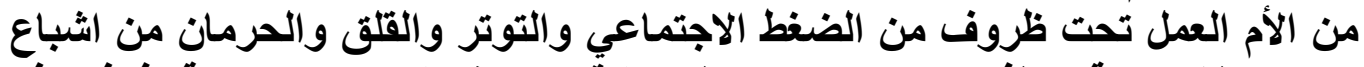

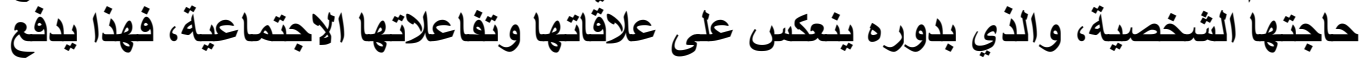
الأم إلى العزلة والانطواءو، لأنه كلما تقدم الطفل في العمر كلما احتاج إلى رعاية مستمرة واهتمام مستمر.

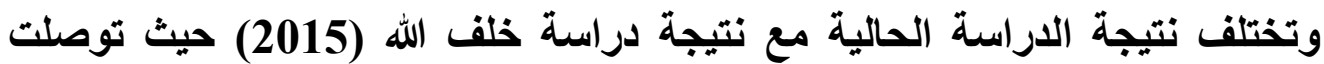

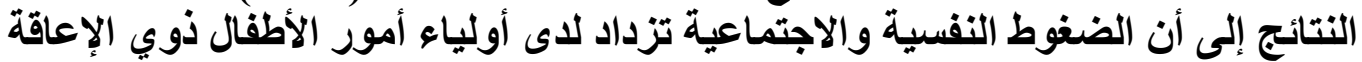
العقلية كلما كان الطقل ذان الضغوي الإعاقة أصغر.

جدول (21) تحليل التباين لارجات أفراد العينة في الضغوط الاجتماعية تبعا لمتغير عمر الأم

\begin{tabular}{|c|c|c|c|c|c|}
\hline الدلالة & قيمة (ف) & الحرية & المربعات & المربعات & عمر الأم \\
\hline \multirow{3}{*}{0.01 دال } & \multirow{2}{*}{51.598} & 2 & 2609.499 & 5218.997 & المجموعات \\
\hline & & 98 & 50.574 & 4956.212 & المجموعات داخل \\
\hline & & 100 & & 10175.209 & المجموع \\
\hline
\end{tabular}

يتضح من جدول (21) إن قيمة (ف) كاتت (51.598) وهي قيمة دالة إحصائيا عند

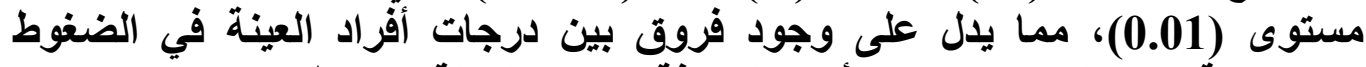

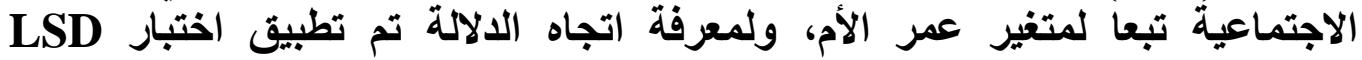

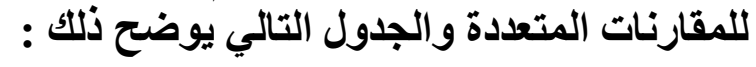
جدول (22) اختبار LSD للمقارنات المتعددة

\begin{tabular}{|c|c|c|c|}
\hline من 45 من فنأكثر & من35 سنة لأقلّ & أقل من 35 سنة & عمر الأم \\
\hline & & - & أقل من 35 سنة \\
\hline & - & $* * 12.456$ & من35 سنة لأقل من 45سنة \\
\hline- & $* * 7.108$ & $* * 19.564$ & من 45 سنة فأكثر \\
\hline
\end{tabular}




\section{ILA الجمعية المصرية للقر اعة والمعرفة عضو الجمعية الدولية للمعرفة}

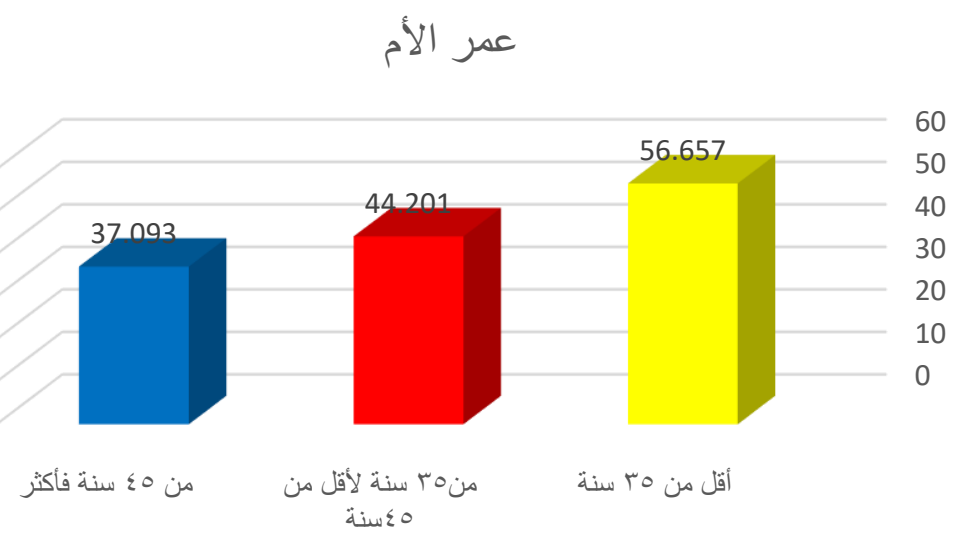

شكل (13) فروق درجات العينة في الضغوط الاجتماعية تبعا لمتغير عمر الأم

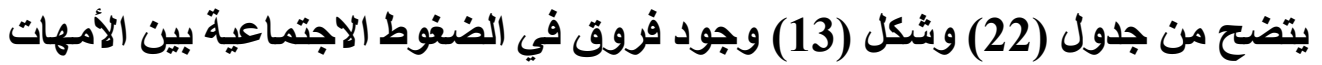

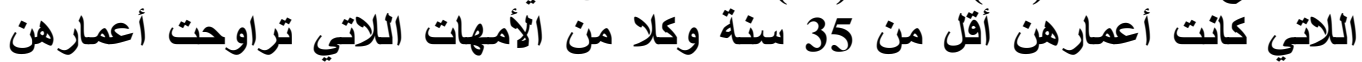

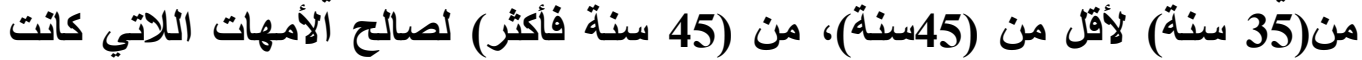

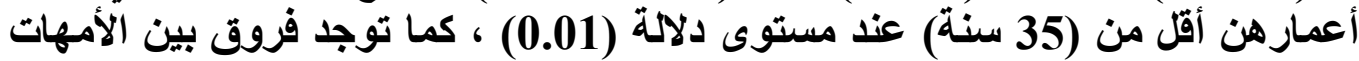

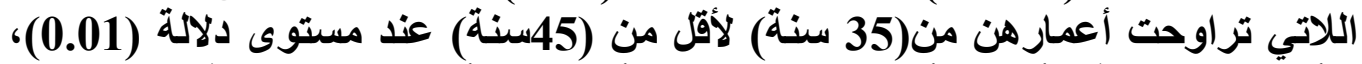

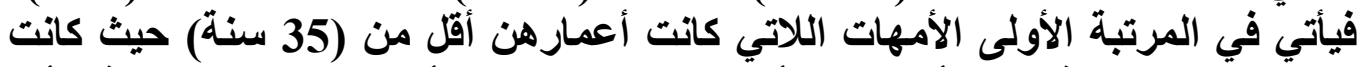

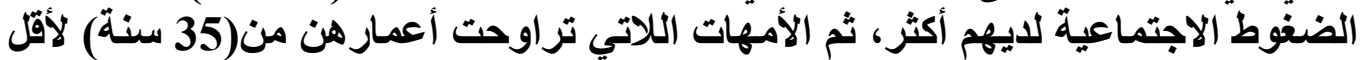
من (45سنة) في المرتبة الثانية ، ثم الأمهات اللاتي كانت أعمار هن من (45 سنة) فأكثر

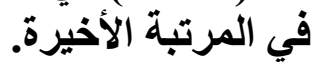

بينت النتائج أن معظم أمهات أطفال ذوي الإعاقة العقلية أعمارهن أقلى من (35) سنة العانة

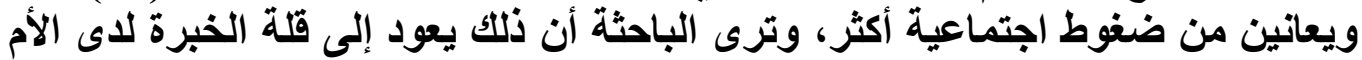

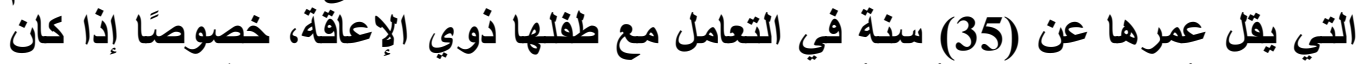

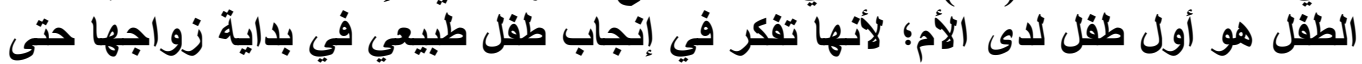

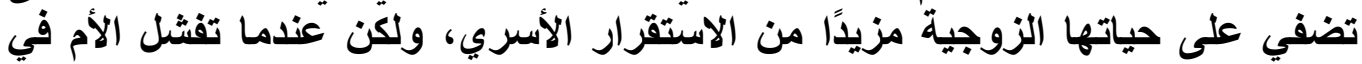

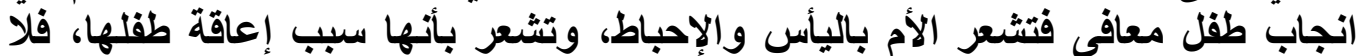

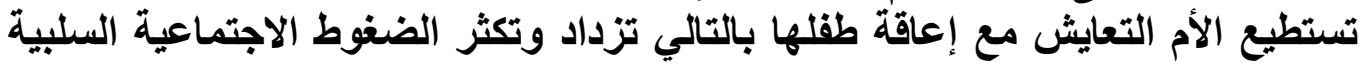
من قبل الآخرين لايها فيؤدي بها إلى العزلة الإلئ الاجتماعية.

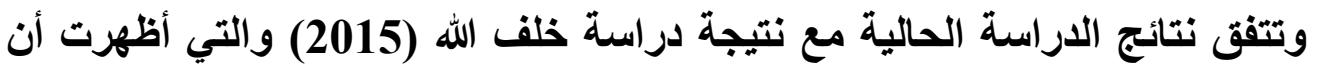

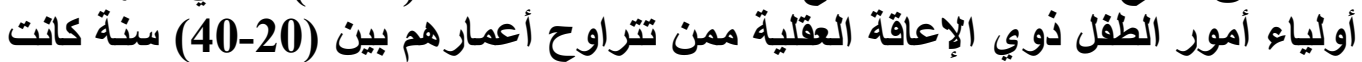

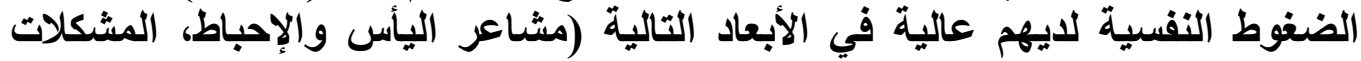

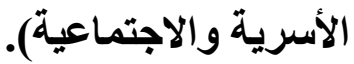




\section{الجمعية المصرية للقر اعة والمعرفة عضو الجمعية الدولية للمعرفة الما}

جدول (23) تحليل التباين لارجات أفراد العينة في الضغوط الاجتماعية تبعا لمتغير الاخل

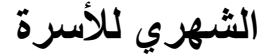

\begin{tabular}{|c|c|c|c|c|c|}
\hline الالالة & قيمة (ف) & الحرية & متوسط المربعات & المربعات & الثهرخ \\
\hline \multirow{3}{*}{$\begin{array}{c}0.01 \\
\text { دال }\end{array}$} & \multirow[b]{2}{*}{30.949} & 2 & 2452.523 & 4905.045 & بين المجموعات \\
\hline & & 98 & 79.245 & 7765.995 & المجموعات \\
\hline & & 100 & & 12671.040 & المجموع \\
\hline
\end{tabular}

يتضح من جدول (23) إن قيمة (ف) كانت (30.949) وهي قيمة دالة إحصائيا عند

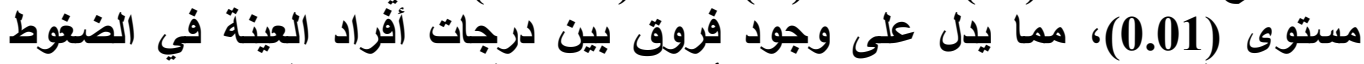

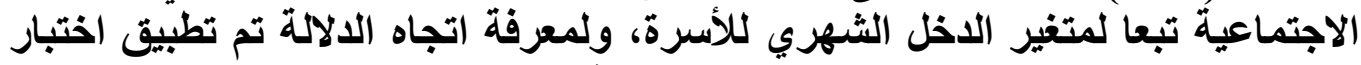

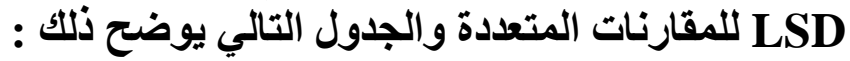
جدول (24) اختبار LSD للمقارنات المتعددة

\begin{tabular}{|c|c|c|c|}
\hline من فأكثر 15000 ريال & 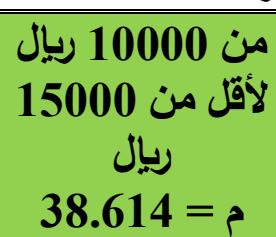 & 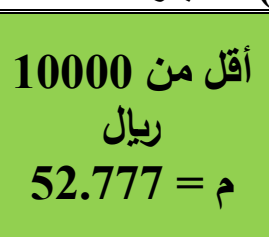 & الدخل الشهري للأسرة \\
\hline & & - & أقل من 10000 ربيال \\
\hline & - & $* * 14.163$ & من من 10000 ريال لأقَّل \\
\hline- & $* 2.519$ & $* * 16.682$ & من 15000 ريال فأكثر \\
\hline
\end{tabular}




\section{الدل الدل الثهري للأسرة}

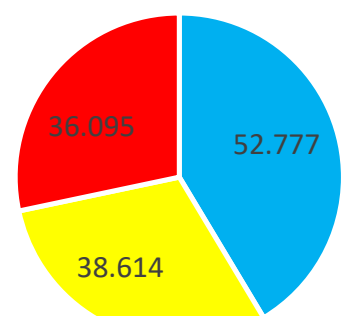

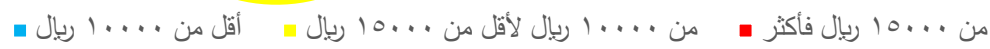

شكل (14) فروق درجات أفراد العينة في الضغوط الاجتماعية تبعا لمتغير الاخل الشهري للأسّرة

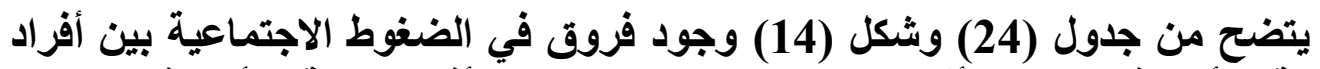

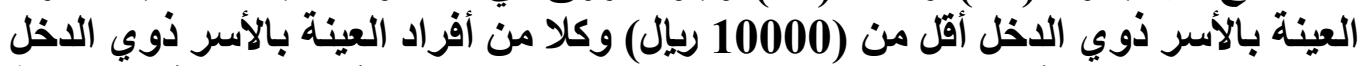

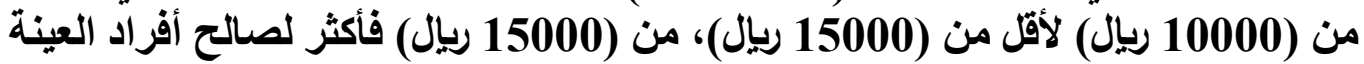

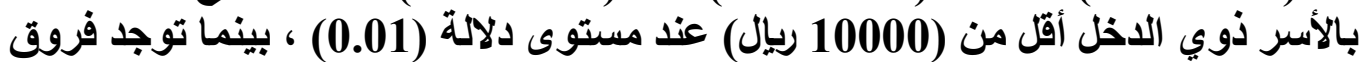

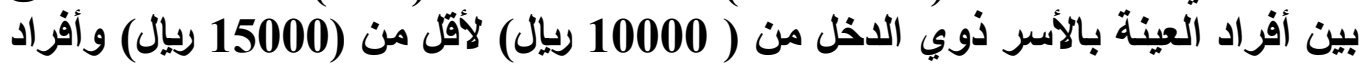

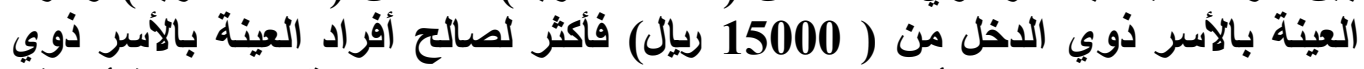

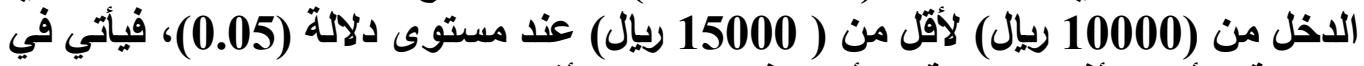

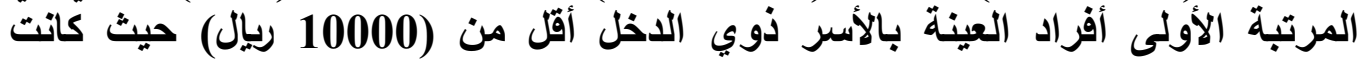

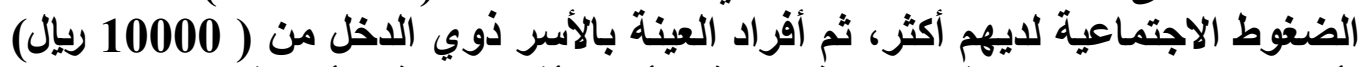

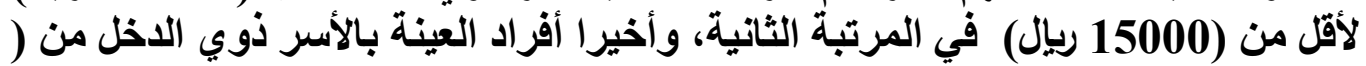
15000 ربيال) فأكثر.

بينت النتائج أن معظم أفراد عينة الدراسة الذين لائن الديهم ضغوط اجتماعية أكثر بالأسر

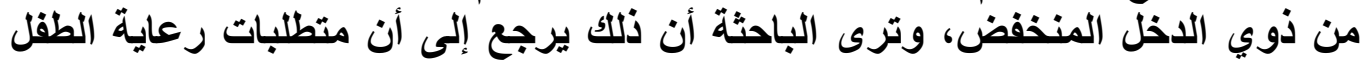

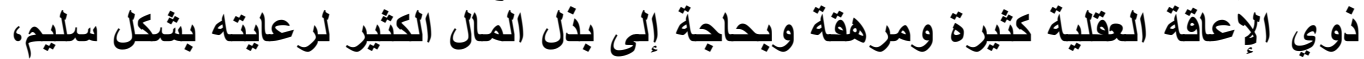

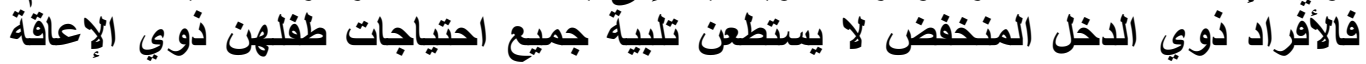

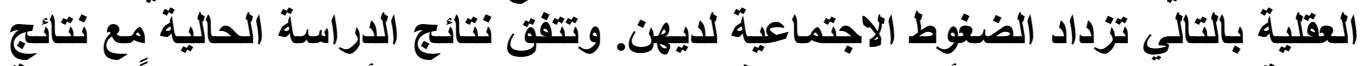

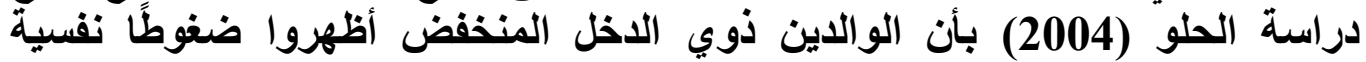

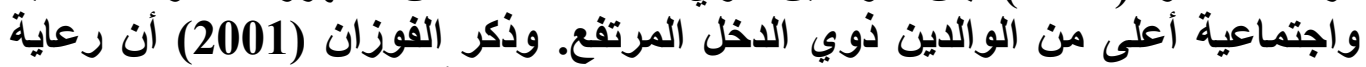

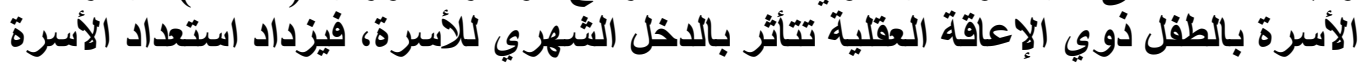

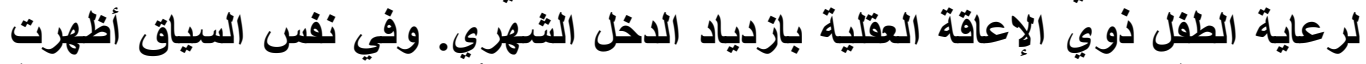

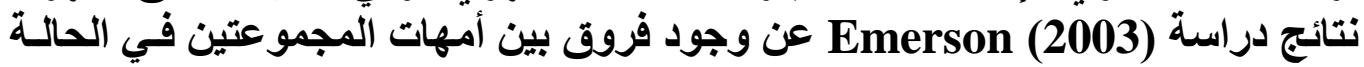




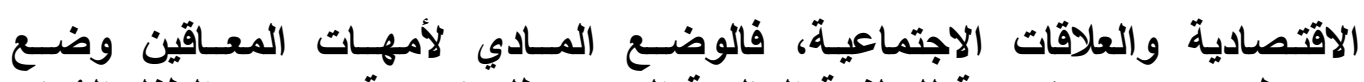

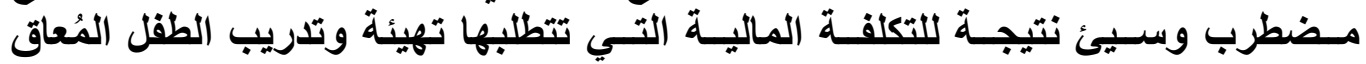

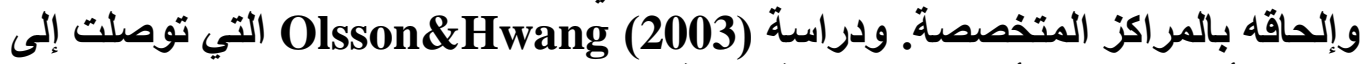

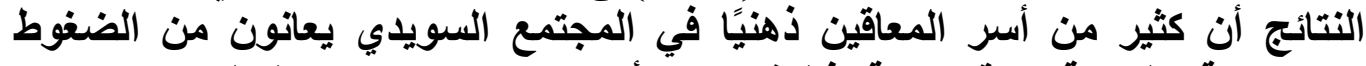

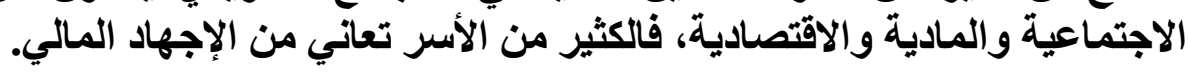

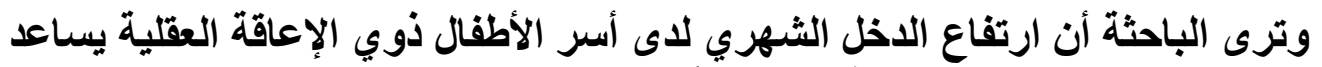

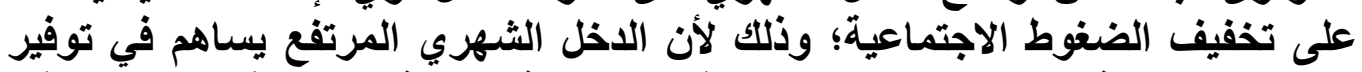

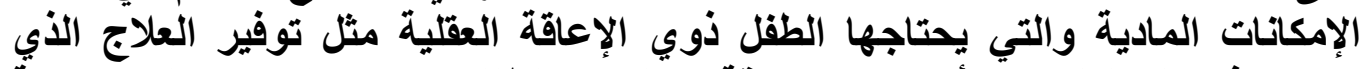

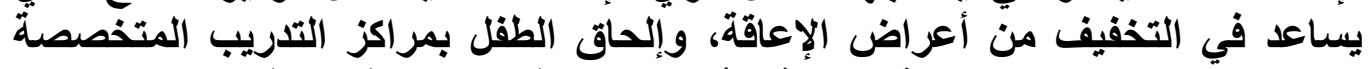

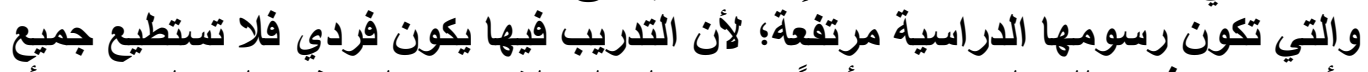

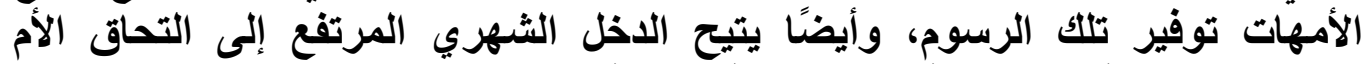

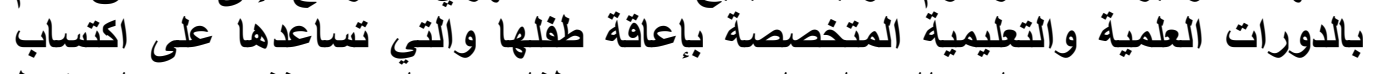

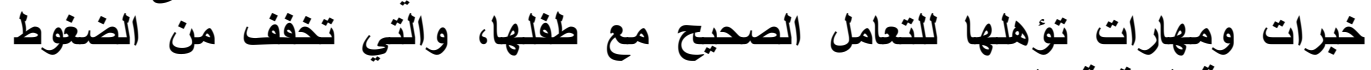
الاجتماعية الواقعة عليها.

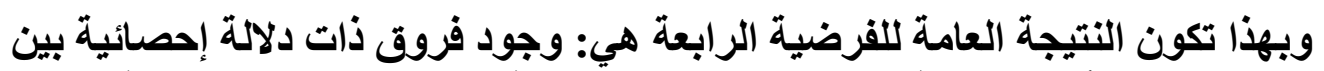

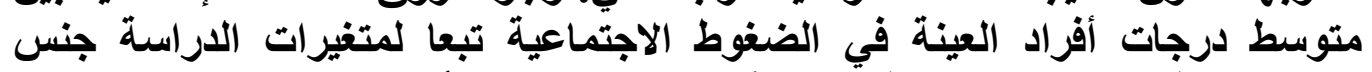

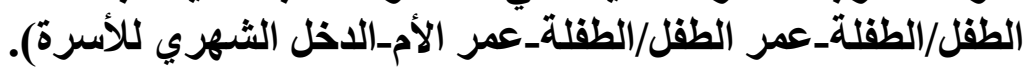

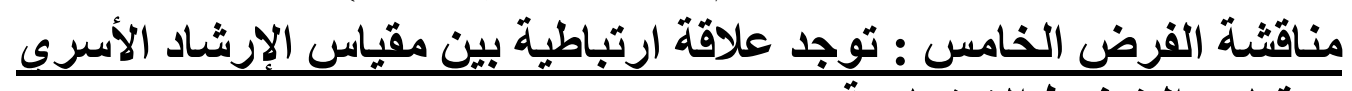
ومقياس الضغوط الفزض الاجتماعية :ونية

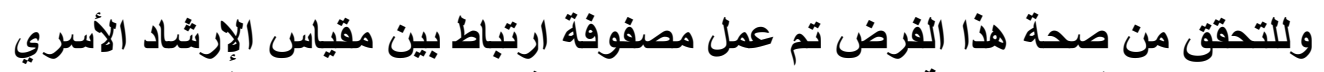

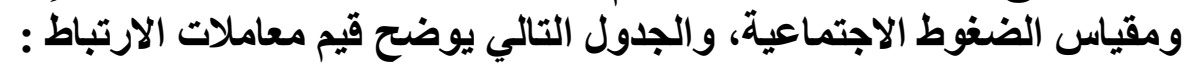

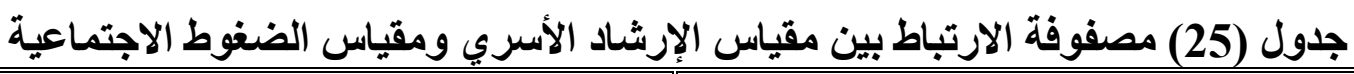

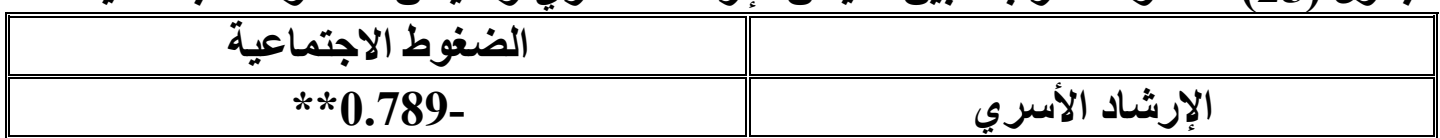

يتضح من الجدول (25) وجود علاقة ارتباط عكسي بين مقياس الإرشاد الأسنري

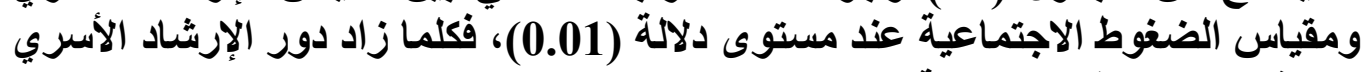
كلما قلت الضغوط الضغوط الاجتماعية.

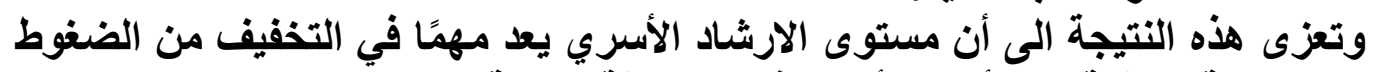
الاجتماعية الواقعة على أمهات أطفال ذوي الإنئة الإعاقة الكقلية.

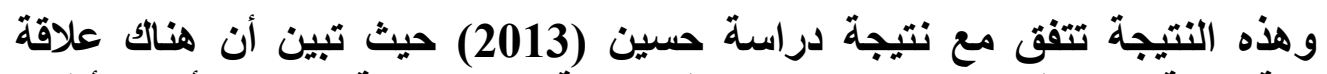

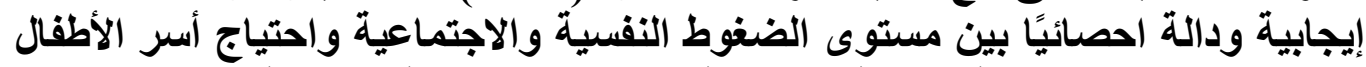
المعاقين عقيًا في المملكة العربية السعودية للخدمات الإرشادية المختلفة. 


\section{ILA الجمعية المصرية للقر اءة والمعرفة عضو الجمعية الدولية للمعرفة}

ويهذا تكون النتيجة العامة للفرضية الخامسة هي: وجود علاقة ارتباطية عكسية بين مقياس الإرشاد الأسري ومقياس الضغئ الضغوط الاجتماعية.

أ ـ التوصيات والمقترحات : التوبيات :

1- نشر الوعي بأهمية برامج الإرشاد الأسري التي تخص الأطفال ذوي الإعاقة 2- على المختصين من ذوال الوي الاختصاص ضرورة تقديم خدمات الارشاد الأسري

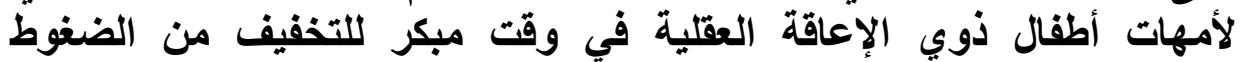

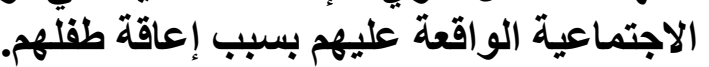

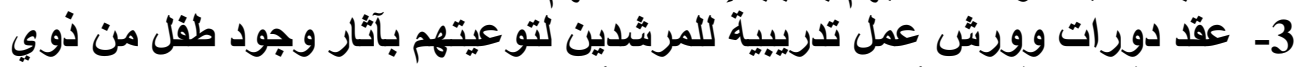

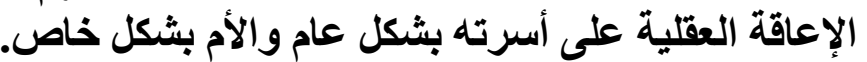

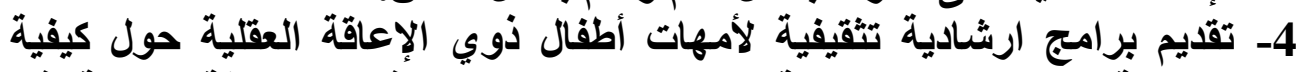
مواجهة الضغوط الاجتماعية عند وجود طقل من ذاية ذوي الإعافة الإعاقة العقلية في

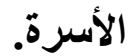
5- تفعيل دور وسائل الإعلام وإعداد برامج تلفزيونية وإذاعية متخصصة والإئة والتي

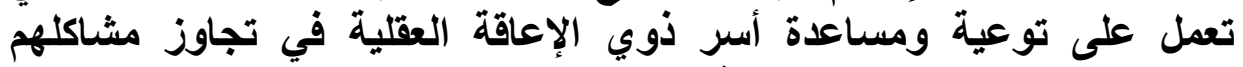

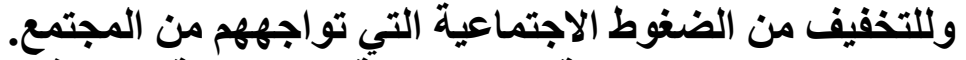

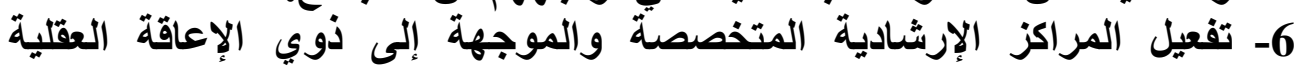
وأسرهم.

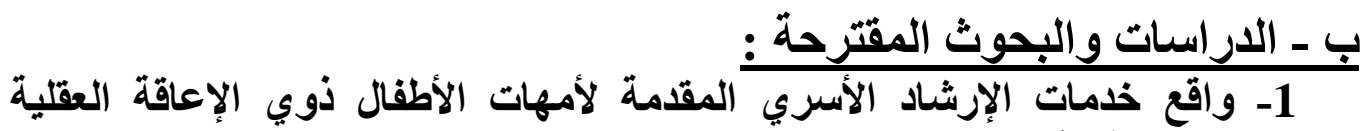
بمحافظة الأحساء. 2- مستوى رضا أمهات الأطفال ذوي الإعاقة العقلية عن خدمات الإرشاد الأسري

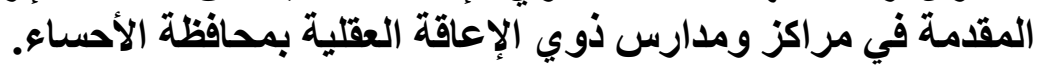

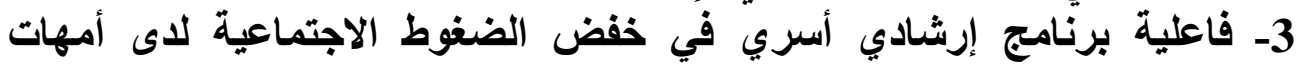
الأطفال ذوي الإعاقة العقلية بمحافظة الأحساء. 
1- أبو العلا، تركي. (2016). دور برنامج الإرشاد الأسري الهاتفي في تعديل

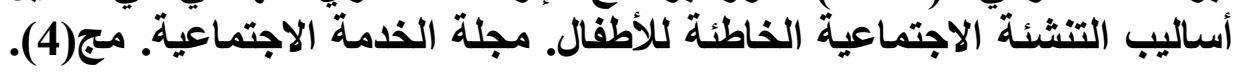

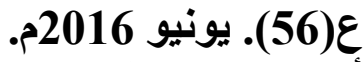
2- أبو عبادة، صالح؛ نيازي، عبد المجيد. (2001). الإرشاد النفسي والاجتماعي.

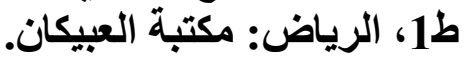

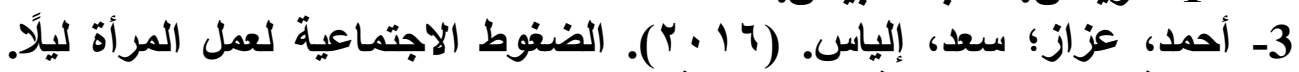

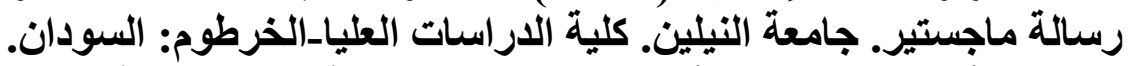

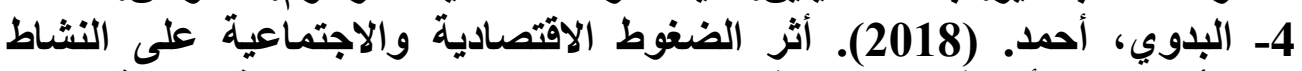

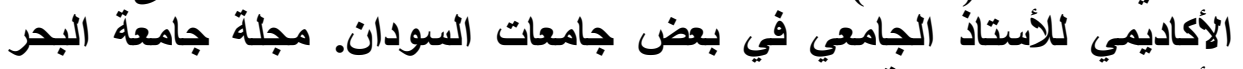

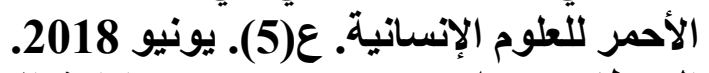
5- البسطامي، سلام (2013). مستوى الإدئة الارة الاستراتيجيات للضغنوط النفسية لدى

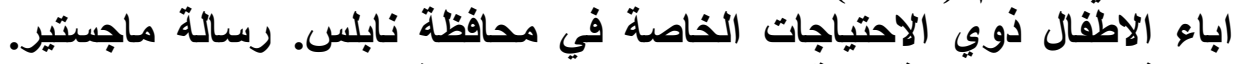

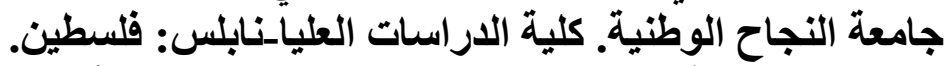

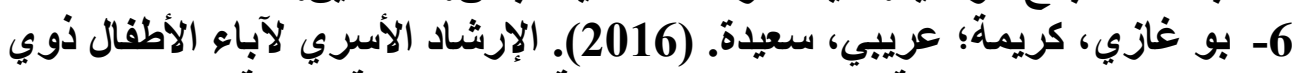

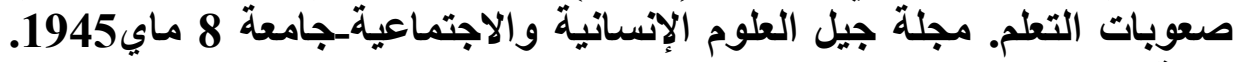

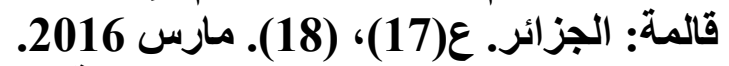
7- جبالي، صباح. (2012). الضغوط النفائل النفسية واستراتيجيات مواجهتها لدى أمهات

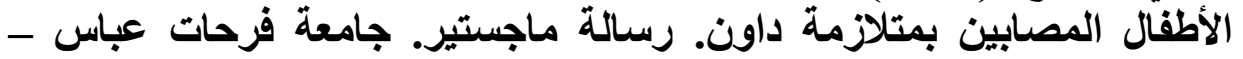

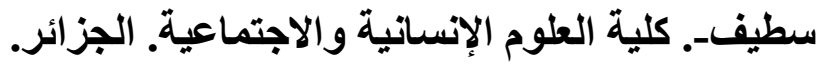

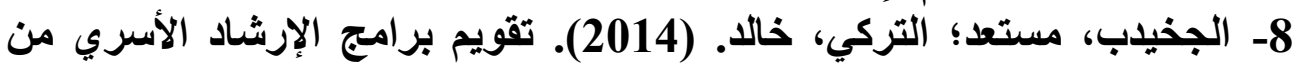

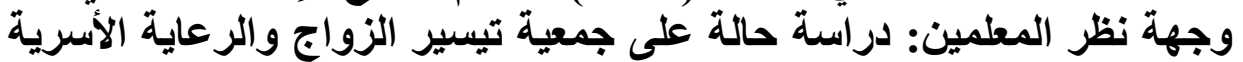

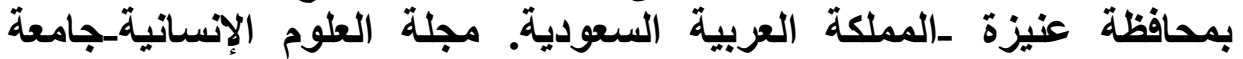

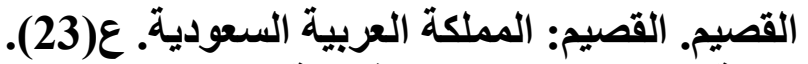

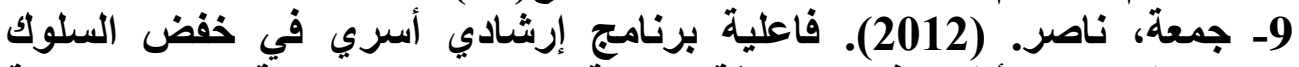

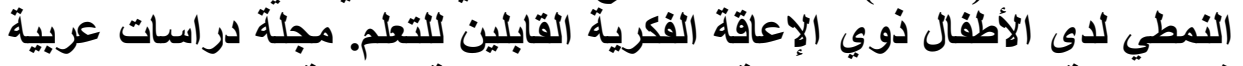

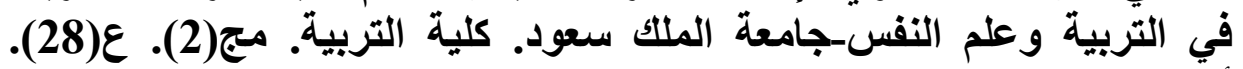

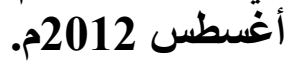

الحربي، بثاير. (2020). اتجاهات الأسرة السعودية نحو الإرشاد

الأسري: دراسة وصفية مسحية. المجلة الدولية للعلوم التربوية والنفسية. 
حسين، رمضان. (2009). المناخ الأسري وعلاقته بالسلوك

التكيفي لاى الأطفال المعاقين عقليا القابلين للتعلم بمدارس التربية الفكرية.

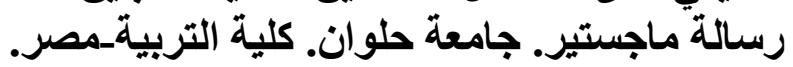
الخصاونة، حربي. (2013). الضغوطات النفسية الاجتماعية لاى النى

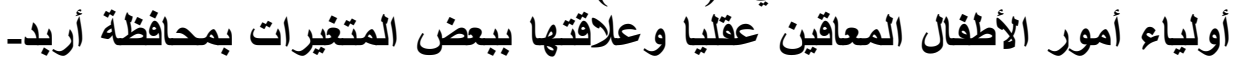

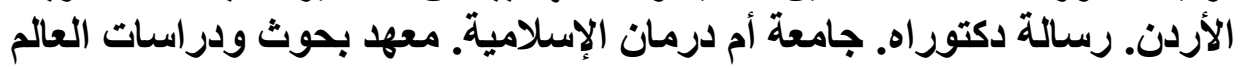

خلف الله، باختة (2015) مستوى الضغوط النفسية والاجتماعية

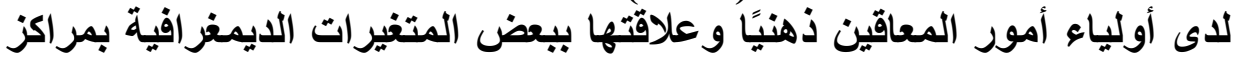

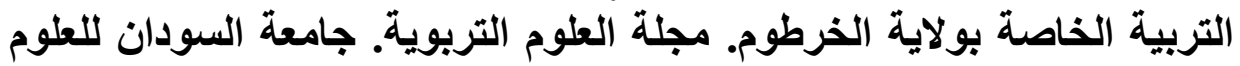

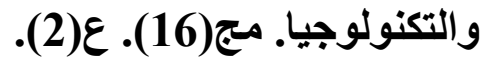

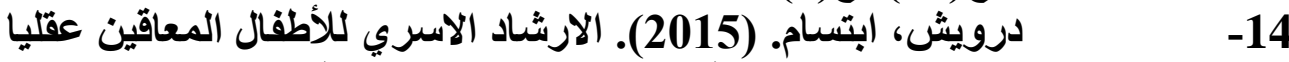

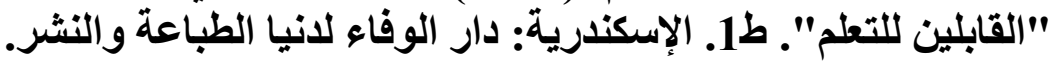

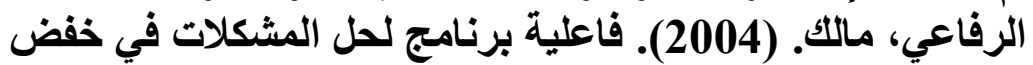

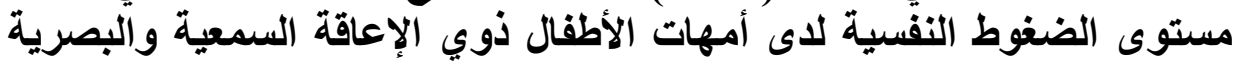
وعلاقته ببعض المتنغيرات. رسالة ماجستير. الجامعة الأردنية. كلية الدراسات

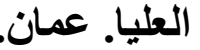

16- الرمادي، نور. (2006). فعالية برنامج ارشادي سلوكي جمعي

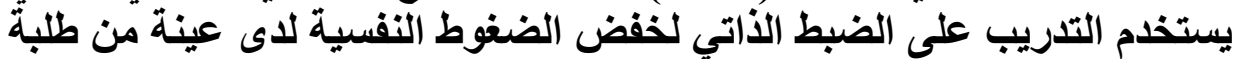
الجامعة. مجلة كلية التربية بالفيوم. ع(4).

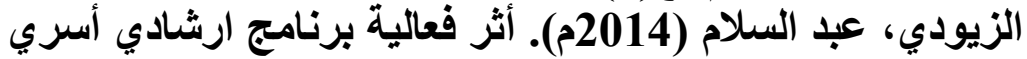

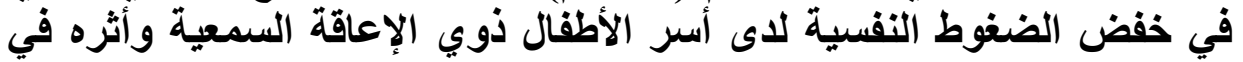

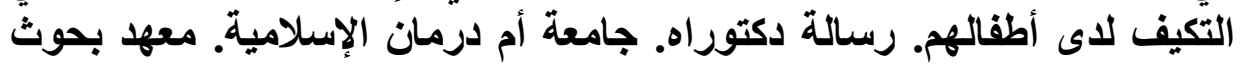
ودراسات العالم الإسلامي. السودان. -18

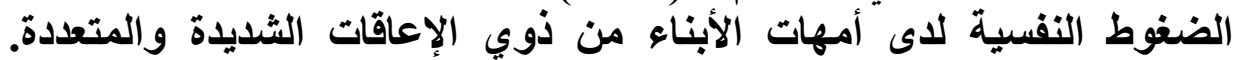

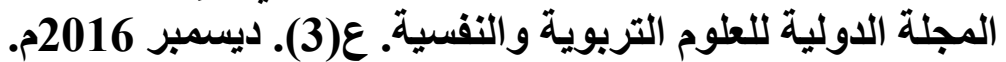

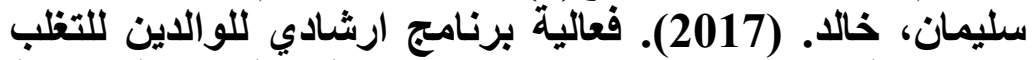
على ردود الفعل السلبية تجاه ولادة طفل معاق فكريًا. مجلة كلية التربية.

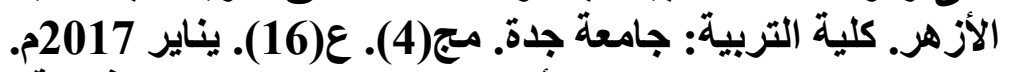

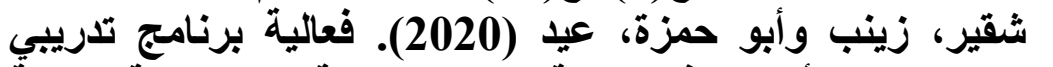

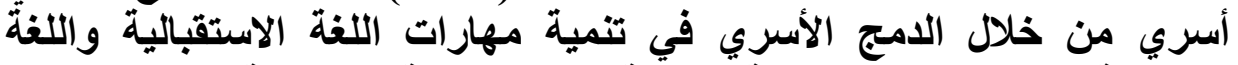
التعبيرية لاى التوحدي. المجلة العربية لطوم الإعاقة والموهبة. ع(10). ينايرة 


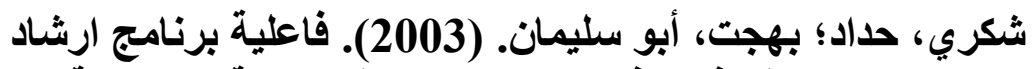

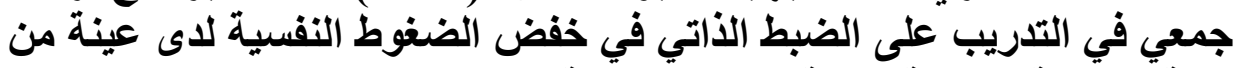

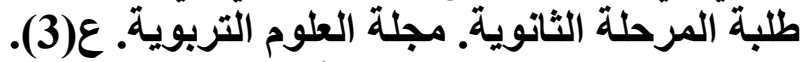

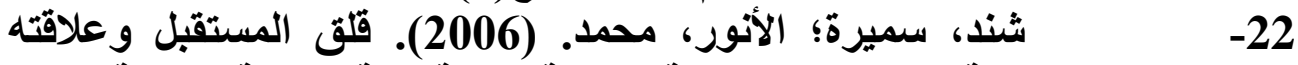

بالضغوط النفسية لدى شرائح مهنية مختلفة. مجلة كلية التربية.

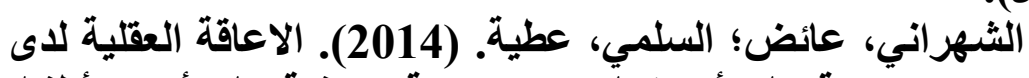

مج(1). ع) ع) (35).

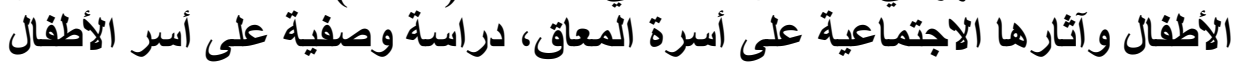

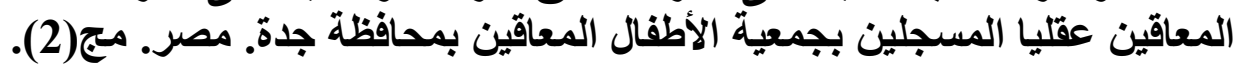

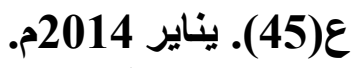

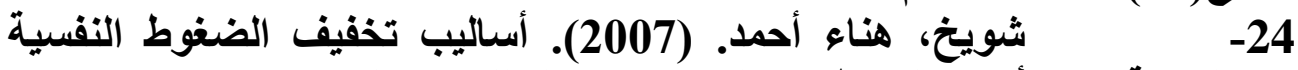
الناتجة عن الأورام السرطاني. القاهرة: إيتراك الك للنشر والتوزيع.

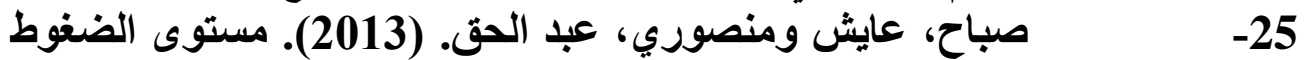

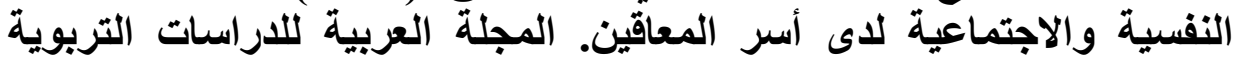

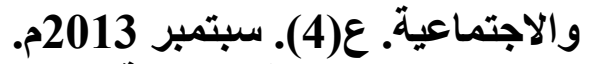
26العقلية. مجلة علوم الإنسان والمجتمع. جامعة بسكرة. الجزائر. ع(9). .2014

طاهر، إيمان. (2017). الإعاقة أنواعها وطرق التظلب عليها. مصر: وكالة الصحافة العربية. طه، فرج. (2005). معجم علم النفس والتحليل النفسي. بيروت: دار النهضة العربية. عبد العزيز، سعيد. (2010). التوجيه المدرسي. الأردن: دار الثقافة.

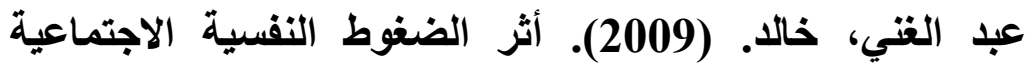
$-30$

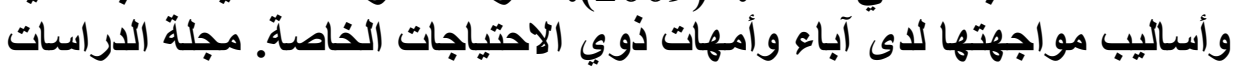

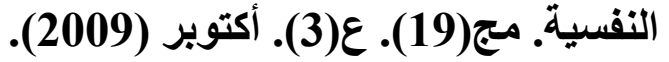

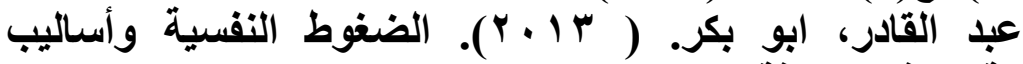
مواجهنها. مجلة رواف المعرفة. ع (Y) (Y).

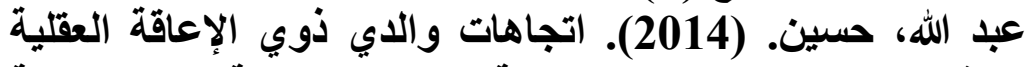

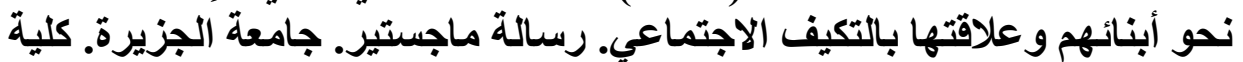
العلوم التربوية_السودان. 
عبد ربه، فاطمة. (2012). الضغوط النفسية لاى آباء الأطفال

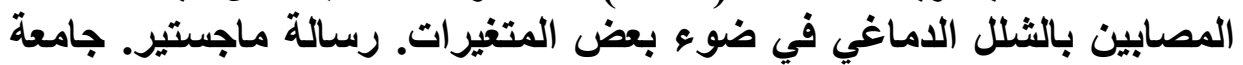

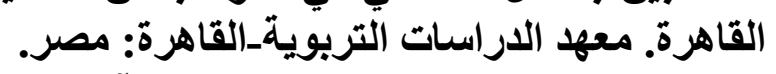

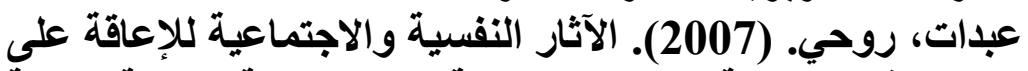
أخوة الأثخاص المعاقين. جامعة الامارات العربية المتحدة-كلية التربية. مدينة الثارقة للخدمات الإنسانية. على، ئاسو؛ عباس حسين. (2015). الارشاد النفسي الاتجاه

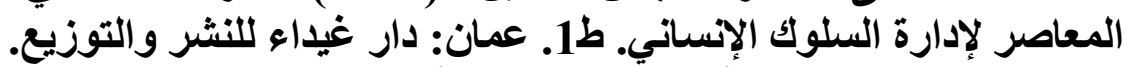

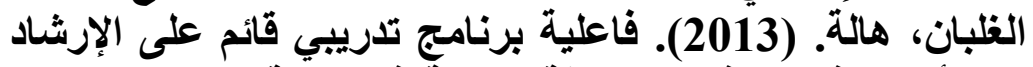

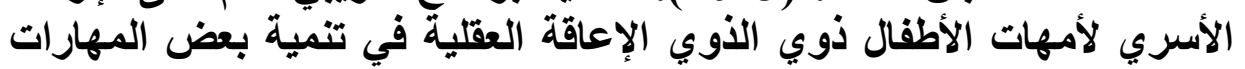

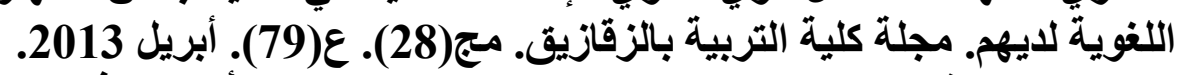

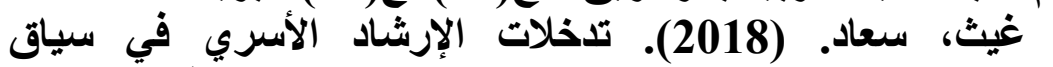

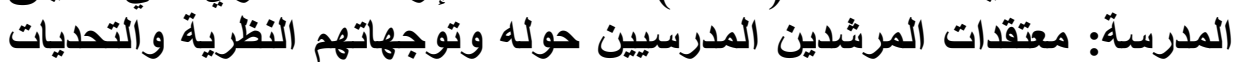

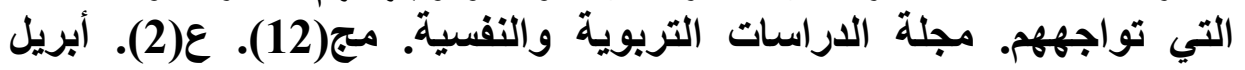
2018. فرح، منى. (2005). الضغوط النفسية وعلاقتها باحتياجات أولياء أمور غير العاديين المعاقين. رسالة ماجستير. جامعة الخرطوم. كلية الآدابـ الفياء

الفقهي، عادل. (2019). أثر الضغوط الاجتماعية وعلاقتها بعملية

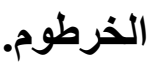

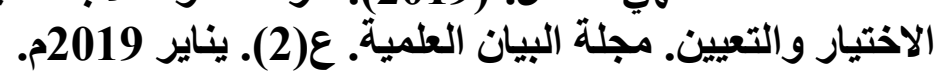

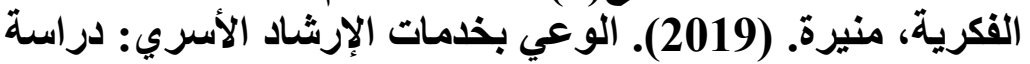

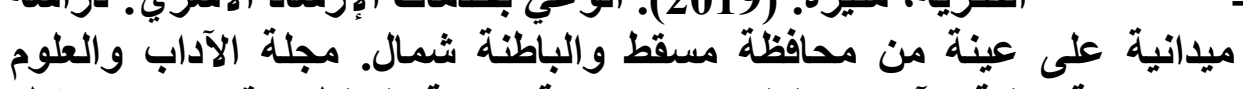

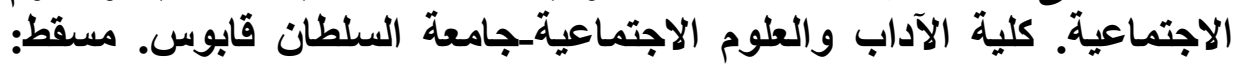
عمان. مج(10). ع(1). ابريل 2019ماعة 2019. قراقيش، صفاء. (2006). الضغوط النفايل النفسية لاى أولياء أمور $-41$

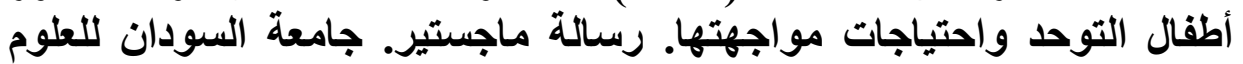
و التكنولوجيا: السودان. قثشقوش، إبراهيم؛ الأحمدي، محد. (2000). العلاقة بين الممارسة المهنية والثنعور بالضغوط النفسية لاى معلمي ومعلمئمات المدارس

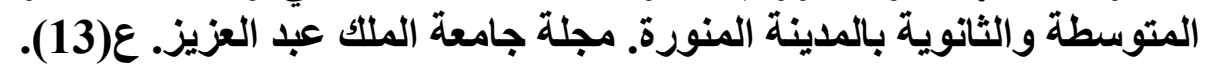

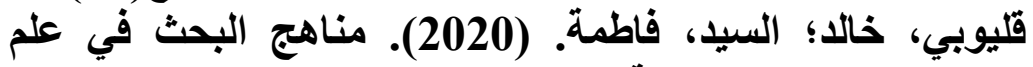
النفس. ط1. مركز النشر العلمي: جامعة الملك عبد العزيز. ماهر، أمين. (2017). المرشد الأسري. حرف للنشر والتوزيع. 
محمد خير، مناهل علي؛ عباس، عبد الرحمن. (2018). دور

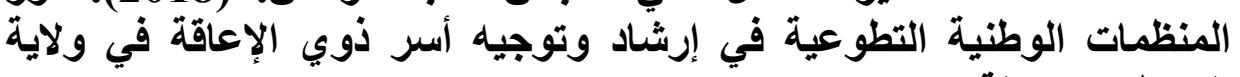
الخرطوم. رسالة ماجستير.

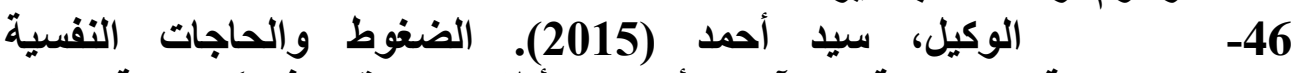

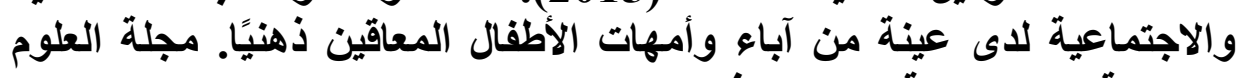
الإنسانية والاجتماعية. ع(35). فبراير 2015 2015م.

يوسف، يحيى. (35). (2019). دور الارشاد الأسري في الحد من ظاهرة

التثرد بولاية الخرطوم. رسالة دكتوراه. جامعة السودان التوان للعلوم والتكنولوجيا.

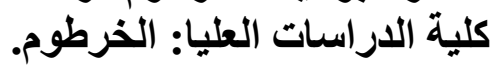

48-

Baxter.C,et.al.(2000). Parental Stress attributed to Family Members with \& without Disability: Longitudinal Study. Journal of International \& Developmental Disability, Vol 25, Issue (2), Pp.105-115. Buchanan, T; Driscoll, D; Mowrer, S; Soller, J;

Thayer, J; Kirschbaum, C. \& Trane, D.(2010). Medial prefrontal cortex damage affects psysiological ang psychological stress responses differently in men and women". Psychoneuroses endocrinology, 35 (1),. Brandon, Peter D. \& Dennis P. Hogan.( 2011).

72-The Effects of Children with Disabilities on Mothers' Exit from Welfare. Joint Center for Poverty Research Working Paper Series. 2011 Sep.

51- Cohen, Ronald J. (2005). Psychology \& Adjustment, values, culture and changes. USA: Bosten Allyn and Bacon..

52-

Emerson, E. (2003). Mothers of Children \& Adolescents with Intellectual Disability: Social and Economic Situation, Mental Health Status \& Self assessed Social\& Psychological Impact of Child's Difficulties. Journal of Intellectual Disability Research, Vol 47, No.4.

53- Hamilton, A. (2009). Research review: goals, intentions and mental states: Challenges for theories of 
autism. Journal of Child Psychology and Psychiatry, $50(8)$,

54

Hanafi, A. (2007). Working with families of people with special needs, teachers and parents guide. Al Riyadh, Kingdome of Saudi Arabia: Science and faith house for publishing and distribution.

Islam, Mohammed. Farjana, Sharmaine \&

Shahnaz, Rona. (2013). Stress among parents of children with mental retardation.

56-

Koydemir,Selda. Tosun, Ulku. (2009). Impact of autistic children on the lives of mothers, Procardia. Social and Behavioral Sciences. School of Education. Yeditepe University. 2009 Jan

2.

P2534-2540. doi:10.1016/j.sbspro.2009.01 .

57- Kussen. C. Tolson. D, Swan. I. Stoti. D and Sullivan. F. (2004). The social and psychological impact of older relative hearing difficulties. Psychology:Health and Medicine, Vol .9 Issues,

58- Olsson, M.B, Hwang, P.C. (2003). Influence of Macrostructure of Society on Life Situation of Families with a child with Intellectual Disability in Sweden. Journal of Intellectual Disability Research, Vol 47, No 4,.

59-

Saleh, M., \& Shafi'i, K. (2015). The effectiveness of family counseling on developing some skills, of self-care among a sample of autistic children. 162(1),

60- Sayiner, B. (2006). Stress level of university students. Istanbul University Journal of Science, 5 (10),

61- Shirani, Newsha .Taebi, Mahboubeh ; Kazemi, Ashraf ; Khalafian, Marzeah .(2015) .The level of depression and its related factors among the mothers with mentally retarded girl children in exceptional primary schools. Iranian Journal of Nursing \& Midwifery Research. College of Nursing and Midwifery. Isfahan 
الجمعية المصرية للقر اءة والمعرفة عضو الجمعية الدولية للمعرفة المي

University of Medical Sciences. Isfahan: Iran. 2013 Nov 24. 20 (1).

62- Woodman Achli C .(2014). Trajectories of stress among parents of children with disabilities: A dyadic analysis Family Relations. University of WisconsinMadison. 2014 Jan 11. 63(1).. doi: 10.1111/fare.12049. 


\section{الجمعية المصرية للقر اءة و المعرفة عضو الجمعية الدولية للمعرفة ال}

\section{ملخص البحث}

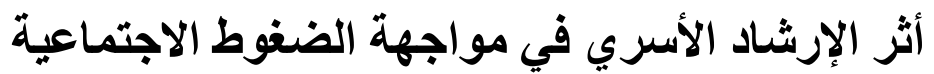

لاى أمهات أطفال ذوي الإعاقة العقلية بمحافظة الأحساء

The Effect of Family Counseling in Facing Social

Pressures for a Family of a Children Having a Mental

Retardation in Al-Ahsa Governorate

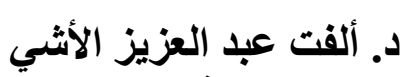

الأستاذ المشارك بجامعة الملك عبد الّزيز الأليز بجدة

كلية الدراسات العليا التربوية
أ. امال أحمد الأقتم

ماجستير التوجيه والإرشاد التمد التربوي

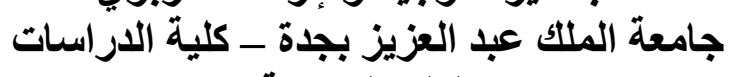

$$
\text { العليا التربوية بجة العزية }
$$

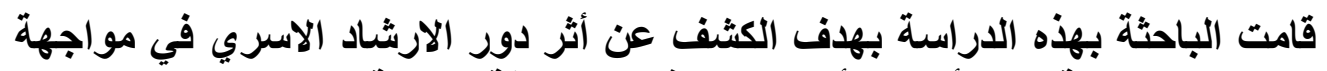

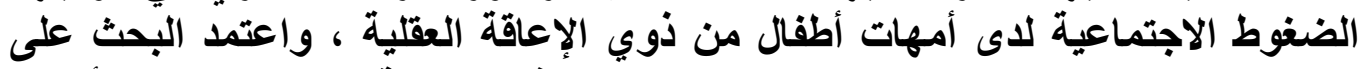

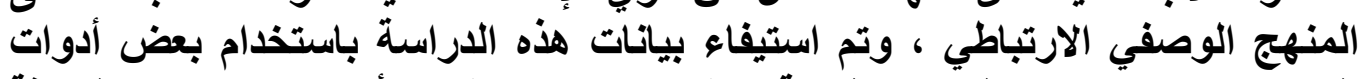

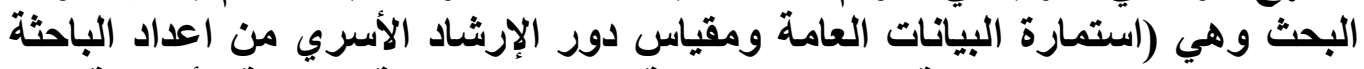

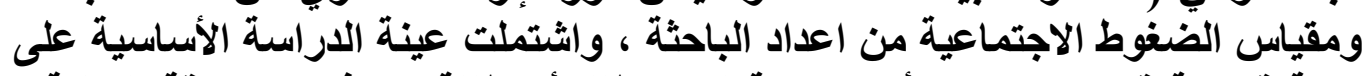

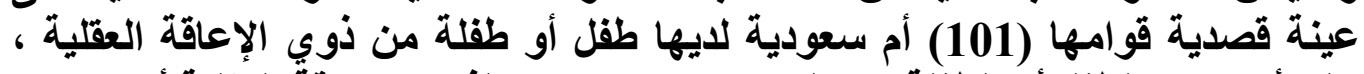

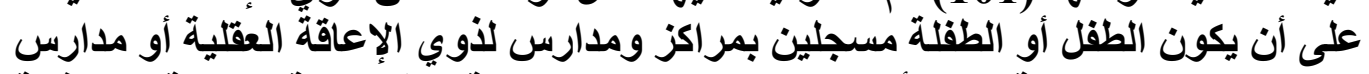

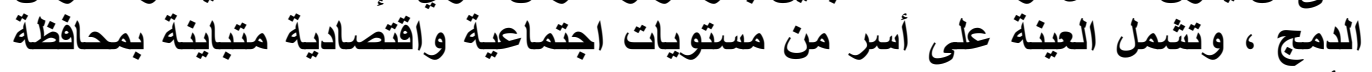
الأحساء

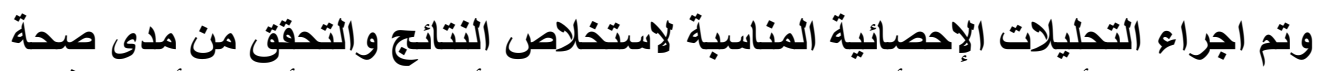

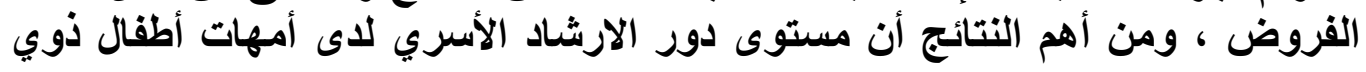




\section{ILA الجمعية المصرية للقر اءة والمعرفة عضو الجمعية الدولية للمعرفة}

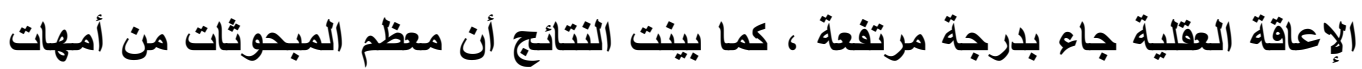

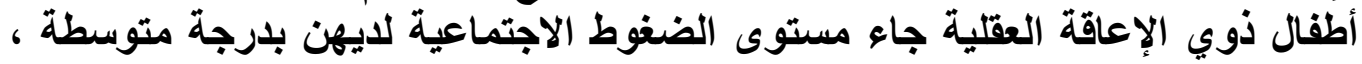

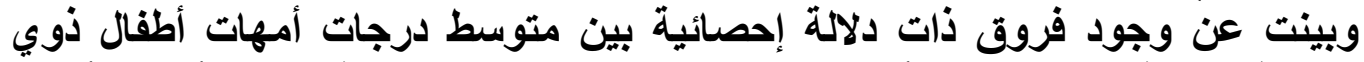

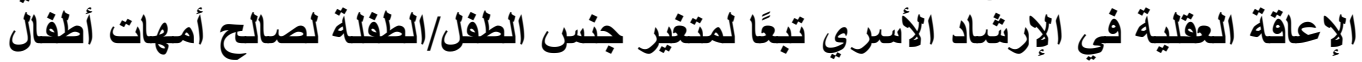

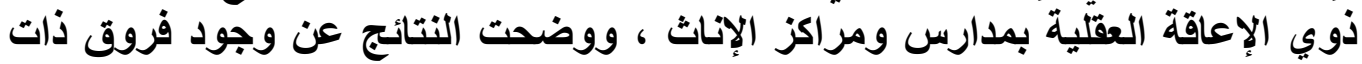

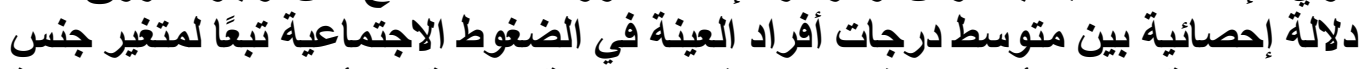

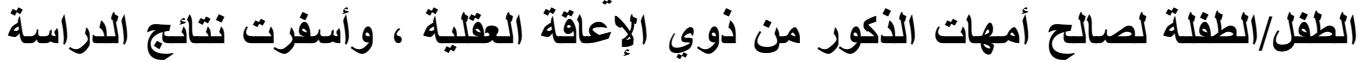
عن وجود علاقة ارتباطية عكسية بين مقياس الإنية الارشاد الأسري ومقياس الضغنوط

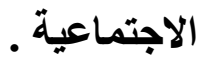

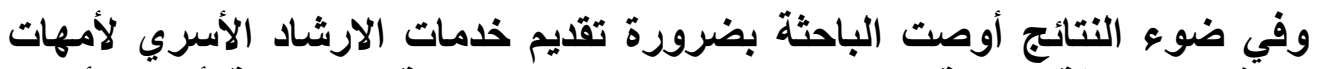

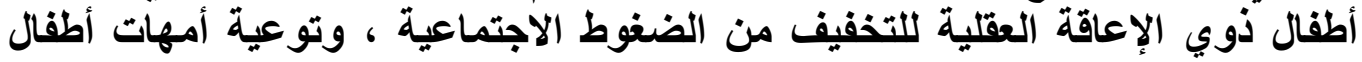

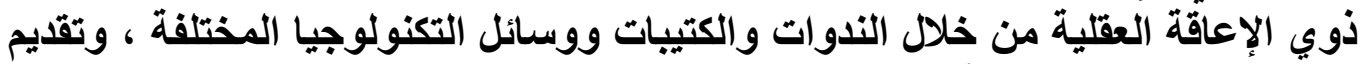

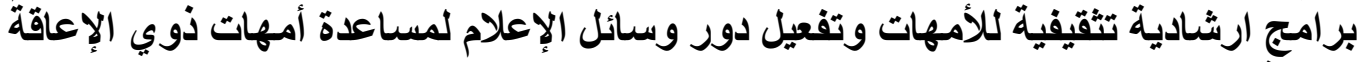




\section{ILA الجمعية المصرية للقر اعة والمعرفة عضو الجمعية الدولية للمعرفة}

\section{Summary}

The researcher conducted this study aiming to expose the role of family counseling in facing the social pressures among mothers of children with mental retardation.

The research relied on the correlational descriptive approach, and the data for this study accomplished using some research tools, which were the general data form, the family counseling role scale and the social pressure prepared by the researcher. The basic study sample included an intentional sample of (101) a Saudi mother who has a child or a girl with a mental retardation, and the child or girl should be registered in centers and schools for the mentally disabled or schools of integration.

The sample includes families of different socio-economic levels in Al-Ahsa governorate, an appropriate statistical analyzes have been conducted to extract results and verify the validity of the hypotheses.

Among the most important results is that the level of the effect of family counseling among mothers of children with mental retardation came with high level.

The results also showed that most of the responder were mothers of children with mental retardation, and the level of social pressure was moderate.

Moreover, it showed statistically significant differences between the average scores of the mothers of children with mental retardation in family counseling according to the child / girl gender variable in favor of mothers of children with mental retardation in female schools and centers.

The results showed statistically significant differences between the average scores of the members with social pressures according to the child / girl gender variable in favor of mothers of males with mental disabilities. 
الجمعية المصرية للقر اءة والمعرفة عضو الجمعية الدولية للمعرفة المئ

In addition, it resulted in an inverse relationship between the family counseling measure and the social stress scale.

In light of these results, the researcher recommended the necessity of providing family counseling services to mothers of children with mental retardation to alleviate social pressures, educate mothers of children with mental disabilities through seminars, brochures and various technology means, provide educational guidance programs for mothers, and activate the role of the media to help mothers with mental retardation. 